\title{
QUANTIFYING THE UNCERTAINTY IN ESTIMATES OF WORLD CONVENTIONAL OIL RESOURCES
}

\author{
A Thesis \\ by \\ Chih-Ming Tien \\ Submitted to the Office of Graduate Studies of \\ Texas A\&M University \\ in partial fulfillment of the requirements for the degree of \\ MASTER OF SCIENCE
}

December 2009

Major Subject: Petroleum Engineering 


\title{
QUANTIFYING THE UNCERTAINTY IN ESTIMATES OF WORLD CONVENTIONAL OIL RESOURCES
}

\author{
A Thesis \\ by \\ Chih-Ming Tien \\ Submitted to the Office of Graduate Studies of \\ Texas A\&M University \\ in partial fulfillment of the requirements for the degree of \\ MASTER OF SCIENCE
}

Approved by:

Chair of Committee, Duane A. McVay

Committee Members, William John Lee

Yuefeng Sun

Head of Department, Stephen A. Holditch

December 2009

Major Subject: Petroleum Engineering 


\begin{abstract}
Quantifying the Uncertainty in Estimates of World Conventional Oil Resources.

(December 2009)

\author{
Chih-Ming Tien, B.S., Tunghai University, Taichung, Taiwan; \\ M.S., National Taiwan University, Taipei, Taiwan \\ Chair of Advisory Committee: Dr. Duane A. McVay
}

Since Hubbert proposed the "peak oil" concept to forecast ultimate recovery of crude oil for the U.S. and the world, there have been countless debates over the timing of peak world conventional oil production rate and ultimate recovery. From review of the literature, forecasts were grouped into those that are like Hubbert's with an imminent peak, and those that do not predict an imminent peak. Both groups have bases for their positions. Viewpoints from the two groups are polarized and the rhetoric is pointed and sometimes personal. A big reason for the large divide between the two groups is the failure of both to acknowledge the significant uncertainty in their estimates. Although some authors attempt to quantify uncertainty, most use deterministic methods and present single values, with no ranges. This research proposes that those that do attempt to quantify uncertainty underestimate it significantly.

The objective of this thesis is to rigorously quantify the uncertainty in estimates of ultimate world conventional oil production and time to peak rate. Two different methodologies are used. The first is a regression technique based on historical 
production data using Hubbert's model and the other methodology uses mathematical models. However, I conduct the analysis probabilistically, considering errors in both the data and the model, which results in likelihood probability distributions for world conventional oil production and time to peak rate. In the second method, I use a multiple-experts analysis to combine estimates from the multitude of papers presented in the literature, yielding an overall distribution of estimated world conventional oil production.

Giving due consideration to uncertainty, Hubbert-type mathematical modeling results in large uncertainty ranges that encompass both groups of forecasts (imminent peak and no imminent peak). These ranges are consistent with those from the multiple-experts analysis. In short, the industry does not have enough information at this time to say with any reliability what the ultimate world conventional oil production will be. It could peak soon, somewhere in the distant future, or somewhere in between. It would be wise to consider all of these possible outcomes in planning and making decisions regarding capital investment and formulation of energy policy. 


\section{DEDICATION}

This thesis is dedicated to my wife and parents who fully support me to pursue the knowledge. 


\section{ACKNOWLEDGEMENTS}

I would like to thank Dr. Duane A. McVay, my advisor, for his sage guidance and hard work during the entire thesis process. Also, I thank Dr. William. John Lee and Dr. Yuefeng Sun, my committee members who provided sound suggestions for this thesis. Finally, I thank the fellows, for their encouragement and support during my studies. 
TABLE OF CONTENTS

Page

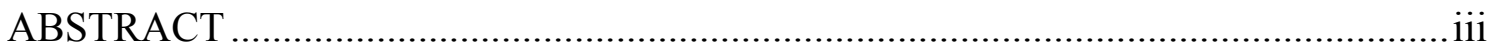

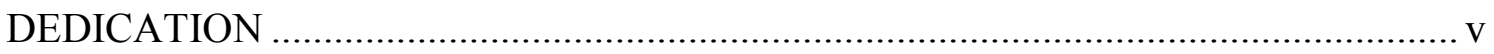

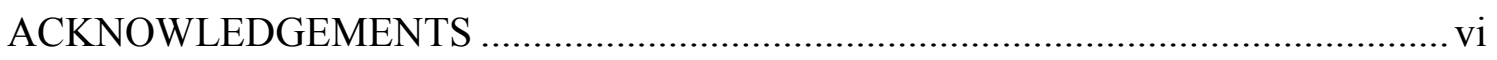

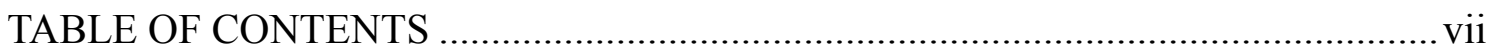

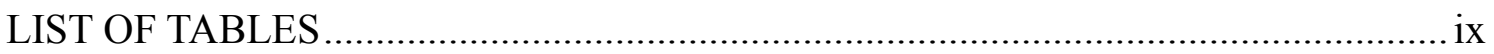

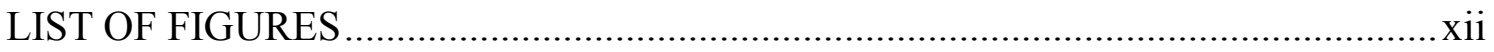

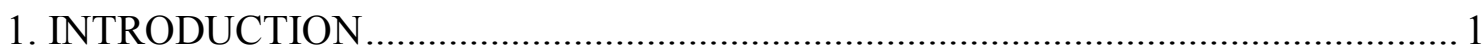

2. BACKGROUND

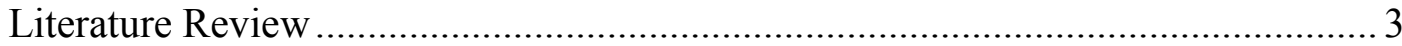

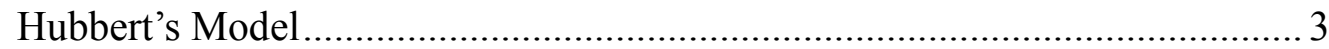

Normal Distribution Model _.............................................................................. 6

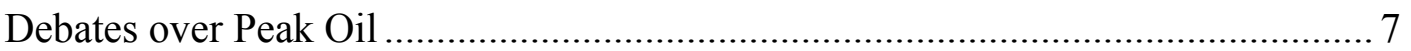

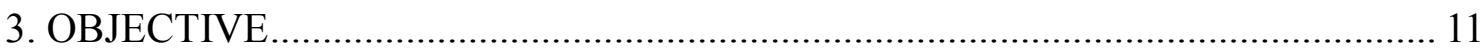

4. METHODOLOGY FOR QUANTIFYING THE UNCERTAINTY ……………........12

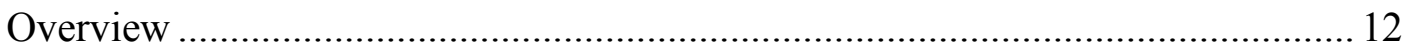

Mathematical Modeling of Uncertainty ............................................................ 12

Multiple Experts System for Analyzing Uncertainty ........................................... 14

5. PRODUCTION DATA ANALYSIS WITH MATHEMATICAL MODEL .................. 17

6. ANALYSIS OF CONVENTIONAL OIL RESOURCES OF THE U.S. 48................ 18

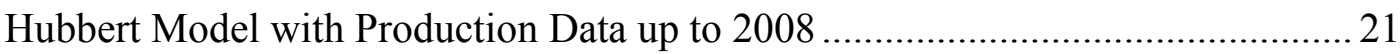

Normal Distribution Model with Production Data up to 2008................................29

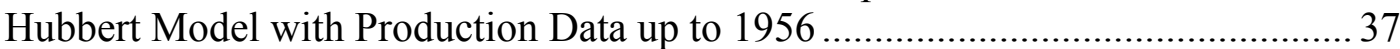

Normal Distribution Model with Production Data up to 1956.................................45

Summary of Uncertainty Analyses for the Lower U.S. 48 by Mathematical

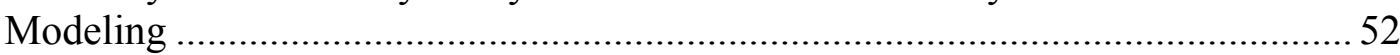


7. ANALYSIS FOR CONVENTIONAL OIL RESOURCES OF THE WORLD..........54

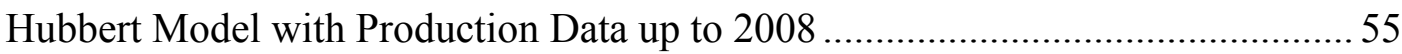

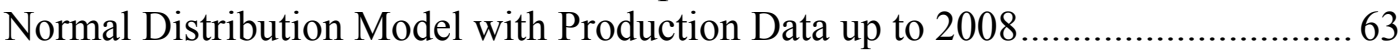

Summary of Uncertainty Analysis for the World by Mathematical Modeling ....... 71

8. MULTIPLE EXPERTS ANALYSIS OF WORLD CONVENTIONAL OIL

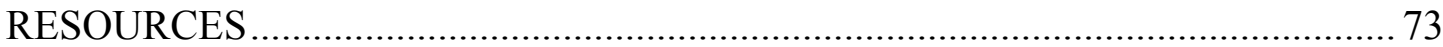

9. CONCLUSIONS AND RECOMMENDATIONS ................................................ 85

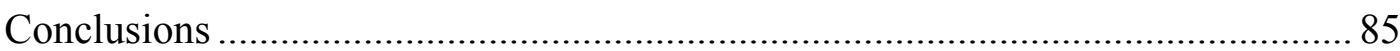

Recommendation for Future Work .............................................................. 86

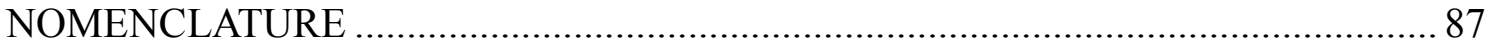

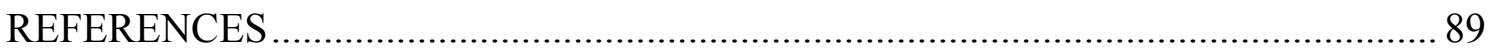

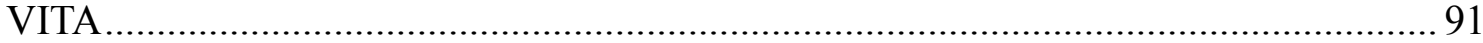




\section{LIST OF TABLES}

Page

Table 1 Different variance ratio for Hubbert model with production data up to 2008 of the lower U.S. 48

Table 2 Probabilistic values of each parameter for Hubbert model with production data up to 2008 of the lower U.S. 48 .

Table 3 Parameter sets for Hubbert model with production data up to 2008 of the

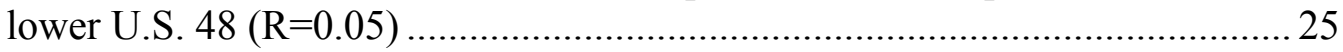

Table 4 Parameter sets for Hubbert model with production data up to 2008 of the

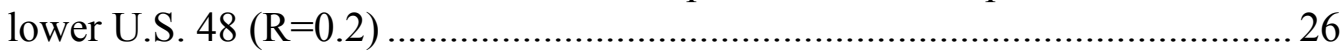

Table 5 Parameter sets for Hubbert model with production data up to 2008 of the

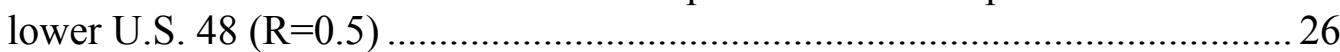

Table 6 Different variance ratio for Normal distribution model with production data up to 2008 of the lower U.S. 48

Table 7 Probabilistic values of each parameter for Normal distribution model with production data up to 2008 of the lower U.S. 48

Table 8 Parameter sets for Normal distribution model with production data up to 2008 of the lower U.S. $48(\mathrm{R}=0.05)$

Table 9 Parameter sets for Normal distribution model with production data up to 2008 of the lower U.S. $48(\mathrm{R}=0.20)$.

Table 10 Parameter sets for Normal distribution model with production data up to 2008 of the lower U.S. $48(\mathrm{R}=0.50)$

Table 11 Different variance ratio for Hubbert model with production data up to 1956 of the lower U.S. 48

Table 12 Probabilistic values of each parameter for Hubbert model with production data up to 1956 of the lower U.S. 48

Table 13 Parameter sets for Hubbert model with production data up to 1956 of the lower U.S. $48(\mathrm{R}=0.01)$ 
Table 14 Parameter sets for Hubbert model with production data up to 1956 of the lower U.S. $48(\mathrm{R}=0.02)$

Table 15 Parameter sets for Hubbert model with production data up to 1956 of the lower U.S. $48(\mathrm{R}=0.155)$

Table 16 Different variance ratio for Normal distribution model with production data up to 1956 of the lower U.S. 48

Table 17 Probabilistic values of each parameter for Normal distribution model with production data up to 1956 of the lower U.S. 48

Table 18 Parameter sets for Normal distribution model with production data up to 1956 of the lower U.S. $48(\mathrm{R}=0.01)$

Table 19 Parameter sets for Normal distribution model with production data up to 1956 of the lower U.S. $48(\mathrm{R}=0.02)$

Table 20 Different variance ratio for Hubbert model with production data up to 2008 of the world ..... 55

Table 21 Probabilistic values of each parameter for Hubbert model with production data up to 2008 of the world.

Table 22 Parameter sets for Hubbert model with production data up to 2008 of the world $(\mathrm{R}=2)$.

Table 23 Parameter sets for Hubbert model with production data up to 2008 of the world $(\mathrm{R}=4)$

Table 24 Parameter sets for Hubbert model with production data up to 2008 of the world $(\mathrm{R}=8)$

Table 25 Different variance ratio for normal distribution model with production data up to 2008 of the world

Table 26 Probabilistic values of each parameter for Normal distribution model with production data up to 2008 of the world

Table 27 Parameter sets for Normal distribution model with production data up to 2008 of the world $(\mathrm{R}=0.2)$ 
Table 28 Parameter sets for Normal distribution model with production data up to

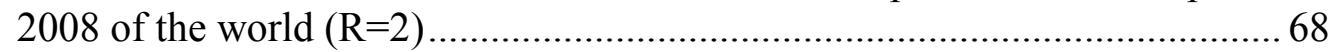

Table 29 Parameter sets for Normal distribution model with production data up to

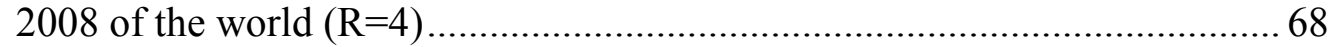

Table 30 World conventional oil ultimate recoverable resources from Group 1 \& Group 2 of Bentley et al. (2008)

Table 31 Probabilistic values of $Q_{\infty}$ and $S_{L}$ at a peak year of 2031 for Hubbert model with overall production data of the world

Table 32 Parameter sets at the peak time 2031 for Hubbert model with overall production data of the world $(\mathrm{R}=8)$.

Table 33 Estimates of world conventional oil resources using multple experts pooling.

Table 34 Parameter sets at the $\mathrm{Q}_{\infty}=2543.3 \mathrm{Bbbl}$ for Hubbert model with overall production data of the world $(\mathrm{R}=8)$.

Table 35 Parameter sets at the $\mathrm{Q}_{\infty}=2900.8 \mathrm{Bbbl}$ for Hubbert model with overall production data of the world $(\mathrm{R}=8)$. 


\section{LIST OF FIGURES}

\section{Page}

Fig. 1 Production curve of the U.S. lower 48 18

Fig. 2 Marginal PDF of $Q_{\infty}$ for Hubbert model with production data up tp 2008 of the lower U.S. 48

Fig. 3 CDF of $Q_{\infty}$ for Hubbert model with production data up to 2008 of the lower U.S. 48 .....

Fig. 4 Marginal PDF of $t_{M}$ for Hubbert model with production data up tp 2008 of the lower U.S. 48 .

Fig. 5 CDF of $t_{M}$ for Hubbert model with production data up to 2008 of the lower U.S. 48

Fig. 6 Marginal PDF of $S_{L}$ for Hubbert model with production data up to 2008 of the lower U.S. 48.

Fig. 7 CDF of $S_{L}$ for Hubbert model with production data up to 2008 of the lower U.S. 48

Fig. 8 Probabilistic forecasts of $\mathrm{Q}_{\infty}$ for Hubbert model with production data up to 2008 of the lower U.S. $48(\mathrm{R}=0.5)$.

Fig. 9 Probabilistic forecasts of $t_{M}$ for Hubbert model with production data up to 2008 of the lower U.S. $48(\mathrm{R}=0.5)$

Fig. 10 Probabilistic forecasts of $S_{L}$ for Hubbert model with production data up to 2008 of the lower U.S. $48(\mathrm{R}=0.5)$

Fig. 11 Marginal PDF of $\mathrm{Q}_{\infty}$ for Normal distribution model with production data up to 2008 of the lower U.S. 48

Fig. 12 CDF of $Q_{\infty}$ for Normal distribution model with production data up to 2008 of the lower U.S. 48

Fig. 13 Marginal PDF of $t_{M}$ for Normal distribution model with production data up to 2008 of the lower U.S. 48 
Fig. 14 CDF of $t_{M}$ for Normal distribution model with production data up to 2008 of the lower U.S. 48

Fig. 15 Marginal PDF of $S_{N}$ for Normal distribution model with production data up to 2008 of the lower U.S. 48

Fig. 16 CDF of $S_{N}$ for Normal distribution model with production data up to 2008 of the lower U.S. 48

Fig. 17 Probabilistic forecasts of $\mathrm{Q}_{\infty}$ for Normal Distribution model with

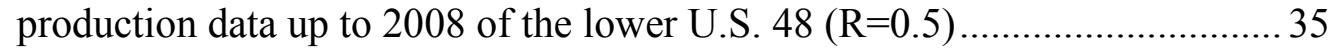

Fig. 18 Probabilistic forecasts of $t_{M}$ for Normal Distribution model with production data up to 2008 of the lower U.S. $48(\mathrm{R}=0.5)$............................. 35

Fig. 19 Probabilistic forecasts of $S_{N}$ for Normal Distribution model with

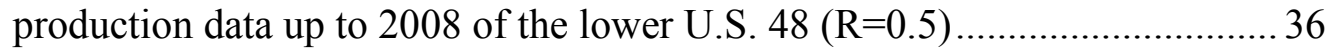

Fig. 20 Marginal PDF of $Q_{\infty}$ for Hubbert model with production data up to 1956 of the lower U.S. 48 .

Fig. 21 CDF of $Q_{\infty}$ for Hubbert model with production data up to 1956 of the lower U.S. 48 . 38

Fig. 22 Marginal PDF of $t_{M}$ for Hubbert model with production data up to 1956 of the lower U.S. 48

Fig. 23 CDF of $t_{M}$ for Hubbert model with production data up to 1956 of the lower U.S. 48 .

Fig. 24 Marginal PDF of $S_{L}$ for Hubbert model with production data up to 1956 of the lower U.S. 48.

Fig. 25 CDF of $S_{L}$ for Hubbert model with production data up to 1956 of the lower U.S. 48

Fig. 26 Probabilistic forecasts of $\mathrm{Q}_{\infty}$ for Hubbert model with production data up to 1956 of the lower U.S. $48(\mathrm{R}=0.155)$.

Fig. 27 Probabilistic forecasts of $t_{M}$ for Hubbert model with production data up to 1956 of the lower U.S. $48(\mathrm{R}=0.155)$. 
Fig. 28 Probabilistic forecasts of $\mathrm{S}_{\mathrm{L}}$ for Hubbert model with production data up to 1956 of the lower U.S. $48(\mathrm{R}=0.155)$.

Fig. 29 Marginal PDF of $\mathrm{Q}_{\infty}$ for Normal distribution model with production data up to 1956 of the lower U.S. 48 46

Fig. 30 CDF of $Q_{\infty}$ for Normal distribution model with production data up to 1956 of the lower U.S. 48

Fig. 31 Marginal PDF of $t_{M}$ for Normal distribution model with production data up to 1956 of the lower U.S. 48 .

Fig. $32 \mathrm{CDF}$ of $\mathrm{t}_{\mathrm{M}}$ for Normal distribution model with production data up to 1956 of the lower U.S. 48 .

Fig. 33 Marginal PDF of $\mathrm{S}_{\mathrm{N}}$ for Normal distribution model with production data up to 1956 of the lower U.S. 48 .

Fig. $34 \mathrm{CDF}$ of $\mathrm{S}_{\mathrm{N}}$ for Normal distribution model with production data up to 1956 of the lower U.S. 48

Fig. 35 Probabilistic forecasts of $\mathrm{Q}_{\infty}$ for Normal Distribution model with production data up to 1956 of the lower U.S. $48(\mathrm{R}=0.01)$...

Fig. 36 Probabilistic forecasts of $\mathrm{t}_{\mathrm{M}}$ for Normal Distribution model with production data up to 1956 of the lower U.S. $48(\mathrm{R}=0.01)$. 50

Fig. 37 Probabilistic forecasts of $\mathrm{S}_{\mathrm{N}}$ for Normal Distribution model with production

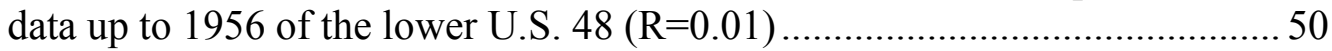

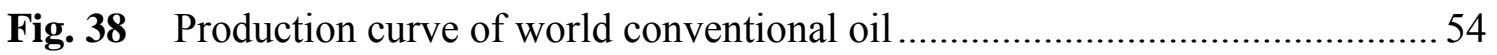

Fig. 39 Marginal PDF of $Q_{\infty}$ for Hubbert model with production data up to 2008 of the world 56

Fig. 40 CDF of $\mathrm{Q}_{\infty}$ for Hubbert model with production data up to 2008 of the world.

Fig. 41 Marginal PDF of $t_{M}$ for Hubbert model with production data up to 2008 of the world. 
Fig. 42 CDF of $t_{M}$ for Hubbert model with production data up to 2008 of the world.

Fig. 43 Marginal PDF of $\mathrm{S}_{\mathrm{L}}$ for Hubbert model with production data up to 2008 of the world.

Fig. 44 CDF of $S_{L}$ for Hubbert model with production data up to 2008 of the world.

Fig. 45 Probabilistic forecasts of $\mathrm{Q}_{\infty}$ for Hubbert model with production data up to $2008(\mathrm{R}=8)$.

Fig. 46 Probabilistic forecasts of $t_{M}$ for Hubbert model with production data up to 2008 of the world $(\mathrm{R}=8)$

Fig. 47 Probabilistic forecasts of $\mathrm{S}_{\mathrm{L}}$ for Hubbert model with production data up to 2008 of the world $(\mathrm{R}=8)$

Fig. 48 Marginal PDF of $\mathrm{Q}_{\infty}$ for Normal distribution model with production data up to 2008 of the world

Fig. 49 CDF of $\mathrm{Q}_{\infty}$ for Normal distribution model with production data up to 2008 of the world

Fig. 50 Marginal PDF of $t_{M}$ for Normal distribution model with production data up to 2008 of the world

Fig. 51 CDF of $t_{M}$ for Normal distribution model with production data up to 2008 of the world

Fig. 52 Marginal PDF of $S_{N}$ for Normal distribution model with production data up to 2008 of the world

Fig. 53 CDF of $S_{N}$ for Normal distribution model with production data up to 2008 of the world 66

Fig. 54 Probabilistic forecasts of $\mathrm{Q}_{\infty}$ for Normal Distribution model with production data up to 2008 of the world $(\mathrm{R}=2)$.

Fig. 55 Probabilistic forecasts of $t_{M}$ for Normal Distribution model with production data up to 2008 of the world $(\mathrm{R}=2)$. 
Fig. 56 Probabilistic forecasts of $\mathrm{S}_{\mathrm{N}}$ for Normal Distribution model with production data up to 2008 of the world $(\mathrm{R}=2)$......................................... 70

Fig. 57 World conventional oil ultimate recoverable resources from Group 1 \& Group 2 of Bentley et al. (2008)

Fig. 58 Probabilistic forecasts of $Q_{\infty}$ at the peak time 2031 for Hubbert Distribution

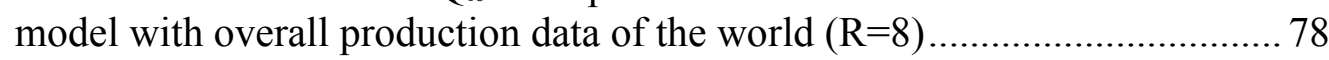

Fig. 59 Probabilistic forecasts of $\mathrm{S}_{\mathrm{L}}$ at the peak time 2031 for Hubbert Distribution

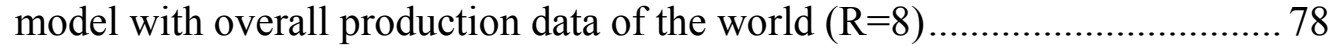

Fig. 60 Histogram and CDF for combining all forecasts of three different Groups.... 80

Fig. 61 Histogram and CDF for combining the forecasts after 1990 of three

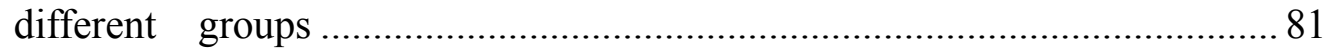

Fig. 62 Probabilistic forecasts of $t_{M}$ at the $Q_{\infty}=2543.3$ for Hubbert Distribution model with overall production data of the world $(\mathrm{R}=8)$.

Fig. 63 Probabilistic forecasts of $t_{M}$ at the $Q_{\infty}=2900.8$ for Hubbert Distribution model with overall production data of the world $(\mathrm{R}=8)$. 


\section{INTRODUCTION}

Fossil fuel is still the main energy source used by humankind. However, with oil price exceeding $\$ 100 / \mathrm{bbl}$ in recent years, questions regarding when we will run out of oil and how much oil we will produce drive us to reexamine this old discussion. In 1956, Hubbert (1956) presented the "peak oil" concept to explain that production of finite, nonrenewable resources should begin at zero, rise to a peak, then decline continuously. The viewpoint of "peak oil" is primary concerned about when the production rate can no longer increase and will plateau or begin to decline, rather than about running out of oil.

There have been numerous debates during the past half-century (e.g., Al-Jarri and Startzman 1997; Campbell 2003; Lynch 2003; Ryan 1966) over the timing of "peak oil" production rate. Because our civilization still depends heavily on oil, and global energy demand is anticipated to increase in the next few decades, it is increasingly important to determine how long the oil supply can meet the world's energy demand.

Bentley et al. (2008) summarized the methodologies and predictions for global oil production by many authors since 1956. The predictions include a wide range of opinions ranging from imminent peaks in oil production rate to no imminent peaks. The causes that resulted in significant prediction inconsistency between these forecasts are due to large uncertainties. The uncertainty comes from different aspects, e.g., measurement or reporting errors within the production data, predictive errors of forecast

This thesis follows the style of Society of Petroleum Engineering. 
models, different language definitions of crude oil, and so on. Besides these uncertainties, other factors that make it hard to determine the "peak oil" are (1) cost and investment risk, (2) technological, political and environmental challenges, and (3) future demand for world oil.

It is important to quantify uncertainty in peak oil in order to have a greater recognition of the range of possible outcomes. Unfortunately, this uncertainty has not been thoroughly studied and quantified, which makes it difficult to make decisions, such as planning capital spending and formulating energy policy. 


\section{BACKGROUND}

\section{Literature Review}

In the middle of the twentieth century, Hubbert (1956) proposed the "peak oil" concept attempting to forecast the ultimate recovery of crude oil for the U.S. and the world. The concept of peak oil recognized that production of finite, nonrenewable resources should begin at zero, rise to a peak, then decline continuously. Furthermore, he emphasized that there is no requirement that such a production curve be symmetrical or that it have only a single maximum. The peak time in his publication is inferred by a hand-drawn production curve given an assessment of a region's ultimate recoverable oil.

Later, Hubbert (1962) combined this idea with a mathematical model (logistic curve) to estimate the ultimate crude oil production of the U.S. from historical data including past production, proved reserves, and proved discoveries. He predicted that crude oil production would peak in the early 1970s for the US lower 48. This prediction turned out to be remarkably accurate.

\section{Hubbert's Model}

Hubbert (1956) presented and illustrated the peak oil concept for finite or nonrenewable resources. Assumptions for the peak oil concept are:

1. In the production of any resource of fixed magnitude, the production rate must begin at zero and must decline again to zero after passing through one or more maxima.

2. The area under the production curve plotted against time equals ultimate oil recovery 
as time approaches infinity.

Hubbert later used one complete production cycle and developed the mathematical model based on the logistic curve by assuming the production rate curve $(\mathrm{q}(\mathrm{t})$ or $\mathrm{dQ} / \mathrm{dt})$ could be expressed as a parabolic function of the cumulative production, Q, (Hubbert 1962, 1982),

$q(t)=\frac{d Q}{d t}=a Q+b Q^{2}$

When cumulative oil production is equal to ultimate oil recovery, $\mathrm{Q}_{\infty}$, the production rate q will be zero. At this point, from Eq. (1),

$$
b=-\frac{a}{Q_{\infty}}
$$

Combining Eq. (2) and Eq. (3),

$$
\frac{d Q}{\left(Q-\frac{Q}{Q_{\infty}}\right)}=a d t
$$

Integrating Eq. (3) from $t=t_{0}$ to $\infty$, the logistic cumulative oil production curve is

$$
\begin{gathered}
Q=\frac{Q_{\infty}}{\left[1+N_{0} e^{-a\left(t-t_{0}\right)}\right]} \\
\text { where } N_{0}=\frac{Q_{\infty}-Q_{0}}{Q_{\infty}}
\end{gathered}
$$

Substituting Eq. (4) into Eq. (1), the production rate curve as a function of time is 


$$
q(t)=\frac{d Q}{d t}=Q_{\infty} \frac{a N_{0} e^{-a\left(t-t_{0}\right)}}{\left[1+N_{0} e^{-a\left(t-t_{0}\right)}\right]^{2}}
$$

The maximum cumulative production rate is obtained by differentiating Eq. (1) and setting it to zero,

$$
Q_{M}=\frac{Q_{\infty}}{2}
$$

The maximum production rate can be obtained by substituting Eq. (7) into Eq. (1),

$$
q_{M}=\frac{a Q_{\infty}}{4}
$$

To find the time at the maximum production rate or maximum cumulative production rate, Eq. (7) can be equated with Eq. (4),

$$
t_{M}=t_{0}+\frac{\ln \left(N_{0}\right)}{a}
$$

There are four parameters for Eq. (4) and Eq. (6). In order to analyze historical production data with these equations conveniently, I can reduce the number of parameters and the complexity of the equations. The cumulative production can be expressed in terms of ultimate oil recovery and peak time by substituting $t_{0}$ from Eq. (9) into Eq. (4),

$$
Q=\frac{Q_{\infty}}{\left[1+e^{-a\left(t-t_{M}\right)}\right]}
$$

Differentiating Eq. (10), 
$q(t)=\frac{d Q}{d t}=\frac{Q_{\infty} a e^{-a\left(t-t_{M}\right)}}{\left[1+e^{-a\left(t-t_{M}\right)}\right]^{2}}$

Eq. (10) is the type of logistic curve found by Verhulst in 1845 with population studies, and its derivative, Eq. (11), is the so-called Hubbert curve. The curve in Eq. (11) can be simplified using the hyperbolic secant function,

$q(t)=\frac{Q_{\infty} \sec h^{2}\left[\frac{\left(t-t_{M}\right)}{2 S_{L}}\right]}{4 S_{L}}$

where $S_{L}=\frac{1}{a}$

Hubbert's model has historical oil production data versus time following a symmetric bell-shaped curve. Hence, another mathematical model often used in fitting historical production data is the normal distribution model because of its similar curve shape compared to Hubbert's logistic model. Bartlett (2000) applied the normal distribution model to predict crude oil production for the U.S and the world.

\section{Normal Distribution Model}

The probability density function for a normal distribution is given by a formula

$f(x)=\frac{1}{\sqrt{2 \pi} \sigma} e^{-\frac{(x-\mu)^{2}}{2 \sigma^{2}}}, \quad-\infty<x<\infty$

where $\mu=$ the mean (the peak of the bell curve), and 
$\sigma=$ the standard deviation ( a measure of the width of the bell curve).

The area under the probability density function in Eq. (14) is equal to one. Thus, I can transfer the original mathematical form of the normal distribution into the production rate curve with the three parameters $\mathrm{Q}_{\infty}, \mathrm{t}_{\mathrm{M}}$, and $\mathrm{S}_{\mathrm{N}}$,

$$
q(t)=\frac{Q_{\infty}}{\sqrt{2 \pi} S_{N}} e^{-\frac{\left(t-t_{M}\right)^{2}}{2 S_{N}^{2}}}
$$

where $\mathrm{Q}_{\infty}=$ ultimate oil recovery,

$t_{M}=$ the time at the maximum production rate, or the timing of peak oil, and $\mathrm{S}_{\mathrm{N}}=$ the width parameter.

Between Eq. (12) and Eq. (15), there exists only one difference between parameters of these two equations, i.e., the width of the curves. In addition, two important parameters, $\mathrm{Q}_{\infty}$ and $\mathrm{t}_{\mathrm{M}}$, are both in Eq. (12) and Eq. (15), and it will be convenient to compare the difference between these two models for uncertainty analyses.

\section{Debates over Peak Oil}

After Hubbert, other authors (Bartlett 2000; Brandt 2007; Laherrere 1997) also developed or utilized different mathematical or statistical models to forecast oil production trends and predict ultimate recoverable resources. Laherrere $(1997,2000)$ pointed out that Hubbert's model applied for forecasting production only works well in nature's domain, unaffected by political or significant economic interference, and for areas having a large number of fields and unfettered activity. In addition, he also found 
that historical production curves from different countries with a smaller number of basins and fields have more than one peak, but almost all of the peaks are individually symmetrical in their upper parts. Because of these constraints and weaknesses in predicting crude oil production with Hubbert's model, Laherrere (1997) modified the Hubbert model and applied multiple-cycle concepts to describe the production trends by fitting historical production data into two or more peaks instead of a complete production cycle. He called this approach "multiple-Hubbert modeling."

A number of authors in Group 1 of Bentley's paper (2008) evaluate conventional world oil resources by adding cumulative production, the $2 \mathrm{P}$ value of discovery data (P50 oil reserves), and estimates of yet-to-find. However, the $2 \mathrm{P}$ value of discovery data cannot be determined effectively because potential prices and technology development can drive it to increase significantly. Although the different kinds of models suggested by these papers rely heavily on analyzing historical production data or projecting the $2 \mathrm{P}$ value of discovery data to predict ultimate recoverable resources of crude oil, they generally neglect uncertainty within the models, the production data and discovery data.

Only a few publications (Brandt 2007; Laherrere 2007) acknowledge or attempt to quantify the considerable uncertainty associated with forecasts of world crude oil production. These papers indicate that uncertainty from inaccurate production data is primarily caused by the motive, language, and reporting data. Inaccurate data may result from political motivations to publish inexact amount of reserves, different reserves definitions, and ambiguous words in reporting data like oil, crude oil, and liquids. Most authors probably realize that uncertainty affects their forecasts, but they do not put much 
emphasis on quantifying the uncertainty associated with forecasting crude oil production.

Since Hubbert presented the concept of peak oil, there has existed a long-standing debate over the optimism (e.g., Lynch 2003) and pessimism (e.g., Campbell 2003) associated with ultimate oil recovery and the timing of peak oil. Campbell (2003) relies primarily on Hubbert-type analyses and argues that there will be an imminent peak and decline in production rate from resource constraints. The position of Lynch (2003) is that there is no imminent peak. He argues that the main flaw in Hubbert-type models is that they consider ultimate recoverable resources as a fixed amount rather than a dynamic number that can be raised from application of new technology, knowledge, capability, and other factors. In addition, these conditions can be combined together to increase recovery by developing new producing areas and lowering economic limitations. Thus, he critiqued problems with Hubbert-type models by pointing out that they ignore the potential impact of price, technology, politics, and other factors.

Edwards (1997) and Bentley et al. (2008) both reviewed publications forecasting global oil production dating from 1956. From Tables 1 of both papers, I find that most previous publications focused on finding reasonable mathematical and statistical models to describe the past history production trend and project the future oil production rate, like Hubbert's, by fitting past production or discovery data in order to forecast oil production trends. Most authors attempted to illustrate how uncertainty played a key role in the forecasts. For example, Laherrere (2007) ever demonstrated that forecasts was affected significantly by uncertainty of data from reserves definitions, reporting errors 
within production data, and language definition of conventional oil, but they still do not quantify the uncertainty well because their assessments usually depend on deterministic methods and yield only single values with no ranges. Bentley et al. (2008) classified the forecasts from individual, organizations and institutions into three different groups: Group 1- quantitative analyses which predict that global oil production will come to a resource-limited peak in the near term and certainly before 2020; Group 2 - forecasts that use quantitative methods, but which appear to have no production peak within the forecasted time period (2020 or 2030); and Group 3- non-quantitative analyses that do not predict a resource-limited oil peak within the foreseeable future. The predictions from these groups covered a wide range, from imminent peaks to no imminent peaks.

Based on review of the literature above, I find it useful to divide between those papers that are like Hubbert's (imminent peak) and those that do not predict an imminent peak. Both groups have bases for their position, but both fail to convincingly quantify the uncertainty in their forecasts. Because of this, viewpoints are polarized and the rhetoric is pointed, and sometimes personal.

The wide range of forecasts made by different groups and summarized by Bentley et al. (2008) easily make us realize that large uncertainty exists in estimates of world crude oil production and peak time. However, most only give a single value rather than a possible range. There is a clear need to develop and apply probabilistic methods in order to quantify the true uncertainty in estimates of world conventional oil resources and time to peak oil production rate. 


\section{OBJECTIVE}

The overall objective of this study is to rigorously quantify the uncertainty in estimates of world conventional oil resources and time to peak world oil production rate. A secondary objective is to quantify the uncertainty in conventional oil production of the lower U.S. 48 as a contrast to the uncertainty in the estimates of world recoverable oil resources. 


\section{METHODOLOGY FOR QUANTIFYING THE UNCERTAINTY}

\section{Overview}

The methodologies applied to quantify the uncertainty in my work are mathematical modeling and multiple experts system. The reason for choosing the mathematical modeling for developing the uncertainty quantification is to examine how the forecasts generated by the models can be significantly affected by the uncertainty existed in production data and model predictive errors. Besides, due consideration to wider range of forecasts for world conventional oil production, it is helpful to conduct multiple experts system for analyzing the uncertainty among these forecasts.

Finally, I will integrate the two methodologies into an overall assessment of the uncertainty in estimates of world conventional resources.

\section{Mathematical Modeling of Uncertainty}

In the petroleum industry, we often apply statistical and probabilistic methods to evaluate original hydrocarbons in place (OHIP) in a reservoir because of the large uncertainty due to scarcity and inaccuracy of data. For the same reason, I will use a regression method based on past production using Hubbert's model and other mathematical models to quantify the uncertainty. However, I conduct the analysis probabilistically, considering errors in both the data and the model, which results in likelihood probability distributions for world conventional oil production and time to peak rate. 
In my analysis, definition of the likelihood function depends on the specification of a model for the uncertainty associated with the observed production data every year. The likelihood function is obtained by combining the production data, $\mathrm{d}^{\text {obs }}$, with a forward model, $\mathrm{g}(\mathrm{x})$, that predicts production data every year implicitly as a function of $\mathrm{Q}_{\infty}, \mathrm{t}_{\mathrm{M}}$, and $\mathrm{S}_{\mathrm{N}}$ for the normal distribution model, and also $\mathrm{Q}_{\infty}, \mathrm{t}_{\mathrm{M}}$, and $\mathrm{S}_{\mathrm{L}}$ for Hubbert's model. The vector $\mathrm{g}(\mathrm{x})$ consists of the predicted production data using the normal distribution or Hubbert's model. The production data misfits (observed data minus forward model) is assumed to follow a normal distribution, which is represented as

$$
f\left(d^{o b s} \mid x\right)=\frac{1}{(2 \pi)^{n_{d} / 2}\left[\operatorname{det}\left(C_{D}\right)\right]^{1 / 2}} \cdot \exp \left\{-\frac{1}{2}\left[\left(g(x)-d^{o b s}\right)^{T} C_{D}^{-1}\left(g(x)-d^{o b s}\right)\right]\right\}
$$

where $\mathrm{n}_{\mathrm{d}}=$ the number of measured (observed) data points.

In Eq. (16), $\mathrm{d}^{\text {obs }}$ is the vector of observed production data for every year and can be expressed as

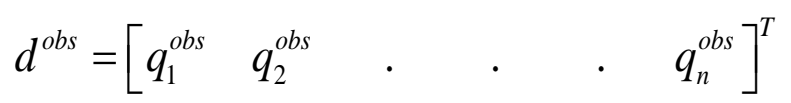

In Eq. (16), $\mathrm{C}_{\mathrm{D}}$ is the data covariance. I assume the errors in the observed production data are uncorrelated and the standard deviations of all observed production data are different. I assume that the variances of historical production data are a specific ratio $(\mathrm{R})$ of the production value of every year, and I can get the covariance matrix:

$$
C_{D}=\left[\begin{array}{ccccc}
\sigma_{q_{1}}^{2} & 0 & \cdot & \cdot & 0 \\
0 & \sigma_{q_{2}}^{2} & 0 & \cdot & \cdot \\
\cdot & 0 & \cdot & 0 & \cdot \\
\cdot & \cdot & 0 & \cdot & 0 \\
0 & \cdot & \cdot & 0 & \sigma_{q_{n_{d}}}^{2}
\end{array}\right]_{n_{d} \times n_{d}}=R\left[\begin{array}{ccccc}
q_{1}^{o b s} & 0 & \cdot & \cdot & 0 \\
0 & q_{2}^{o b s} & 0 & \cdot & \cdot \\
\cdot & 0 & \cdot & 0 & \cdot \\
\cdot & \cdot & 0 & \cdot & 0 \\
0 & \cdot & \cdot & 0 & q_{n_{d}}^{o b s}
\end{array}\right]_{n_{d} \times n_{d}}
$$


In Eq. (16), $\mathrm{g}(\mathrm{x})$ is the vector of production data of every year predicted by the forward model and can be written as

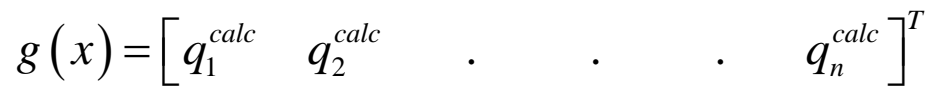

The variances in Eq. (18) include both the uncertainty in the model and errors within the data. I can effectively analyze the uncertainty existing in the model and data by choosing a reasonable variance and comparing the goodness of fit between the model prediction and data using either Hubbert's model or the normal distribution model. I use the sum-of-square norm to indicate the mismatch between the production data and model prediction. The sum-of-square norm can be defined as

$S_{o} S=\frac{1}{n} \sum_{i=1}^{n}\left[\frac{\left(q_{i}^{o b s}-q_{i}^{c a l}\right)}{\sigma_{i}}\right]^{2}$

The standard deviation in Eq. (20) is expressed as a ratio of the production data

$\sigma_{i}^{2}=R q_{i}^{o b s}$

Combining Eq. (20) and Eq. (21),

$S_{o} S=\frac{1}{n} \sum_{i=1}^{n}\left[\frac{\left(q_{i}^{o b s}-q_{i}^{c a l}\right)}{\sqrt{R q_{i}^{o b s}}}\right]^{2}=\frac{1}{n R} \sum_{i=1}^{n} \frac{\left(q_{i}^{o b s}-q_{i}^{c a l}\right)^{2}}{q_{i}^{o b s}}$

\section{Multiple Experts System for Analyzing Uncertainty}

Over a long period of time, expert judgments have been used to provide useful information in forecasting, decision-making, and assessing risks, and its application 
fields are quite diverse, including aerospace, medicine, the nuclear industry, veterinary science, agriculture, meteorology, economics, and psychology.

Experts play an important role in risk and decision analysis because their judgments can provide valuable information, especially considering the limited availability of hard data related to a great number of important uncertainties in risk analysis. Simply speaking, the purpose of using multiple experts is to obtain additional information that can generate more accurate forecasts or estimates. The decision-maker must choose and decide which expert(s) to consult to obtain information such as estimates or probabilities. Forecast accuracy can be improved by combining individual forecasts from multiple experts.

The objective of a multiple expert analysis is usually to obtain a single distribution that covers the beliefs of a number of experts. A specific distribution is specified by each expert individually. These distributions are usually considered to be independent of one another. Then, these distributions are aggregated into a single distribution mathematically.

A simple mathematical technique used widely to combine each the distributions of multiple experts is linear opinion pooling. The individual distributions $\left\{\mathrm{f}_{1}(\varphi), \ldots\right.$, $\left.\mathrm{f}_{\mathrm{n}}(\varphi)\right\}$, from each expert can be combined to obtain a consensus distribution, $\mathrm{f}(\varphi)$, by the following function,

$$
f(\varphi)=\sum_{i=1}^{n} \alpha_{i} f_{i}(\varphi)
$$

Eq. (23) is a weighted average of the individual distributions from each expert, and 
the weighting parameter $\alpha_{i}$ sums to 1 . Here, I may choose larger weighting parameters for some experts than others. When the decision maker considers all expert's views reasonable and his/her beliefs encompass the full range of the opinions from all experts, the linear opinion pooling is more appropriate. This method puts more emphasis on the area where most values of $\varphi$ overlap, but it does not exclude the low or high values of $\varphi \quad$ suggested by only one expert (Clemen 1989; O’Hagan et al. 2006).

In my study, I use a multiple-experts analysis to combine estimates from the multitude of papers presented in the literature to build an opinion pool, and then produce a probabilistic distribution of assessments in world conventional oil resources. 


\section{PRODUCTION DATA ANALYSIS WITH MATHEMATICAL MODEL}

Conventional oil production data from the U.S. and the world are analyzed in many publications because of abundant historical production data and accessible data sources. I obtained production data from the Energy Information Administration (EIA 1996, 2009) for my analysis.

I select the Hubbert model and normal distribution model as my forward model, and then I attempt to find the ranges for the three parameters that yields the $3 \mathrm{D}$ parameter space that bounds all significant probability. I can obtain the overall possible predicted production data by sampling the three parameters within their ranges. Substituting the predicting production data into Eq. (16), I get the likelihood function value for every set of three parameters. In quantifying the uncertainty, all possible outcomes of uncertain events could be considered and designated probabilities to give a reliable probability density function of the result of interest. Hence, from the overall parameter space, I will find the marginal probability function and cumulative density function for each parameter, and classify the cumulative probability function into P90, P50, P10 and mean value.

From the standpoint of the probabilistic method, it will be helpful to realize the uncertainty in the estimates of ultimate oil recovery and maximum peak year. In addition, I am also interested to examine how the uncertainty from the scarcity of production data can significantly affect the forecasts by choosing past production data only before 1956 . 


\section{ANALYSIS OF CONVENTIONAL OIL RESOURCES OF THE U.S. 48}

I obtained conventional oil production data of the U.S. lower 48 from Energy Information Administration of the U.S. (EIA, 1996; 2009). Fig. 1 is the production plot from the year 1860 to 2008 . There is a clear peak in the production rate and a clearly established decline.

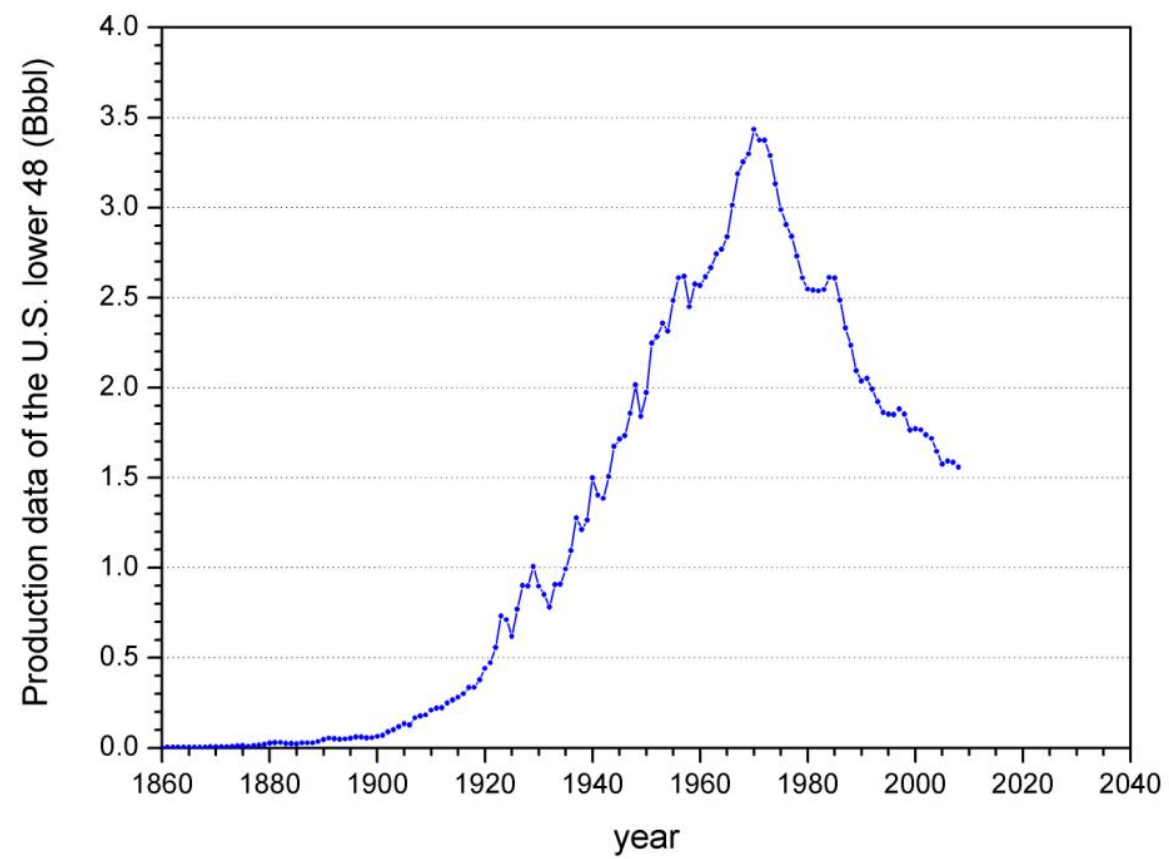

Fig. 1 - Production curve of the U.S. lower 48

The variance ratio (R) in Eq. (18) determines the model plus data errors for the uncertainty analyses in the likelihood function. Because I do not know what the actual variance ratio is, I choose different variance ratios to determine the extent of uncertainty 
that can results from various data and model predictive errors. I developed and compared the uncertainty quantification in these scenarios for both Hubbert's model and the normal distribution model.

To do the analysis for any scenario, I have to determine the specific data range for each parameter. After obtaining the value of likelihood function of all parameter sets, I may find that some parameter sets have extremely small (or zero) probability or my parameter ranges do not include all possible values with significant probability. Thus, I need to examine and modify my data intervals until I cover all the possible parameter values with significant probability.

From the likelihood function values within the parameter space, marginal probability density functions (PDF) and cumulative density distributions (CDF) for each parameter can be easily obtained. In addition, I find the parameter set with maximum likelihood function value in the parameter space. This is the parameter set that would be obtained as the best fitting parameters estimated by using a least square method, which is independent of the variance ratio. I get the P90, P50, P10, and mean values for each parameter from the CDF plots, and find the other parameters with its corresponding maximum likelihood function value from the parameter space.

For the uncertainty analyses of conventional oil resources of the lower U.S. 48, I first take all production data up to 2008 to analyze with both Hubbert's model and Normal distribution model. Second, I only use the data before the year 1956, and this was done primarily to gain insights into the degree of uncertainty associated with forecasts made prior to peak rate (as was the case for U.S. lower 48 production in 1956), which should 
help in the analysis of world oil production, which has apparently not yet reached a peak rate. This was also done as a historical curiosity, in order to quantify the uncertainty in U.S. production at the time Hubbert made his famous prediction. Finally, I compare and interpret the results of uncertainty analyses for these four schemes in the summary section. 


\section{Hubbert Model with Production Data up to 2008}

Table 1 lists the data intervals and number of data points that define the discretized parameter space for different variance ratios.

Table 1 - Different variance ratio for Hubbert model with production data up to 2008 of the lower U.S. 48

\begin{tabular}{c|cc|cc|cc}
\hline \multirow{2}{*}{$\begin{array}{c}\text { Variance } \\
\text { Ratio }\end{array}$} & \multicolumn{2}{|c|}{$\mathrm{R}=0.05$} & \multicolumn{2}{|c|}{$\mathrm{R}=0.20$} & \multicolumn{2}{|c}{$\mathrm{R}=0.50$} \\
\cline { 2 - 6 } & Data Interval & points & Data Interval & points & Data Interval & Points \\
\hline $\mathrm{Q}_{\infty}(\mathrm{Bbbl})$ & $101 \sim 400$ & 300 & $101 \sim 400$ & 300 & $101 \sim 400$ & 300 \\
$\mathrm{t}_{\mathrm{M}}(\mathrm{yr})$ & $1961 \sim 1980.8$ & 200 & $1961 \sim 1980.8$ & 100 & $1961 \sim 1990.7$ & 100 \\
$\mathrm{~S}_{\mathrm{L}}(1 / \mathrm{yr})$ & $11 \sim 20.95$ & 200 & $11 \sim 20.9$ & 100 & $6 \sim 25.8$ & 100 \\
\hline
\end{tabular}

Fig. 2, Fig. 4, and Fig. 6 are the plots of normalized PDF for each parameter $\mathrm{Q}_{\infty}, \mathrm{t}_{\mathrm{M}}$, and $S_{L}$. Fig. 3, Fig. 5, and Fig. 7 are the plots of CDF for these three parameters, respectively. I obtained the P90, P50, P10, and mean values from the CDF of each parameter, which are shown in Table 2. Parameter sets found with maximum likelihood function value by taking the probabilistic value of each parameter are listed in Table 3, Table 4, and Table 5, and the sum-of-square norm $\left(\mathrm{S}_{0} \mathrm{~S}\right)$ values are also calculated. I choose one scenario $(\mathrm{R}=0.5)$ to plot the probabilistic forecasts for each parameter (Fig. 8, Fig. 9, and Fig. 10). 


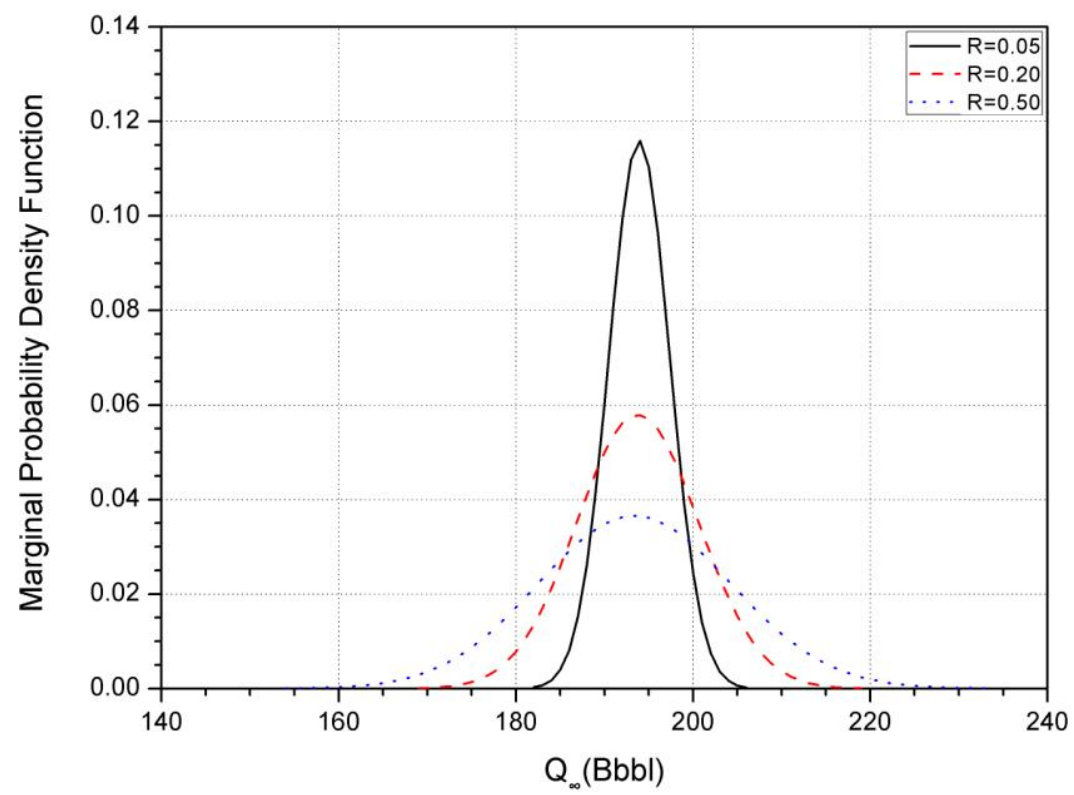

Fig. 2 - Marginal PDF of $Q_{\infty}$ for Hubbert model with production data up tp 2008 of the lower U.S. 48

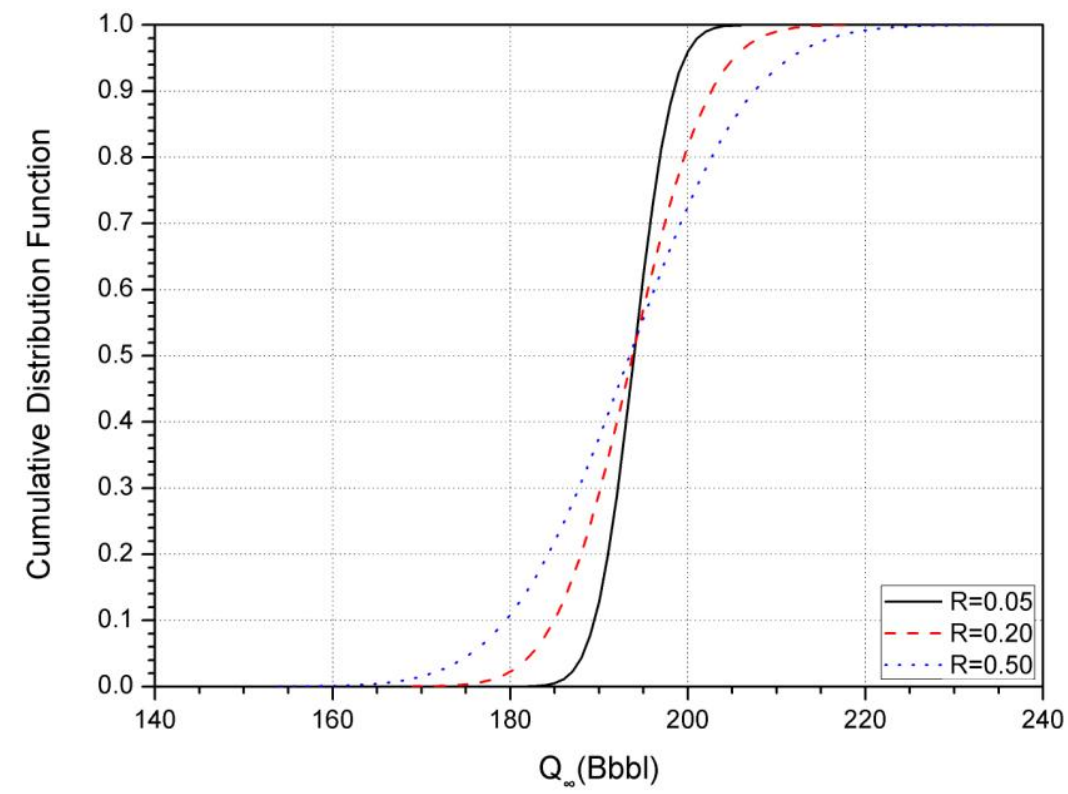

Fig. 3 - CDF of $Q_{\infty}$ for Hubbert model with production data up to 2008 of the lower U.S. 48 


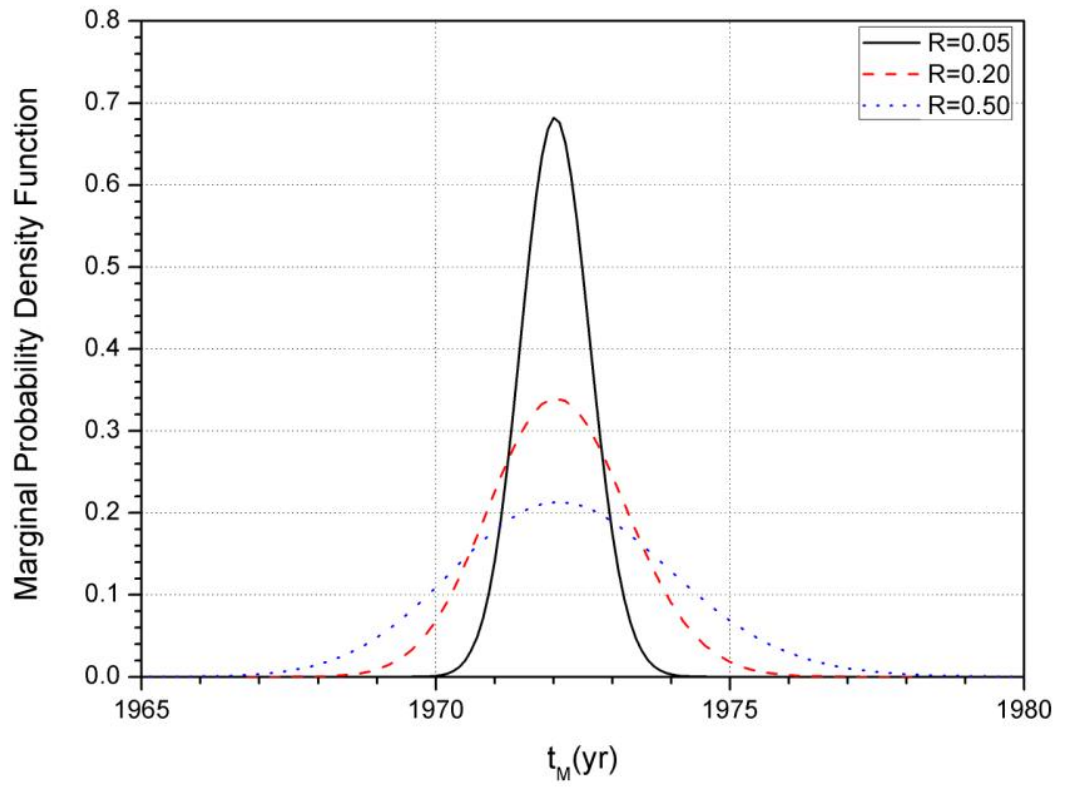

Fig. 4 - Marginal PDF of $t_{M}$ for Hubbert model with production data up tp 2008 of the lower U.S. 48

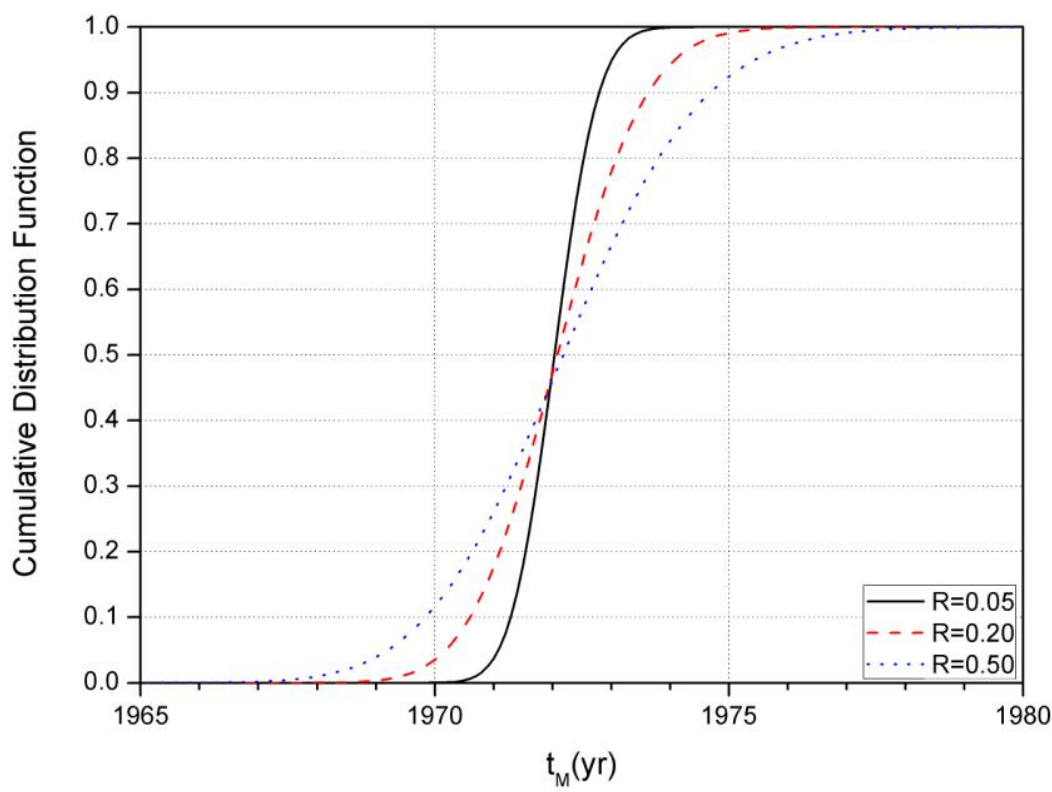

Fig. 5 - CDF of $t_{M}$ for Hubbert model with production data up to 2008 of the lower U.S. 48 


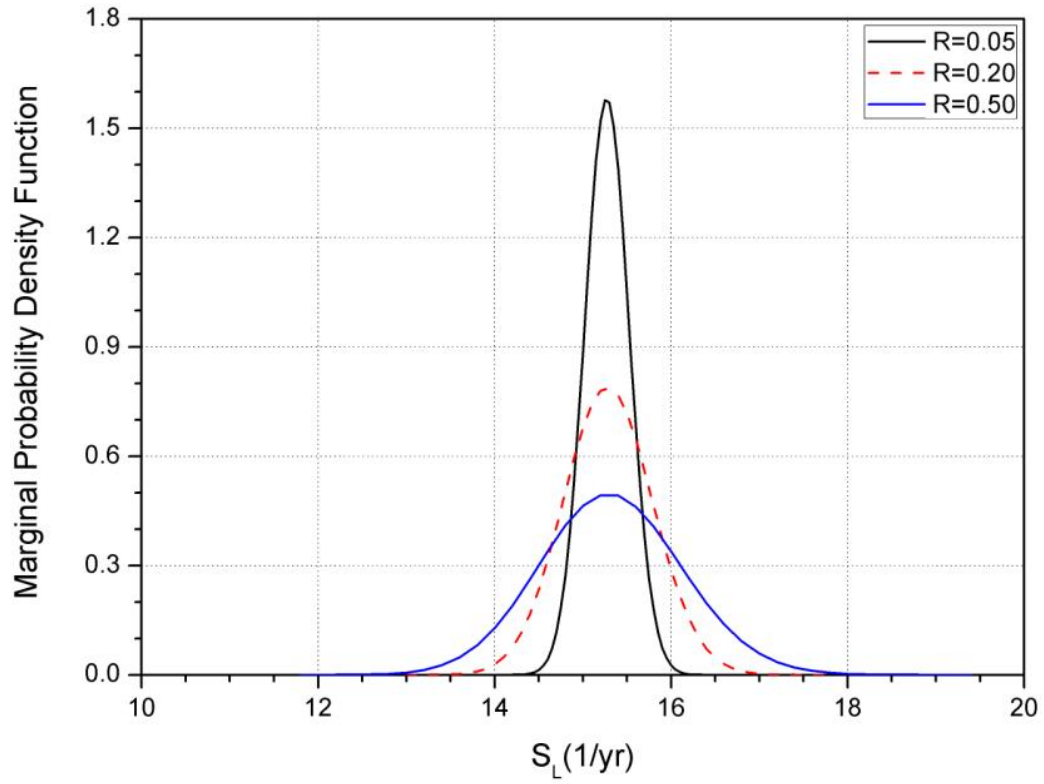

Fig. 6 - Marginal PDF of $S_{L}$ for Hubbert model with production data up to 2008 of the lower U.S. 48

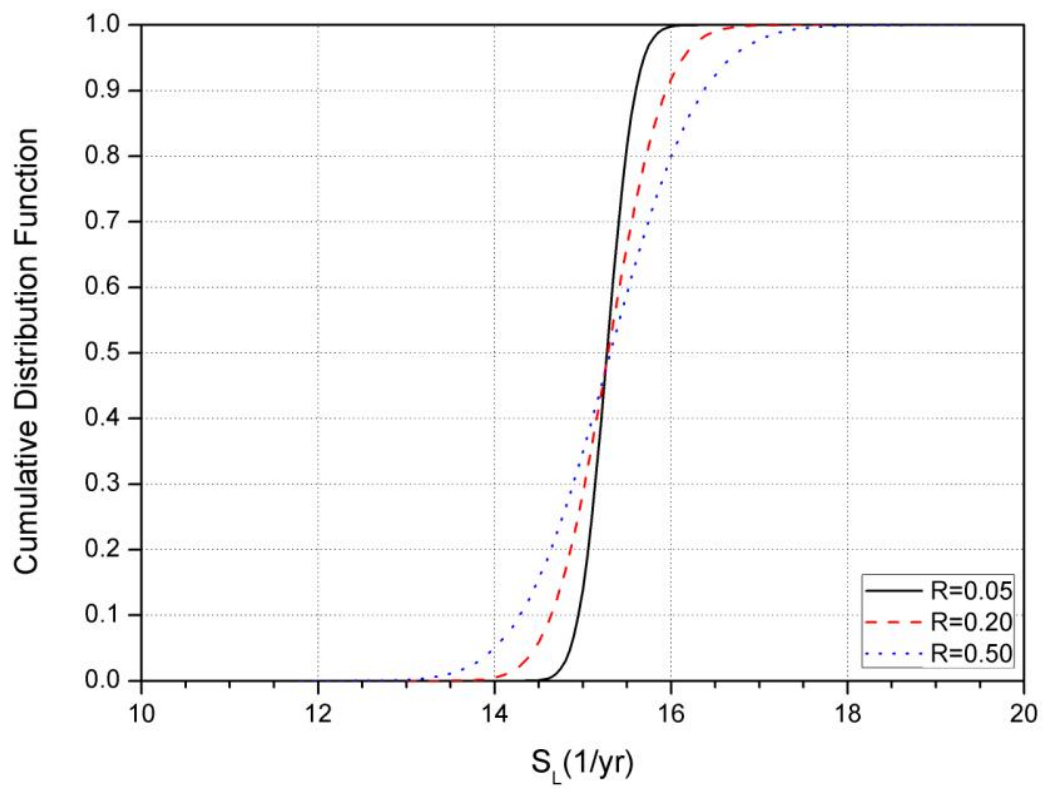

Fig. 7 - CDF of $S_{L}$ for Hubbert model with production data up to 2008 of the lower U.S. 48 
Table 2 - Probabilistic values of each parameter for Hubbert model with production data up to 2008 of the lower U.S. 48

\begin{tabular}{c|ccc|ccc|ccc}
\hline $\begin{array}{c}\text { Variance } \\
\text { Ratio }\end{array}$ & \multicolumn{3}{c}{$\mathrm{R}=0.05$} & \multicolumn{3}{c|}{$\mathrm{R}=0.20$} & & \multicolumn{2}{c}{$\mathrm{R}=0.50$} \\
\hline & $\mathrm{Q}_{\infty}$ & $\mathrm{t}_{\mathrm{M}}$ & $\mathrm{S}_{\mathrm{L}}$ & $\mathrm{Q}_{\infty}$ & $\mathrm{t}_{\mathrm{M}}$ & $\mathrm{S}_{\mathrm{L}}$ & $\mathrm{Q}_{\infty}$ & $\mathrm{t}_{\mathrm{M}}$ & $\mathrm{S}_{\mathrm{L}}$ \\
& $(\mathrm{Bbbl})$ & $(\mathrm{yr})$ & $(1 / \mathrm{yr})$ & $(\mathrm{Bbbl})$ & $(\mathrm{yr})$ & $(1 / \mathrm{yr})$ & $(\mathrm{Bbbl})$ & $(\mathrm{yr})$ & $(1 / \mathrm{yr})$ \\
\hline P90 & 189.497 & 1971.287 & 14.950 & 184.946 & 1970.600 & 14.641 & 179.497 & 1969.846 & 14.291 \\
P50 & 193.925 & 1972.031 & 15.272 & 193.760 & 1972.080 & 15.285 & 193.435 & 1972.182 & 15.311 \\
P10 & 198.365 & 1972.790 & 15.598 & 202.619 & 1973.622 & 15.942 & 207.487 & 1974.676 & 16.366 \\
Mean & 193.928 & 1972.035 & 15.273 & 193.774 & 1972.099 & 15.289 & 193.470 & 1972.231 & 15.322 \\
Best-fit & 194 & 1972.0 & 15.25 & 194 & 1972.0 & 15.30 & 194 & 1971.8 & 15.20 \\
\hline
\end{tabular}

Table 3 - Parameter sets for Hubbert model with production data up to 2008 of the lower U.S. 48 (R=0.05)

\begin{tabular}{|c|c|c|c|c|c|c|c|c|c|c|c|c|}
\hline \multirow{2}{*}{$\mathrm{R}=0.05$} & \multicolumn{4}{|c|}{$\mathrm{Q}_{\infty}$} & \multicolumn{4}{|c|}{$t_{M}$} & \multicolumn{4}{|c|}{$\mathrm{S}_{\mathrm{L}}$} \\
\hline & $\begin{array}{c}\mathrm{Q}_{\infty} \\
(\mathrm{Bbbl})\end{array}$ & $\begin{array}{l}\mathrm{t}_{\mathrm{M}} \\
(\mathrm{yr})\end{array}$ & $\begin{array}{c}\mathrm{S}_{\mathrm{L}} \\
(1 / \mathrm{yr})\end{array}$ & $\mathrm{S}_{\mathrm{o}} \mathrm{S}$ & $\begin{array}{c}\mathrm{Q}_{\infty} \\
(\mathrm{Bbbl})\end{array}$ & $\begin{array}{l}\mathrm{t}_{\mathrm{M}} \\
(\mathrm{yr})\end{array}$ & $\begin{array}{c}\mathrm{S}_{\mathrm{L}} \\
(1 / \mathrm{yr})\end{array}$ & $\mathrm{S}_{\mathrm{o}} \mathrm{S}$ & $\begin{array}{c}\mathrm{Q}_{\infty} \\
(\mathrm{Bbbl})\end{array}$ & $\begin{array}{l}\mathrm{t}_{\mathrm{M}} \\
(\mathrm{yr})\end{array}$ & $\begin{array}{c}\mathrm{S}_{\mathrm{L}} \\
(1 / \mathrm{yr})\end{array}$ & $\mathrm{S}_{\mathrm{o}} \mathrm{S}$ \\
\hline P90 & 189 & 1971.8 & 15.15 & 0.4731 & 193 & 1971.3 & 15.10 & 0.4692 & 193 & 1971.7 & 14.95 & 0.4698 \\
\hline P50 & 194 & 1972.0 & 15.25 & 0.4589 & 194 & 1972.0 & 15.25 & 0.4589 & 194 & 1972.0 & 15.25 & 0.4589 \\
\hline P10 & 198 & 1972.2 & 15.35 & 0.4681 & 195 & 1972.8 & 15.45 & 0.4708 & 195 & 1972.4 & 15.60 & 0.4705 \\
\hline Mean & 194 & 1972.0 & 15.25 & 0.4589 & 194 & 1972.0 & 15.25 & 0.4589 & 194 & 1972.0 & 15.25 & 0.4589 \\
\hline
\end{tabular}


Table 4 - Parameter sets for Hubbert model with production data up to 2008 of the lower U.S. 48 (R=0.2)

\begin{tabular}{|c|c|c|c|c|c|c|c|c|c|c|c|c|}
\hline \multirow{2}{*}{$\mathrm{R}=0.2$} & \multicolumn{4}{|c|}{$\mathrm{Q}_{\infty}$} & \multicolumn{4}{|c|}{$\mathrm{t}_{\mathrm{M}}$} & \multicolumn{4}{|c|}{$\mathrm{S}_{\mathrm{L}}$} \\
\hline & $\begin{array}{c}\mathrm{Q}_{\infty} \\
(\mathrm{Bbbl})\end{array}$ & $\begin{array}{c}\mathrm{t}_{\mathrm{M}} \\
(\mathrm{yr})\end{array}$ & $\begin{array}{c}\mathrm{S}_{\mathrm{L}} \\
(1 / \mathrm{yr})\end{array}$ & $\mathrm{S}_{\mathrm{O}} \mathrm{S}$ & $\begin{array}{c}\mathrm{Q}_{\infty} \\
(\mathrm{Bbbl})\end{array}$ & $\begin{array}{c}\mathrm{t}_{\mathrm{M}} \\
(\mathrm{yr})\end{array}$ & $\begin{array}{c}\mathrm{S}_{\mathrm{L}} \\
(1 / \mathrm{yr})\end{array}$ & $\mathrm{S}_{\mathrm{o}} \mathrm{S}$ & $\begin{array}{c}\mathrm{Q}_{\infty} \\
(\mathrm{Bbbl})\end{array}$ & $\begin{array}{c}\mathrm{t}_{\mathrm{M}} \\
(\mathrm{yr})\end{array}$ & $\begin{array}{c}\mathrm{S}_{\mathrm{L}} \\
(1 / \mathrm{yr})\end{array}$ & $\mathrm{S}_{\mathrm{o}} \mathrm{S}$ \\
\hline P90 & 185 & 1971.6 & 15.1 & 0.1262 & 192 & 1970.6 & 15.0 & 0.1250 & 191 & 1971.4 & 14.6 & 0.1268 \\
\hline P50 & 194 & 1972.0 & 15.3 & 0.1148 & 194 & 1972.0 & 15.3 & 0.1148 & 194 & 1972.0 & 15.3 & 0.1148 \\
\hline P10 & 203 & 1972.4 & 15.4 & 0.1263 & 196 & 1973.6 & 15.6 & 0.1266 & 196 & 1972.8 & 15.9 & 0.1251 \\
\hline Mean & 194 & 1972.0 & 15.3 & 0.1148 & 194 & 1972.0 & 15.3 & 0.1148 & 194 & 1972.0 & 15.3 & 0.1148 \\
\hline
\end{tabular}

Table 5 - Parameter sets for Hubbert model with production data up to 2008 of the lower U.S. 48 (R=0.5)

\begin{tabular}{|c|c|c|c|c|c|c|c|c|c|c|c|c|}
\hline \multirow{2}{*}{$\mathrm{R}=0.5$} & \multicolumn{4}{|c|}{$\mathrm{Q}_{\infty}$} & \multicolumn{4}{|c|}{$\mathrm{t}_{\mathrm{M}}$} & \multicolumn{4}{|c|}{$\mathrm{S}_{\mathrm{L}}$} \\
\hline & $\begin{array}{c}\mathrm{Q}_{\infty} \\
(\mathrm{Bbbl})\end{array}$ & $\begin{array}{c}\mathrm{t}_{\mathrm{M}} \\
(\mathrm{yr})\end{array}$ & $\begin{array}{c}\mathrm{S}_{\mathrm{L}} \\
(1 / \mathrm{yr})\end{array}$ & $\mathrm{S}_{\mathrm{O}} \mathrm{S}$ & $\begin{array}{c}\mathrm{Q}_{\infty} \\
(\mathrm{Bbbl})\end{array}$ & $\begin{array}{c}\mathrm{t}_{\mathrm{M}} \\
(\mathrm{yr})\end{array}$ & $\begin{array}{c}\mathrm{S}_{\mathrm{L}} \\
(1 / \mathrm{yr})\end{array}$ & $\mathrm{S}_{\mathrm{o}} \mathrm{S}$ & $\begin{array}{c}\mathrm{Q}_{\infty} \\
(\mathrm{Bbbl})\end{array}$ & $\begin{array}{c}\mathrm{t}_{\mathrm{M}} \\
(\mathrm{yr})\end{array}$ & $\begin{array}{c}\mathrm{S}_{\mathrm{L}} \\
(1 / \mathrm{yr})\end{array}$ & $\mathrm{S}_{\mathrm{o}} \mathrm{S}$ \\
\hline P90 & 179 & 1971.5 & 15.0 & 0.0588 & 190 & 1969.7 & 14.8 & 0.0570 & 189 & 1970.9 & 14.2 & 0.0583 \\
\hline P50 & 193 & 1971.8 & 15.2 & 0.0460 & 194 & 1972.1 & 15.2 & 0.0460 & 194 & 1972.1 & 15.4 & 0.0461 \\
\hline P10 & 207 & 1972.7 & 15.6 & 0.0555 & 198 & 1974.8 & 16.0 & 0.0600 & 198 & 1973.6 & 16.4 & 0.0589 \\
\hline Mean & 193 & 1971.8 & 15.2 & 0.0460 & 194 & 1972.1 & 15.2 & 0.0460 & 194 & 1972.1 & 15.4 & 0.0461 \\
\hline
\end{tabular}




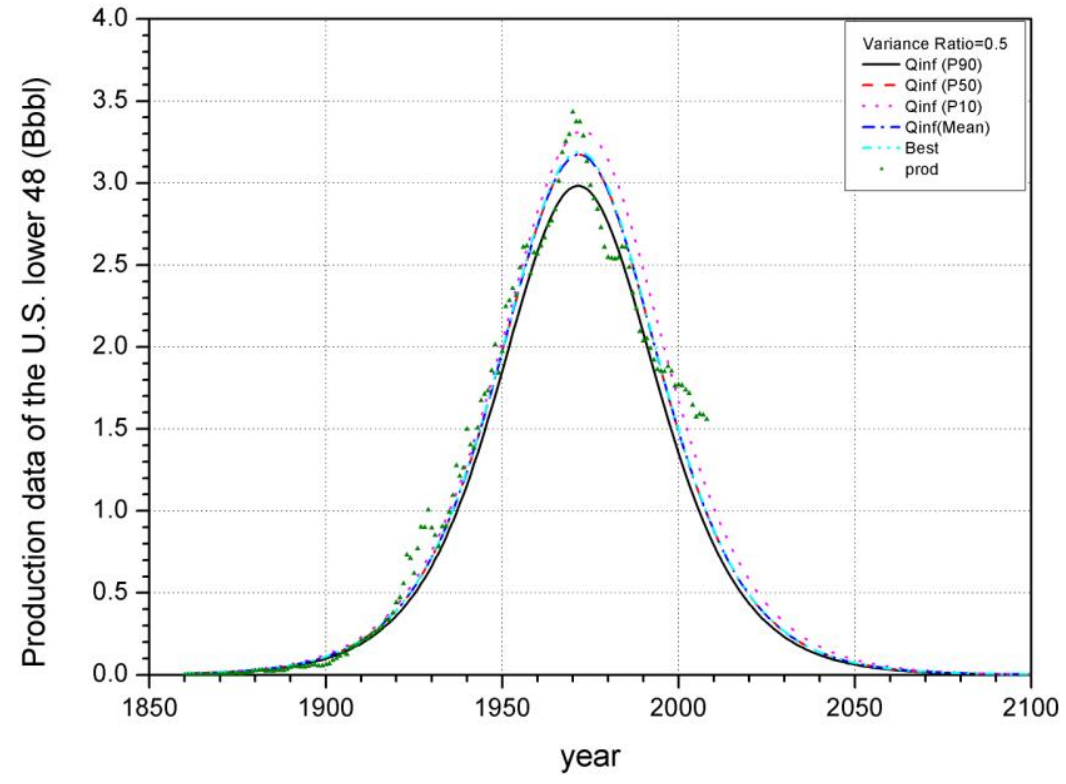

Fig. 8 - Probabilistic forecasts of $\mathrm{Q}_{\infty}$ for Hubbert model with production data up to 2008 of the lower U.S. $48(\mathrm{R}=0.5)$

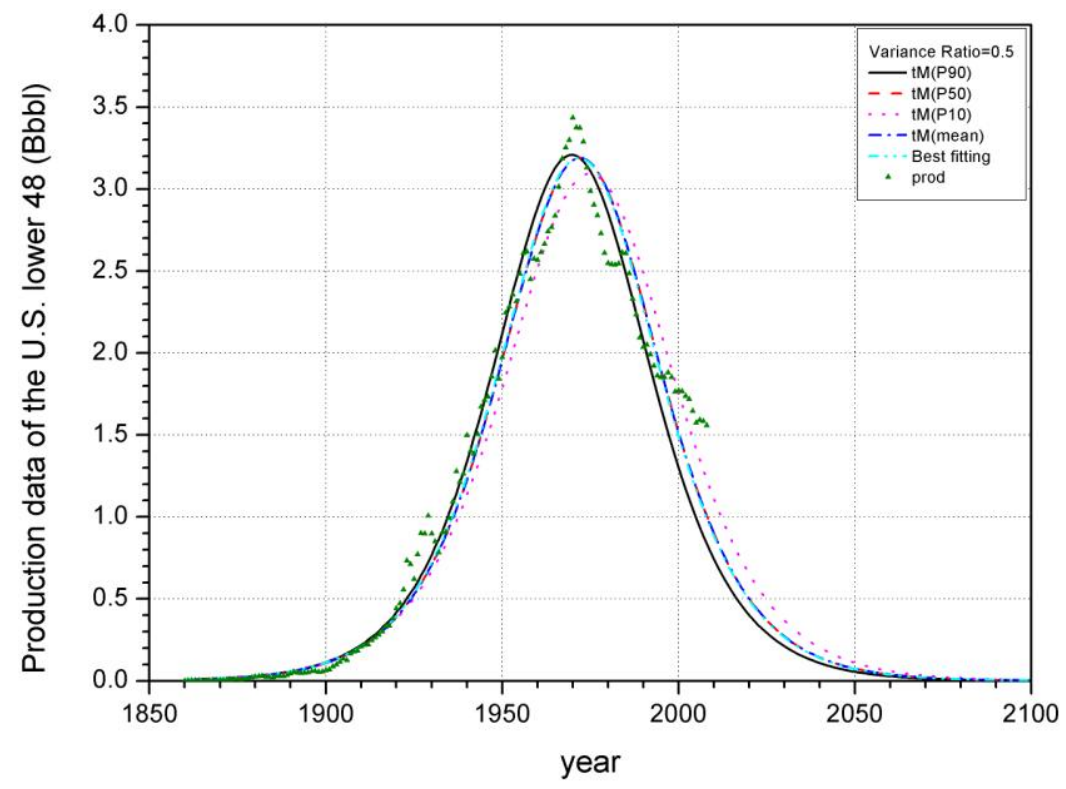

Fig. 9 - Probabilistic forecasts of $t_{M}$ for Hubbert model with production data up to 2008 of the lower U.S. $48(\mathrm{R}=0.5)$ 


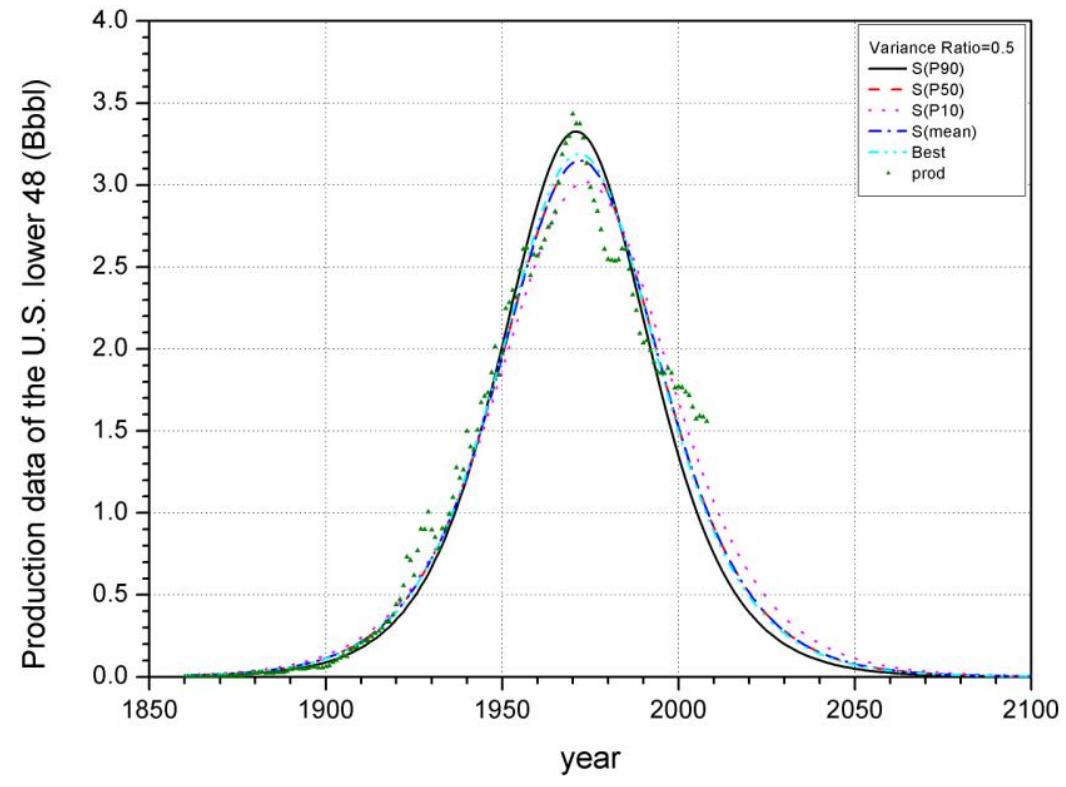

Fig. 10 - Probabilistic forecasts of $S_{L}$ for Hubbert model with production data up to 2008 of the lower U.S. $48(\mathrm{R}=0.5)$ 


\section{Normal Distribution Model with Production Data up to 2008}

Table 6 lists the data intervals and number of data points that define the discretized parameter space for different variance ratios.

Table 6 - Different variance ratio for Normal distribution model with production data up to 2008 of the lower U.S. 48

\begin{tabular}{c|cc|cc|cc}
\hline $\begin{array}{c}\text { Variance } \\
\text { Ratio }\end{array}$ & \multicolumn{2}{|c|}{$\mathrm{R}=0.05$} & \multicolumn{2}{|c}{$\mathrm{R}=0.20$} & \multicolumn{2}{c}{$\mathrm{R}=0.50$} \\
\hline $\mathrm{Q}_{\infty}$ & Data Interval & points & Data Interval & points & Data Interval & points \\
$(\mathrm{Bbbl})$ & $101 \sim 400$ & 300 & $101 \sim 400$ & 300 & $101 \sim 400$ & 300 \\
$\mathrm{t}_{\mathrm{M}}(\mathrm{yr})$ & $1961 \sim 1980.9$ & 200 & $1961 \sim 1980.8$ & 100 & $1961 \sim 1990.7$ & 100 \\
$\mathrm{~S}_{\mathrm{N}}(1 / \mathrm{yr})$ & $21 \sim 40.9$ & 200 & $21 \sim 40.8$ & 100 & $16 \sim 45.7$ & 100 \\
\hline
\end{tabular}

Fig. 11, Fig. 13, and Fig. 15 are the plots of normalized PDF for each parameter $\mathrm{Q}_{\infty}, \mathrm{t}_{\mathrm{M}}$, and $\mathrm{S}_{\mathrm{N}}$. Fig. 12, Fig. 14, and Fig. 16 are the plots of CDF for these three parameters, respectively. I obtained the P90, P50, P10, and mean value from the CDF of each parameter, which are shown in Table 7. Parameter sets found with maximum likelihood function value by taking the probabilistic value of each parameter are listed in Table 8, Table 9, and Table 10, and the sum-of-square norm $\left(\mathrm{S}_{0} \mathrm{~S}\right)$ values are also calculated. I chose one scenario $(\mathrm{R}=0.5)$ to plot the probabilistic forecasts for each parameter (Fig. 17, Fig. 18 and Fig. 19). 


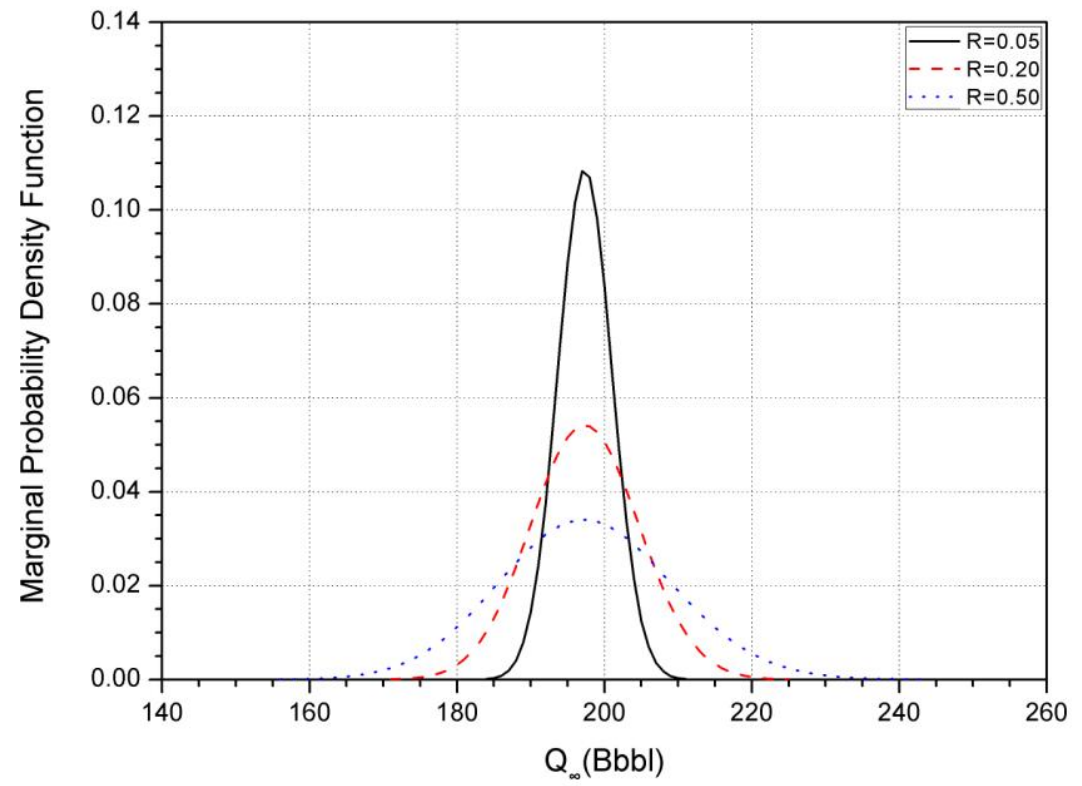

Fig. 11 - Marginal PDF of $Q_{\infty}$ for Normal distribution model with production data up to 2008 of the lower U.S. 48

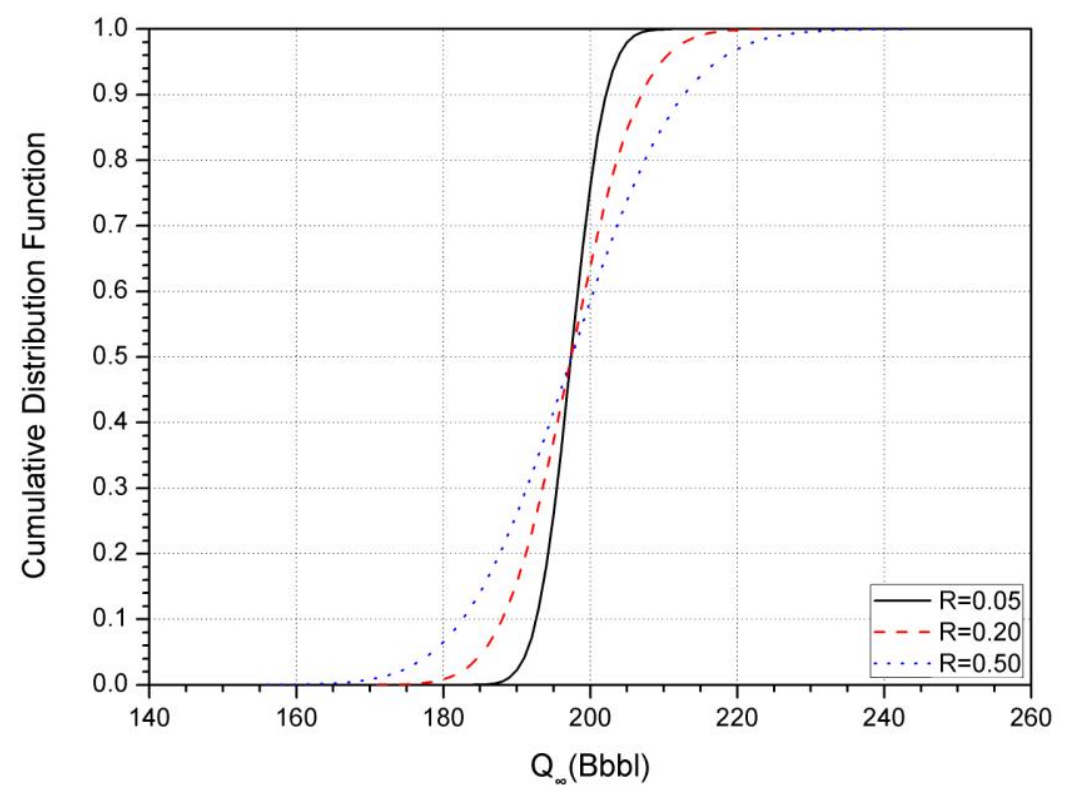

Fig. 12 - CDF of $Q_{\infty}$ for Normal distribution model with production data up to 2008 of the lower U.S. 48 


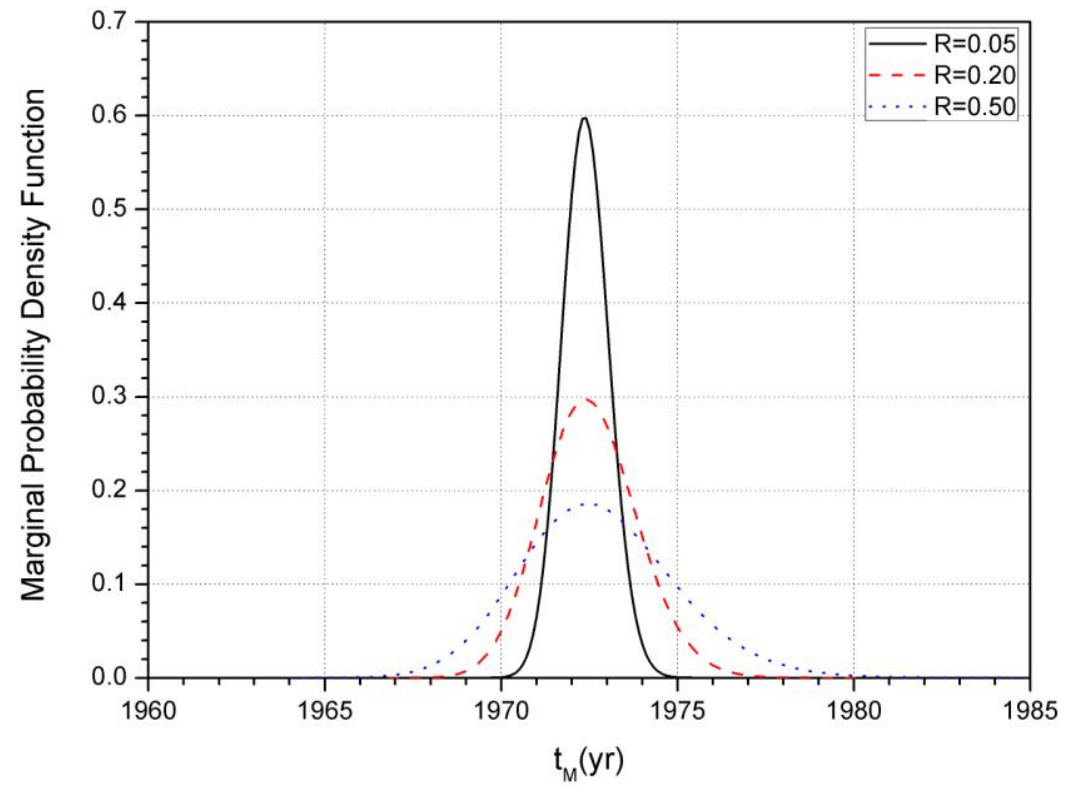

Fig. 13 - Marginal PDF of $t_{M}$ for Normal distribution model with production data up to 2008 of the lower U.S. 48

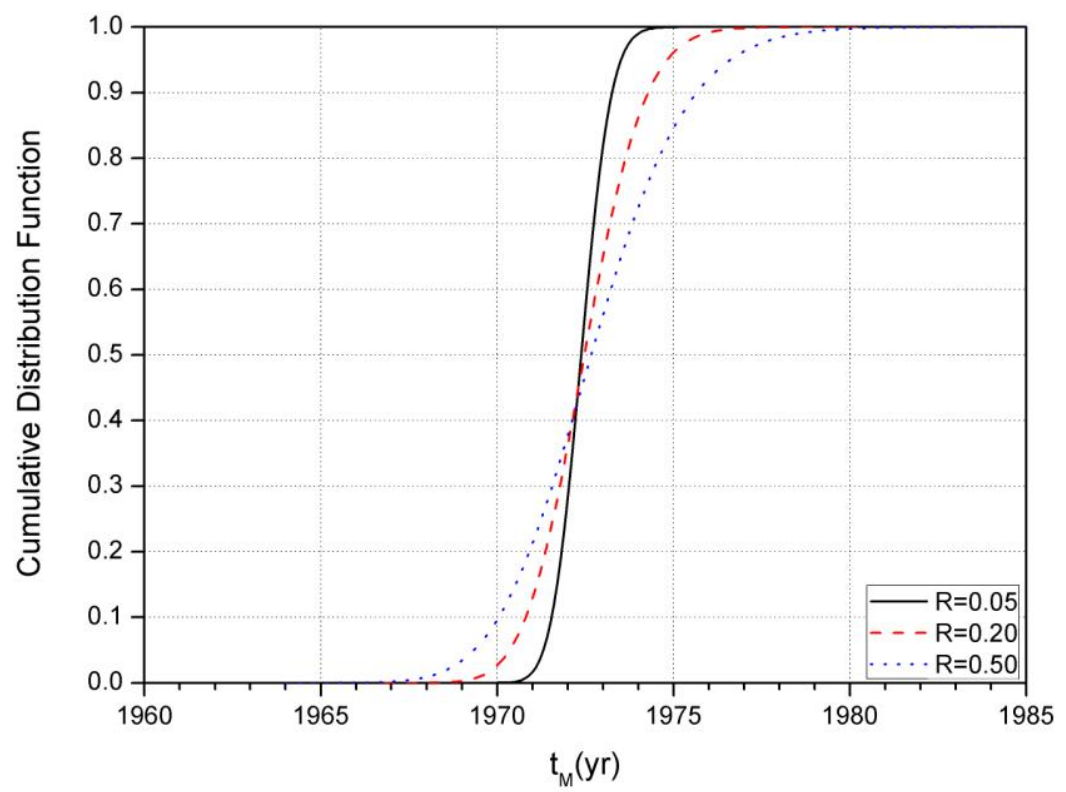

Fig. 14 - CDF of $t_{M}$ for Normal distribution model with production data up to 2008 of the lower U.S. 48 


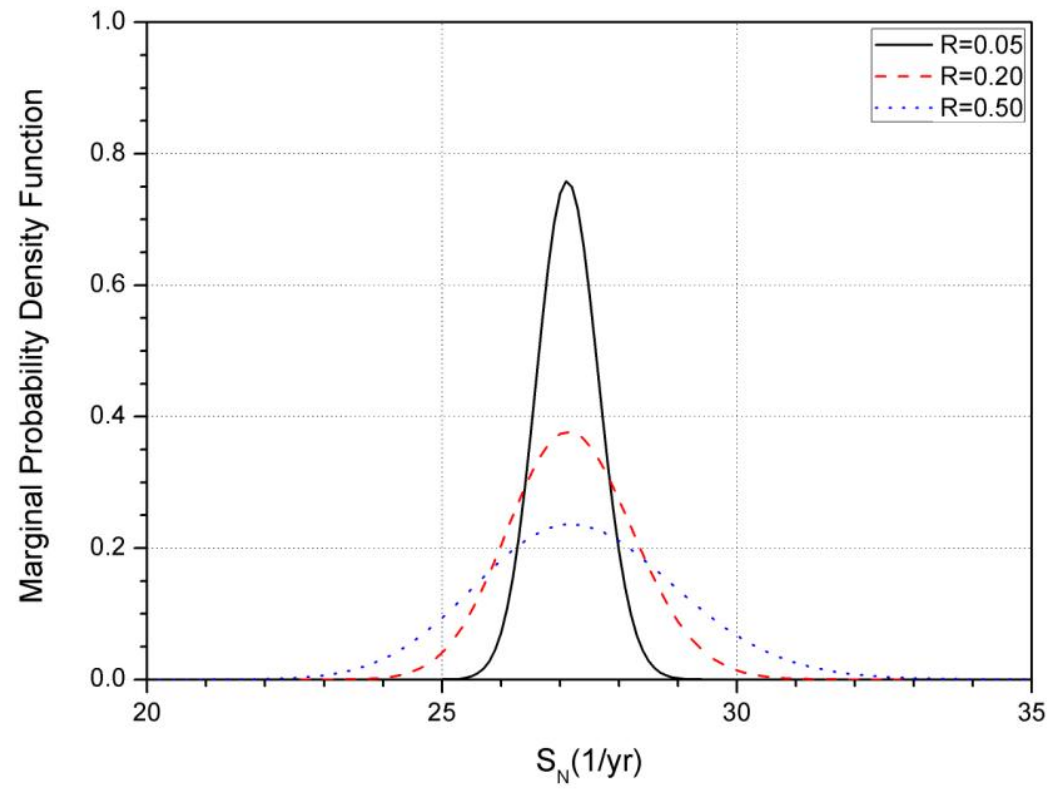

Fig. 15 - Marginal PDF of $\mathrm{S}_{\mathrm{N}}$ for Normal distribution model with production data up to 2008 of the lower U.S. 48

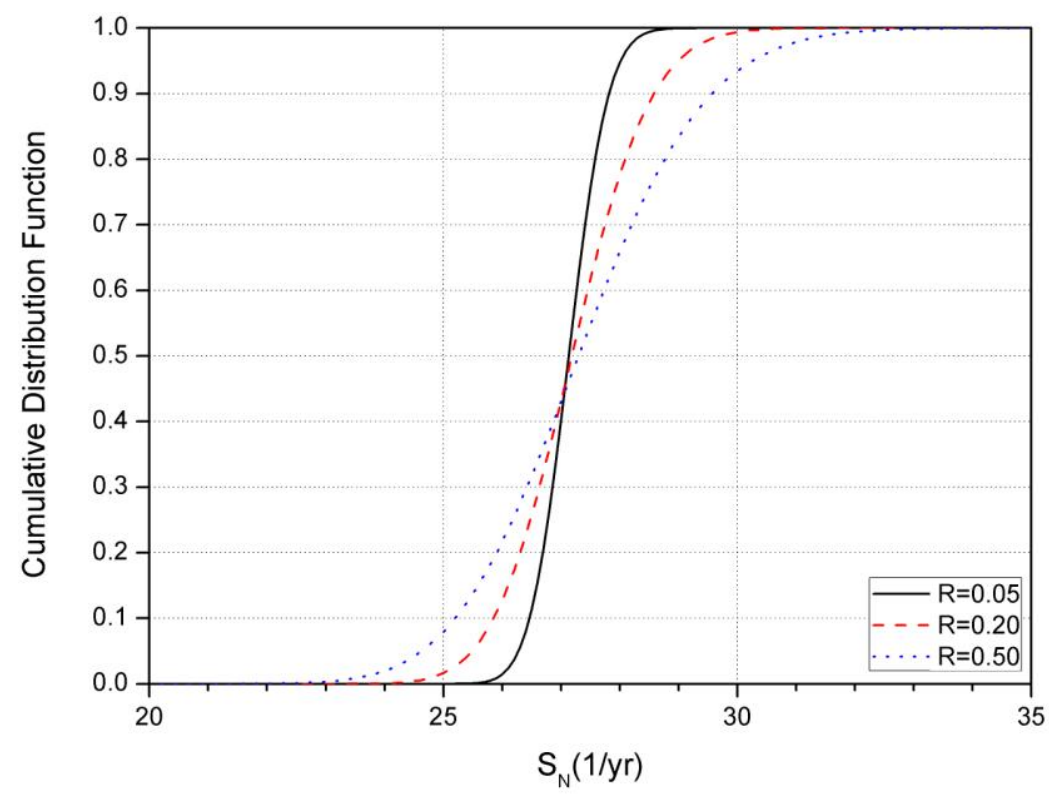

Fig. 16 - CDF of $S_{N}$ for Normal distribution model with production data up to 2008 of the lower U.S. 48 
Table 7 - Probabilistic values of each parameter for Normal distribution model with production data up to 2008 of the lower U.S. 48

\begin{tabular}{|c|c|c|c|c|c|c|c|c|c|}
\hline \multirow[t]{2}{*}{$\begin{array}{c}\text { Variance } \\
\text { Ratio }\end{array}$} & \multicolumn{3}{|c|}{$\mathrm{R}=0.05$} & \multicolumn{3}{|c|}{$\mathrm{R}=0.20$} & \multicolumn{3}{|c|}{$\mathrm{R}=0.50$} \\
\hline & $\begin{array}{c}\mathrm{Q}_{\infty} \\
(\mathrm{Bbbl})\end{array}$ & $\begin{array}{c}\mathrm{t}_{\mathrm{M}} \\
(\mathrm{yr})\end{array}$ & $\begin{array}{c}\mathrm{S}_{\mathrm{N}} \\
(1 / \mathrm{yr})\end{array}$ & $\begin{array}{c}\mathrm{Q}_{\infty} \\
(\mathrm{Bbbl})\end{array}$ & $\begin{array}{c}\mathrm{t}_{\mathrm{M}} \\
(\mathrm{yr})\end{array}$ & $\begin{array}{c}\mathrm{S}_{\mathrm{N}} \\
(1 / \mathrm{yr})\end{array}$ & $\begin{array}{c}\mathrm{Q}_{\infty} \\
(\mathrm{Bbbl})\end{array}$ & $\begin{array}{c}\mathrm{t}_{\mathrm{M}} \\
(\mathrm{yr})\end{array}$ & $\begin{array}{c}\mathrm{S}_{\mathrm{N}} \\
(1 / \mathrm{yr})\end{array}$ \\
\hline P90 & 192.650 & 1971.538 & 26.461 & 188.012 & 1970.808 & 25.856 & 182.616 & 1970.046 & 25.205 \\
\hline P50 & 197.360 & 1972.378 & 27.129 & 197.379 & 1972.471 & 27.184 & 197.440 & 1972.664 & 27.297 \\
\hline P10 & 202.110 & 1973.251 & 27.814 & 206.914 & 1974.273 & 28.578 & 212.716 & 1975.652 & 29.565 \\
\hline Mean & 197.372 & 1972.388 & 27.134 & 197.430 & 1972.514 & 27.204 & 197.579 & 1972.778 & 27.351 \\
\hline Best-fit & 197 & 1972.3 & 27.1 & 198 & 1972.4 & 27.2 & 197 & 1972.4 & 27.1 \\
\hline
\end{tabular}

Table 8 - Parameter sets for Normal distribution model with production data up to 2008 of the lower U.S. 48 (R=0.05)

\begin{tabular}{|c|c|c|c|c|c|c|c|c|c|c|c|c|}
\hline \multirow{2}{*}{$\mathrm{R}=0.05$} & \multicolumn{4}{|c|}{$\mathrm{Q}_{\infty}$} & \multicolumn{4}{|c|}{$\mathrm{t}_{\mathrm{M}}$} & \multicolumn{4}{|c|}{$\mathrm{S}_{\mathrm{N}}$} \\
\hline & $\begin{array}{c}\mathrm{Q}_{\infty} \\
(\mathrm{Bbbl})\end{array}$ & $\begin{array}{l}\mathrm{t}_{\mathrm{M}} \\
(\mathrm{yr})\end{array}$ & $\begin{array}{c}\mathrm{S}_{\mathrm{N}} \\
(1 / \mathrm{yr})\end{array}$ & $\mathrm{S}_{\mathrm{o}} \mathrm{S}$ & $\begin{array}{c}\mathrm{Q}_{\infty} \\
(\mathrm{Bbbl})\end{array}$ & $\begin{array}{l}\mathrm{t}_{\mathrm{M}} \\
(\mathrm{yr})\end{array}$ & $\begin{array}{c}\mathrm{S}_{\mathrm{N}} \\
(1 / \mathrm{yr})\end{array}$ & $\mathrm{S}_{\mathrm{O}} \mathrm{S}$ & $\begin{array}{c}\mathrm{Q}_{\infty} \\
(\mathrm{Bbbl})\end{array}$ & $\begin{array}{l}\mathrm{t}_{\mathrm{M}} \\
(\mathrm{yr})\end{array}$ & $\begin{array}{c}\mathrm{S}_{\mathrm{N}} \\
(1 / \mathrm{yr})\end{array}$ & $\mathrm{S}_{\mathrm{O}} \mathrm{S}$ \\
\hline P90 & 193 & 1972.1 & 26.9 & 0.2288 & 195 & 1971.5 & 26.7 & 0.2307 & 196 & 1971.9 & 26.5 & 0.2286 \\
\hline P50 & 197 & 1972.3 & 27.1 & 0.2193 & 197 & 1972.4 & 27.1 & 0.2194 & 197 & 1972.3 & 27.1 & 0.2193 \\
\hline P10 & 202 & 1971.7 & 27.4 & 0.2299 & 199 & 1973.2 & 27.5 & 0.2299 & 199 & 1972.9 & 27.8 & 0.2305 \\
\hline Mean & 197 & 1972.3 & 27.1 & 0.2193 & 197 & 1972.4 & 27.1 & 0.2194 & 197 & 1972.3 & 27.1 & 0.2193 \\
\hline
\end{tabular}


Table 9 - Parameter sets for Normal distribution model with production data up to 2008 of the lower U.S. 48 (R=0.20)

\begin{tabular}{|c|c|c|c|c|c|c|c|c|c|c|c|c|}
\hline \multirow{2}{*}{$\mathrm{R}=0.20$} & \multicolumn{4}{|c|}{$\mathrm{Q}_{\infty}$} & \multicolumn{4}{|c|}{$t_{M}$} & \multicolumn{4}{|c|}{$\mathrm{S}_{\mathrm{N}}$} \\
\hline & $\begin{array}{c}\mathrm{Q}_{\infty} \\
(\mathrm{Bbbl})\end{array}$ & $\begin{array}{c}\mathrm{t}_{\mathrm{M}} \\
(\mathrm{yr})\end{array}$ & $\begin{array}{c}\mathrm{S}_{\mathrm{N}} \\
(1 / \mathrm{yr})\end{array}$ & $\mathrm{S}_{\mathrm{o}} \mathrm{S}$ & $\begin{array}{c}\mathrm{Q}_{\infty} \\
(\mathrm{Bbbl})\end{array}$ & $\begin{array}{c}\mathrm{t}_{\mathrm{M}} \\
(\mathrm{yr})\end{array}$ & $\begin{array}{c}\mathrm{S}_{\mathrm{N}} \\
(1 / \mathrm{yr})\end{array}$ & $\mathrm{S}_{\mathrm{o}} \mathrm{S}$ & $\begin{array}{c}\mathrm{Q}_{\infty} \\
(\mathrm{Bbbl})\end{array}$ & $\begin{array}{c}\mathrm{t}_{\mathrm{M}} \\
(\mathrm{yr})\end{array}$ & $\begin{array}{c}\mathrm{S}_{\mathrm{N}} \\
(1 / \mathrm{yr})\end{array}$ & $\mathrm{S}_{\mathrm{o}} \mathrm{S}$ \\
\hline P90 & 188 & 1971.8 & 26.6 & 0.0660 & 194 & 1970.8 & 26.4 & 0.0645 & 194 & 1971.4 & 25.8 & 0.0658 \\
\hline P50 & 197 & 1972.2 & 27 & 0.0549 & 198 & 1972.4 & 27.2 & 0.0549 & 198 & 1972.4 & 27.2 & 0.0549 \\
\hline P10 & 207 & 1973 & 27.6 & 0.0663 & 201 & 1974.2 & 28 & 0.0668 & 201 & 1973.6 & 28.6 & 0.0676 \\
\hline Mean & 197 & 1972.2 & 27 & 0.0549 & 198 & 1972.6 & 27.2 & 0.0551 & 198 & 1972.4 & 27.2 & 0.0549 \\
\hline
\end{tabular}

Table 10 - Parameter sets for Normal distribution model with production data up to 2008 of the lower U.S. 48 (R=0.50)

\begin{tabular}{|c|c|c|c|c|c|c|c|c|c|c|c|c|}
\hline \multirow{2}{*}{$\mathrm{R}=0.50$} & \multicolumn{4}{|c|}{$\mathrm{Q}_{\infty}$} & \multicolumn{4}{|c|}{$t_{M}$} & \multicolumn{4}{|c|}{$\mathrm{S}_{\mathrm{N}}$} \\
\hline & $\begin{array}{c}\mathrm{Q}_{\infty} \\
(\mathrm{Bbbl})\end{array}$ & $\begin{array}{c}\mathrm{t}_{\mathrm{M}} \\
(\mathrm{yr})\end{array}$ & $\begin{array}{c}\mathrm{S}_{\mathrm{N}} \\
(1 / \mathrm{yr})\end{array}$ & $\mathrm{S}_{\mathrm{o}} \mathrm{S}$ & $\begin{array}{c}\mathrm{Q}_{\infty} \\
(\mathrm{Bbbl})\end{array}$ & $\begin{array}{c}\mathrm{t}_{\mathrm{M}} \\
(\mathrm{yr})\end{array}$ & $\begin{array}{c}\mathrm{S}_{\mathrm{N}} \\
(1 / \mathrm{yr})\end{array}$ & $\mathrm{S}_{\mathrm{o}} \mathrm{S}$ & $\begin{array}{c}\mathrm{Q}_{\infty} \\
(\mathrm{Bbbl})\end{array}$ & $\begin{array}{c}\mathrm{t}_{\mathrm{M}} \\
(\mathrm{yr})\end{array}$ & $\begin{array}{c}\mathrm{S}_{\mathrm{N}} \\
(1 / \mathrm{yr})\end{array}$ & $\mathrm{S}_{\mathrm{o}} \mathrm{S}$ \\
\hline P90 & 183 & 1971.5 & 26.5 & 0.0325 & 192 & 1970.0 & 26.2 & 0.0312 & 192 & 1971.2 & 25.3 & 0.0304 \\
\hline P50 & 197 & 1972.4 & 27.1 & 0.0219 & 198 & 1972.7 & 27.4 & 0.0222 & 198 & 1972.7 & 27.4 & 0.0222 \\
\hline P10 & 213 & 1973.6 & 28 & 0.0338 & 205 & 1975.7 & 28.9 & 0.0364 & 204 & 1974.5 & 29.5 & 0.0346 \\
\hline Mean & 198 & 1972.4 & 27.1 & 0.0220 & 198 & 1972.7 & 27.4 & 0.0222 & 198 & 1972.7 & 27.4 & 0.0222 \\
\hline
\end{tabular}




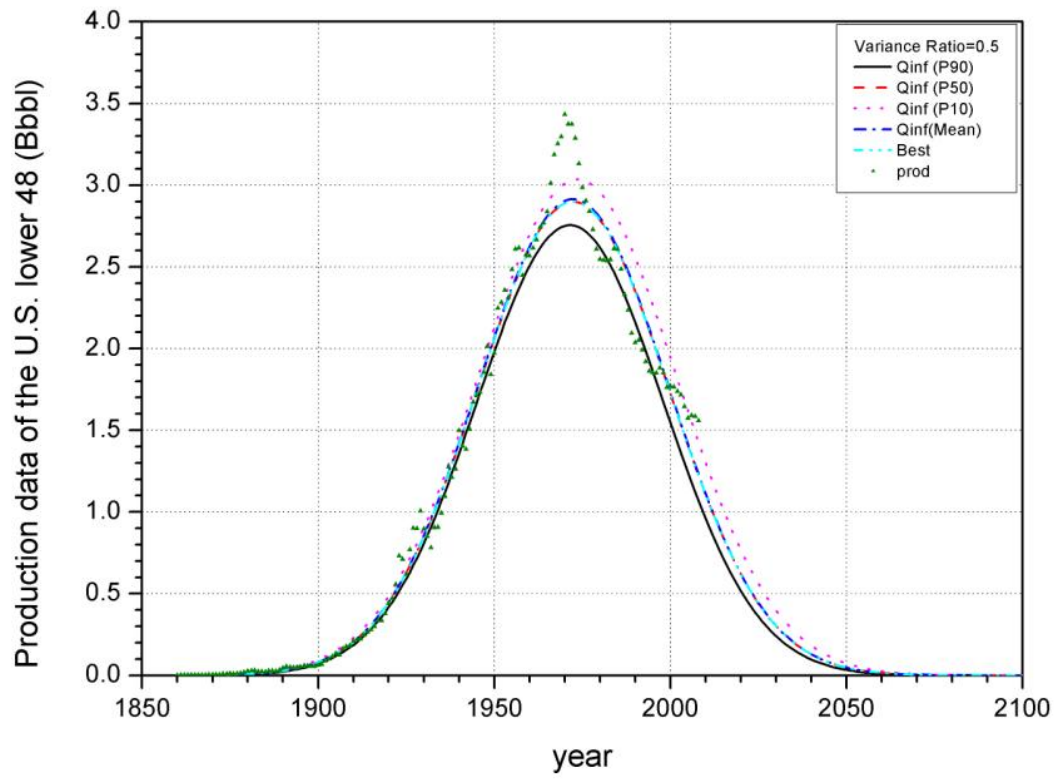

Fig. 17 - Probabilistic forecasts of $\mathrm{Q}_{\infty}$ for Normal Distribution model with production data up to 2008 of the lower U.S. $48(\mathrm{R}=0.5)$

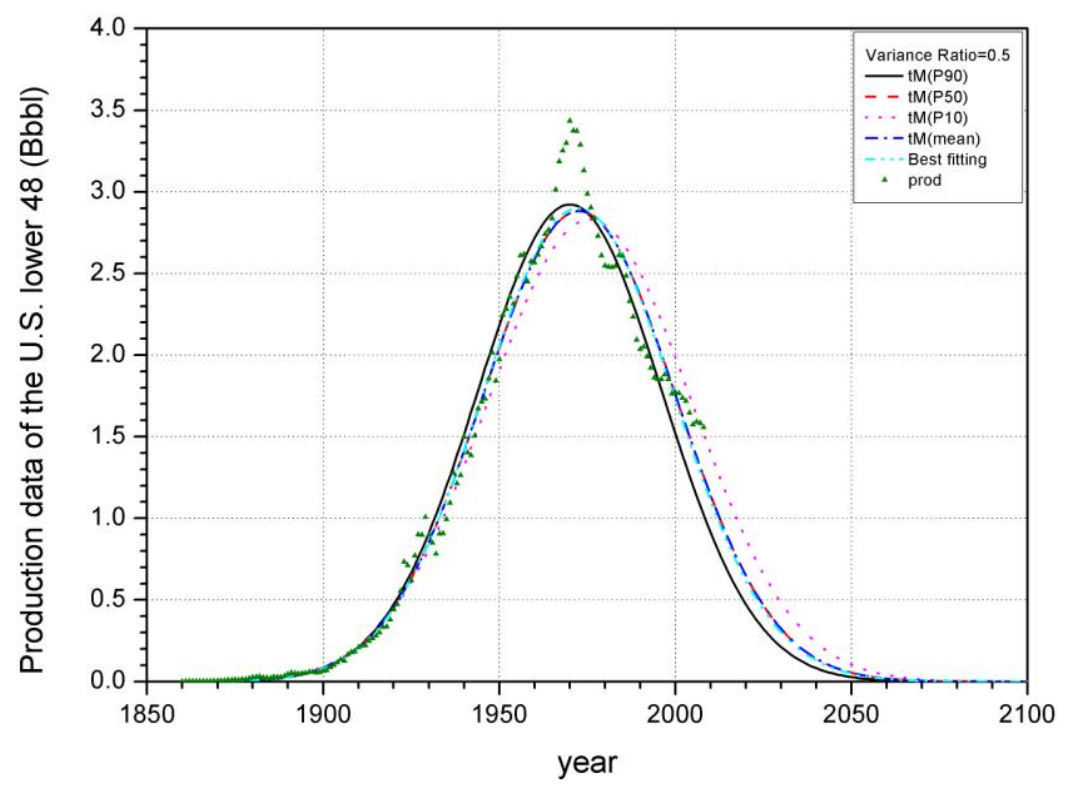

Fig. 18 - Probabilistic forecasts of $t_{M}$ for Normal Distribution model with production data up to 2008 of the lower U.S. $48(\mathrm{R}=0.5)$ 


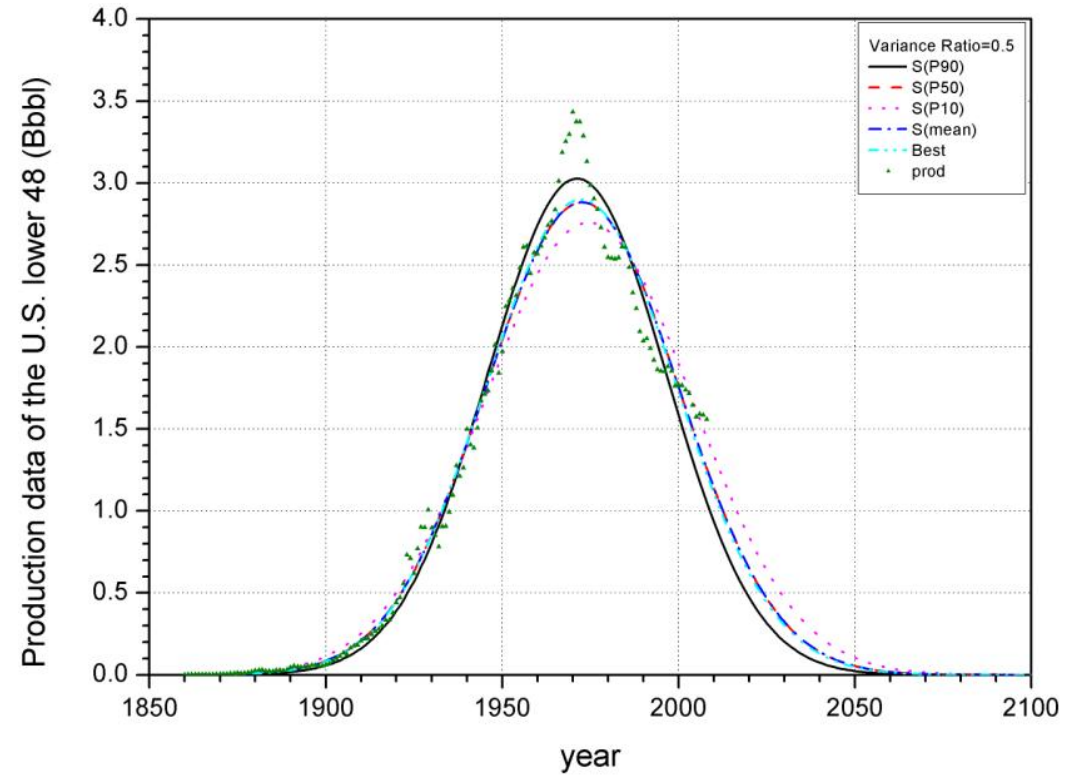

Fig. 19 - Probabilistic forecasts of $S_{N}$ for Normal Distribution model with production data up to 2008 of the lower U.S. $48(\mathrm{R}=0.5)$ 


\section{Hubbert Model with Production Data up to 1956}

Table 11 lists the data intervals and number of data points that define the discretized parameter space for different variance ratios.

Table 11 - Different variance ratio for Hubbert model with production data up to 1956 of the lower U.S. 48

\begin{tabular}{c|cc|cc|cc}
\hline \multirow{2}{*}{$\begin{array}{c}\text { Variance } \\
\text { Ratio }\end{array}$} & \multicolumn{2}{|c|}{$\mathrm{R}=0.01$} & \multicolumn{2}{|c}{$\mathrm{R}=0.02$} & \multicolumn{2}{|c}{$\mathrm{R}=0.155$} \\
\cline { 2 - 6 } & Data Interval & points & Data Interval & points & Data Interval & points \\
\hline $\mathrm{Q}_{\infty}$ & $101 \sim 200.5$ & 200 & $81 \sim 180$ & 100 & $51 \sim 1049$ & 500 \\
$(\mathrm{Bbbl})$ & & & & & & 100 \\
$\mathrm{t}_{\mathrm{M}}(\mathrm{yr})$ & $1951 \sim 1970.9$ & 200 & $1951 \sim 1970.8$ & 100 & $1941 \sim 2040$ & \\
$\mathrm{~S}_{\mathrm{L}}(1 / \mathrm{yr})$ & $6 \sim 15.95$ & 200 & $6 \sim 15.95$ & 200 & $6 \sim 25.8$ & 100 \\
\hline
\end{tabular}

Fig. 20, Fig. 22, and Fig. 24 are the plots of normalized PDF for each parameter $\mathrm{Q}_{\infty}, \mathrm{t}_{\mathrm{M}}$, and $\mathrm{S}_{\mathrm{L}}$. Fig. 21, Fig. 23, and Fig. 25 are the plots of CDF for these three parameters, respectively. I obtained the P90, P50, P10, and mean value from the CDF of each parameter - Table 12. Parameter sets found with maximum likelihood function value by taking the probabilistic value of each parameter are listed in Table 13, Table 14, and Table 15, and the sum-of-square norm $\left(\mathrm{S}_{\mathrm{o}} \mathrm{S}\right)$ values are also calculated. I choose one scenario $(\mathrm{R}=0.155)$ to plot the probabilistic forecasts for each parameter (Fig. 26, Fig. 27, and Fig. 28). 


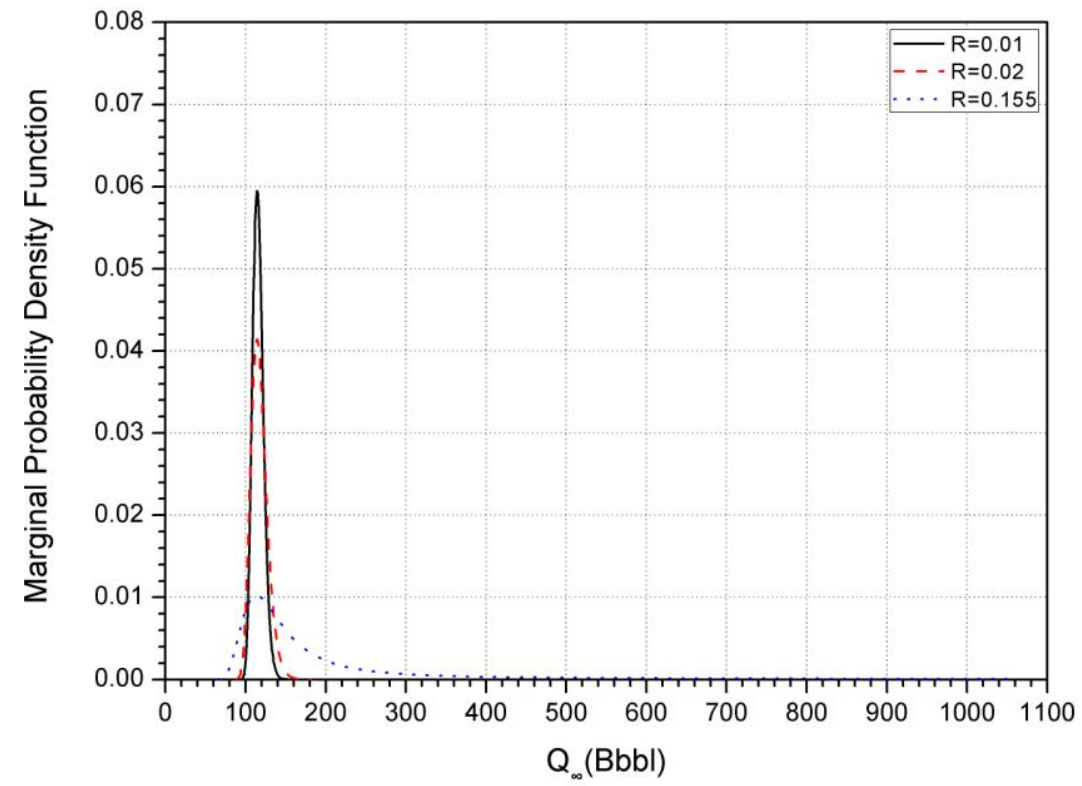

Fig. 20 - Marginal PDF of $Q_{\infty}$ for Hubbert model with production data up to 1956 of the lower U.S. 48

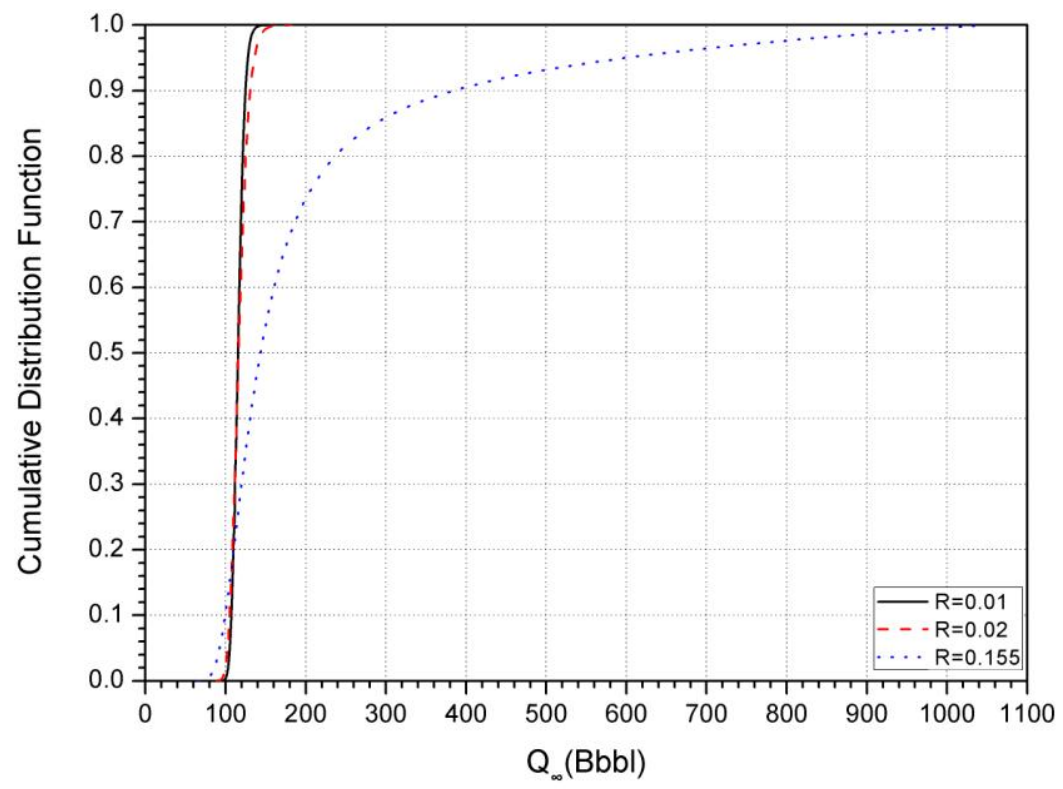

Fig. 21 - CDF of $\mathrm{Q}_{\infty}$ for Hubbert model with production data up to 1956 of the lower U.S. 48 


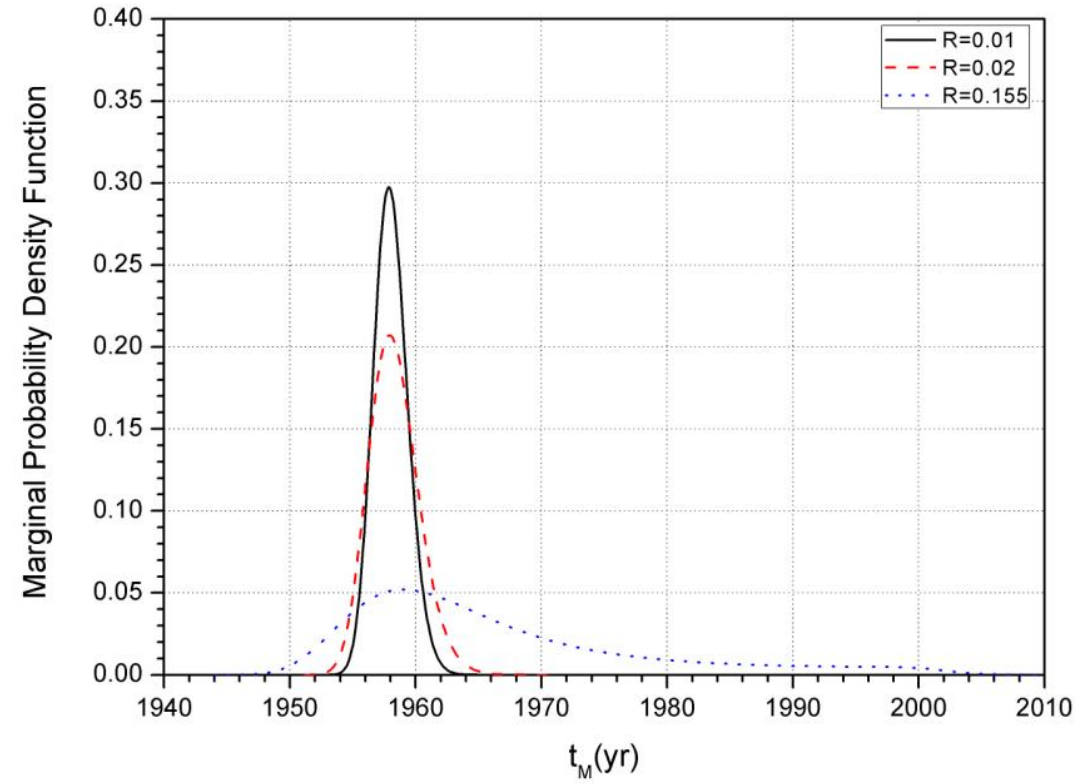

Fig. 22 - Marginal PDF of $t_{M}$ for Hubbert model with production data up to 1956 of the lower U.S. 48

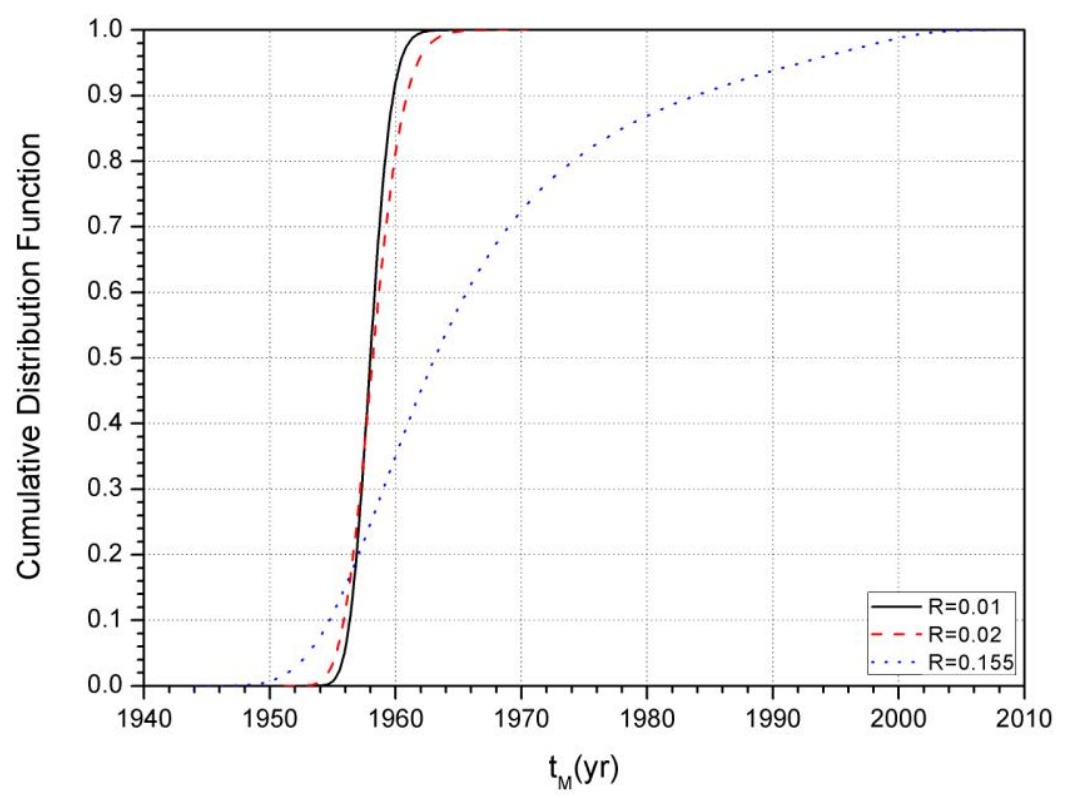

Fig. 23 - CDF of $t_{M}$ for Hubbert model with production data up to 1956 of the lower U.S. 48 


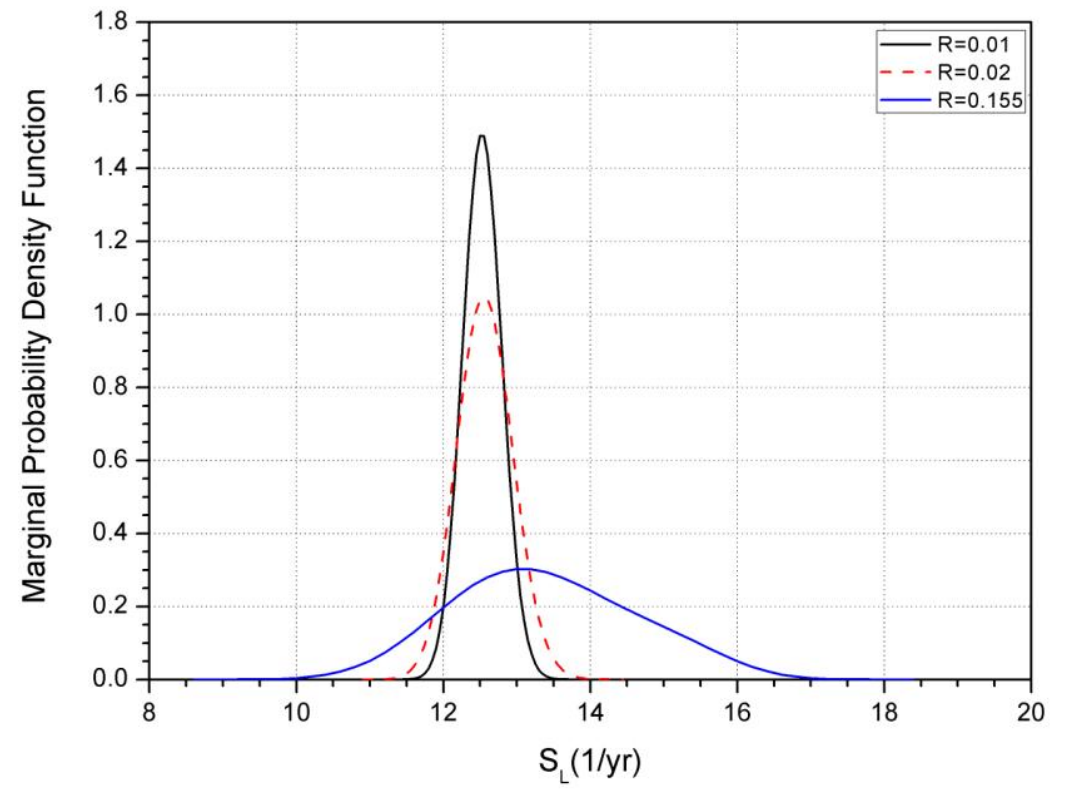

Fig. 24 - Marginal PDF of $\mathrm{S}_{\mathrm{L}}$ for Hubbert model with production data up to 1956 of the lower U.S. 48

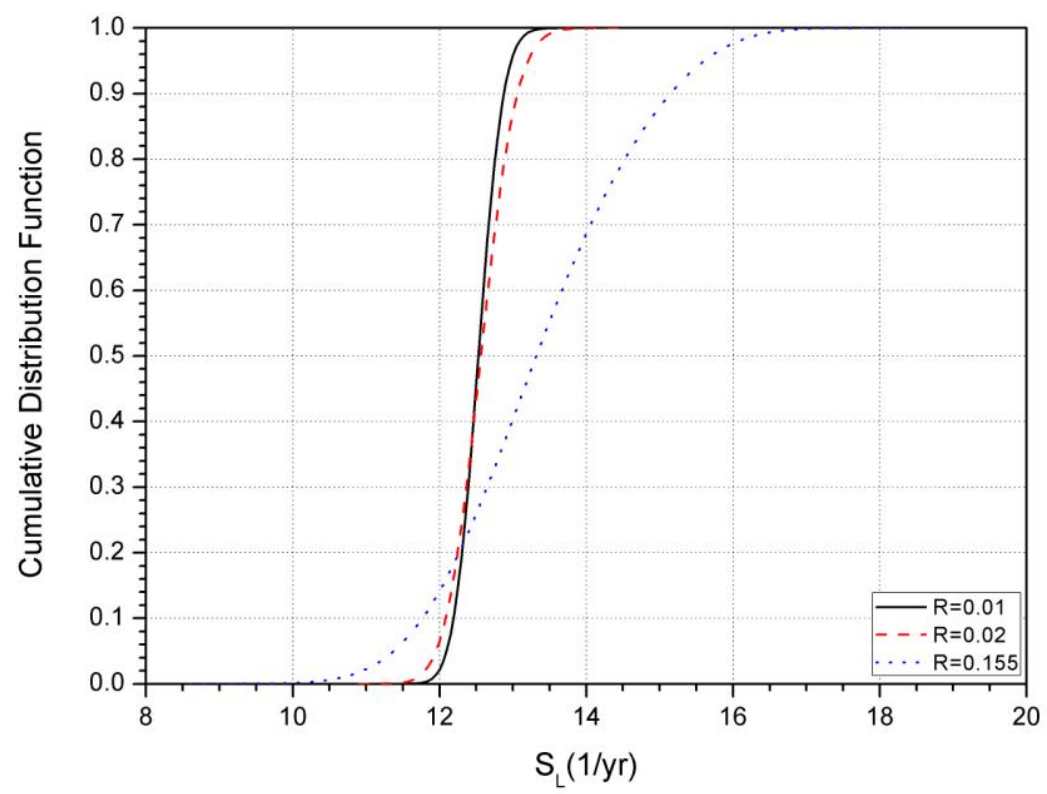

Fig. 25 - CDF of $S_{L}$ for Hubbert model with production data up to 1956 of the lower U.S. 48 
Table 12 - Probabilistic values of each parameter for Hubbert model with production data up to 1956 of the lower U.S. 48

\begin{tabular}{c|ccc|ccc|ccc}
\hline $\begin{array}{c}\text { Variance } \\
\text { Ratio }\end{array}$ & \multicolumn{3}{c}{$\mathrm{R}=0.01$} & & & & & & $\mathrm{R}=0.02$ \\
& $\mathrm{Q}_{\infty}$ & $\mathrm{t}_{\mathrm{M}}$ & $\mathrm{S}_{\mathrm{L}}$ & $\mathrm{Q}_{\infty}$ & $\mathrm{t}_{\mathrm{M}}$ & $\mathrm{S}_{\mathrm{L}}$ & $\mathrm{Q}_{\infty}$ & $\mathrm{t}_{\mathrm{M}}$ & $\mathrm{S}_{\mathrm{L}}$ \\
& $(\mathrm{Bbbl})$ & $(\mathrm{yr})$ & $(1 / \mathrm{yr})$ & $(\mathrm{Bbbl})$ & $(\mathrm{yr})$ & $(1 / \mathrm{yr})$ & $(\mathrm{Bbbl})$ & $(\mathrm{yr})$ & $(1 / \mathrm{yr})$ \\
\hline P90 & 107.259 & 1956.345 & 12.190 & 105.020 & 1955.871 & 12.083 & 99.426 & 1954.733 & 11.769 \\
P50 & 115.221 & 1957.980 & 12.529 & 116.163 & 1958.175 & 12.562 & 143.350 & 1963.093 & 13.317 \\
P10 & 124.790 & 1959.807 & 12.876 & 130.739 & 1960.884 & 13.059 & 384.210 & 1983.830 & 15.144 \\
Mean & 115.714 & 1958.039 & 12.531 & 117.228 & 1958.299 & 12.568 & 203.82 & 1966.247 & 13.388 \\
Best-fit & 115 & 1957.9 & 12.5 & 114 & 1957.8 & 12.5 & 115 & 1958 & 12.6 \\
\hline
\end{tabular}

Table 13 - Parameter sets for Hubbert model with production data up to 1956 of the lower U.S. 48 (R=0.01)

\begin{tabular}{|c|c|c|c|c|c|c|c|c|c|c|c|c|}
\hline \multirow{2}{*}{$\mathrm{R}=0.01$} & \multicolumn{4}{|c|}{$\mathrm{Q}_{\infty}$} & \multicolumn{4}{|c|}{$t_{M}$} & \multicolumn{4}{|c|}{$\mathrm{S}_{\mathrm{N}}$} \\
\hline & $\begin{array}{c}\mathrm{Q}_{\infty} \\
(\mathrm{Bbbl})\end{array}$ & $\begin{array}{c}\mathrm{t}_{\mathrm{M}} \\
(\mathrm{yr})\end{array}$ & $\begin{array}{c}\mathrm{S}_{\mathrm{L}} \\
(1 / \mathrm{yr})\end{array}$ & $\mathrm{S}_{\mathrm{o}} \mathrm{S}$ & $\begin{array}{c}\mathrm{Q}_{\infty} \\
(\mathrm{Bbbl})\end{array}$ & $\begin{array}{c}\mathrm{t}_{\mathrm{M}} \\
(\mathrm{yr})\end{array}$ & $\begin{array}{c}\mathrm{S}_{\mathrm{L}} \\
(1 / \mathrm{yr})\end{array}$ & $\mathrm{S}_{\mathrm{o}} \mathrm{S}$ & $\begin{array}{c}\mathrm{Q}_{\infty} \\
(\mathrm{Bbbl})\end{array}$ & $\begin{array}{c}\mathrm{t}_{\mathrm{M}} \\
(\mathrm{yr})\end{array}$ & $\begin{array}{c}\mathrm{S}_{\mathrm{L}} \\
(1 / \mathrm{yr})\end{array}$ & $\mathrm{S}_{\mathrm{o}} \mathrm{S}$ \\
\hline P90 & 107 & 1956.3 & 12.25 & 0.7179 & 107 & 1956.3 & 12.25 & 0.7179 & 109 & 1956.6 & 12.20 & 0.7162 \\
\hline P50 & 115 & 1957.9 & 12.50 & 0.7028 & 115 & 1958.0 & 12.55 & 0.7034 & 116 & 1958.1 & 12.55 & 0.7032 \\
\hline P10 & 125 & 1959.8 & 12.80 & 0.7247 & 125 & 1959.8 & 12.80 & 0.7247 & 123 & 1959.6 & 12.90 & 0.7263 \\
\hline Mean & 116 & 1958.1 & 12.55 & 0.7032 & 115 & 1958.0 & 12.55 & 0.7034 & 116 & 1958.1 & 12.55 & 0.7032 \\
\hline
\end{tabular}


Table 14 - Parameter sets for Hubbert model with production data up to 1956 of the lower U.S. 48 (R=0.02)

\begin{tabular}{|c|c|c|c|c|c|c|c|c|c|c|c|c|}
\hline \multirow{2}{*}{$\mathrm{R}=0.02$} & \multicolumn{4}{|c|}{$\mathrm{Q}_{\infty}$} & \multicolumn{4}{|c|}{$t_{M}$} & \multicolumn{4}{|c|}{$\mathrm{S}_{\mathrm{N}}$} \\
\hline & $\begin{array}{c}\mathrm{Q}_{\infty} \\
(\mathrm{Bbbl})\end{array}$ & $\begin{array}{c}\mathrm{t}_{\mathrm{M}} \\
(\mathrm{yr})\end{array}$ & $\begin{array}{c}\mathrm{S}_{\mathrm{L}} \\
(1 / \mathrm{yr})\end{array}$ & $\mathrm{S}_{\mathrm{o}} \mathrm{S}$ & $\begin{array}{c}\mathrm{Q}_{\infty} \\
(\mathrm{Bbbl})\end{array}$ & $\begin{array}{c}\mathrm{t}_{\mathrm{M}} \\
(\mathrm{yr})\end{array}$ & $\begin{array}{c}\mathrm{S}_{\mathrm{L}} \\
(1 / \mathrm{yr})\end{array}$ & $\mathrm{S}_{\mathrm{o}} \mathrm{S}$ & $\begin{array}{c}\mathrm{Q}_{\infty} \\
(\mathrm{Bbbl})\end{array}$ & $\begin{array}{c}\mathrm{t}_{\mathrm{M}} \\
(\mathrm{yr})\end{array}$ & $\begin{array}{c}\mathrm{S}_{\mathrm{L}} \\
(1 / \mathrm{yr})\end{array}$ & $\mathrm{S}_{\mathrm{o}} \mathrm{S}$ \\
\hline P90 & 105 & 1956.0 & 12.20 & 0.3645 & 105 & 1955.8 & 12.15 & 0.3648 & 107 & 1956.2 & 12.10 & 0.3633 \\
\hline P50 & 116 & 1958.2 & 12.55 & 0.3520 & 116 & 1958.2 & 12.55 & 0.3520 & 115 & 1958.0 & 12.55 & 0.3517 \\
\hline P10 & 131 & 1960.8 & 12.95 & 0.3753 & 130 & 1960.8 & 13.00 & 0.3737 & 126 & 1960.2 & 13.05 & 0.3735 \\
\hline Mean & 117 & 1958.4 & 12.60 & 0.3525 & 116 & 1958.2 & 12.55 & 0.3520 & 115 & 1958.0 & 12.55 & 0.3517 \\
\hline
\end{tabular}

Table 15 - Parameter sets for Hubbert model with production data up to 1956 of the lower U.S. 48 (R=0. 155)

\begin{tabular}{|c|c|c|c|c|c|c|c|c|c|c|c|c|}
\hline \multirow{2}{*}{$\mathrm{R}=0.155$} & \multicolumn{4}{|c|}{$\mathrm{Q}_{\infty}$} & \multicolumn{4}{|c|}{$t_{M}$} & \multicolumn{4}{|c|}{$\mathrm{S}_{\mathrm{N}}$} \\
\hline & $\begin{array}{c}\mathrm{Q}_{\infty} \\
(\mathrm{Bbbl})\end{array}$ & $\begin{array}{c}\mathrm{t}_{\mathrm{M}} \\
(\mathrm{yr})\end{array}$ & $\begin{array}{c}\mathrm{S}_{\mathrm{L}} \\
(1 / \mathrm{yr})\end{array}$ & $\mathrm{S}_{\mathrm{o}} \mathrm{S}$ & $\begin{array}{c}\mathrm{Q}_{\infty} \\
(\mathrm{Bbbl})\end{array}$ & $\begin{array}{c}\mathrm{t}_{\mathrm{M}} \\
(\mathrm{yr})\end{array}$ & $\begin{array}{c}\mathrm{S}_{\mathrm{L}} \\
(1 / \mathrm{yr})\end{array}$ & $\mathrm{S}_{\mathrm{o}} \mathrm{S}$ & $\begin{array}{c}\mathrm{Q}_{\infty} \\
(\mathrm{Bbbl})\end{array}$ & $\begin{array}{c}t_{M} \\
(y r)\end{array}$ & $\begin{array}{c}\mathrm{S}_{\mathrm{L}} \\
(1 / \mathrm{yr})\end{array}$ & $\mathrm{S}_{\mathrm{o}} \mathrm{S}$ \\
\hline P90 & 99 & 1955 & 12.0 & 0.0513 & 101 & 1955 & 12.0 & 0.0491 & 101 & 1955 & 11.8 & 0.0503 \\
\hline P50 & 143 & 1963 & 13.2 & 0.0533 & 143 & 1963 & 13.2 & 0.0533 & 137 & 1962 & 13.4 & 0.0528 \\
\hline $\mathrm{P} 10$ & 385 & 1984 & 15.2 & 0.1142 & 383 & 1984 & 15.2 & 0.1141 & 249 & 1976 & 15.2 & 0.1028 \\
\hline Mean & 203 & 1971 & 14.2 & 0.0774 & 163 & 1966 & 13.6 & 0.0615 & 137 & 1962 & 13.4 & 0.0528 \\
\hline
\end{tabular}




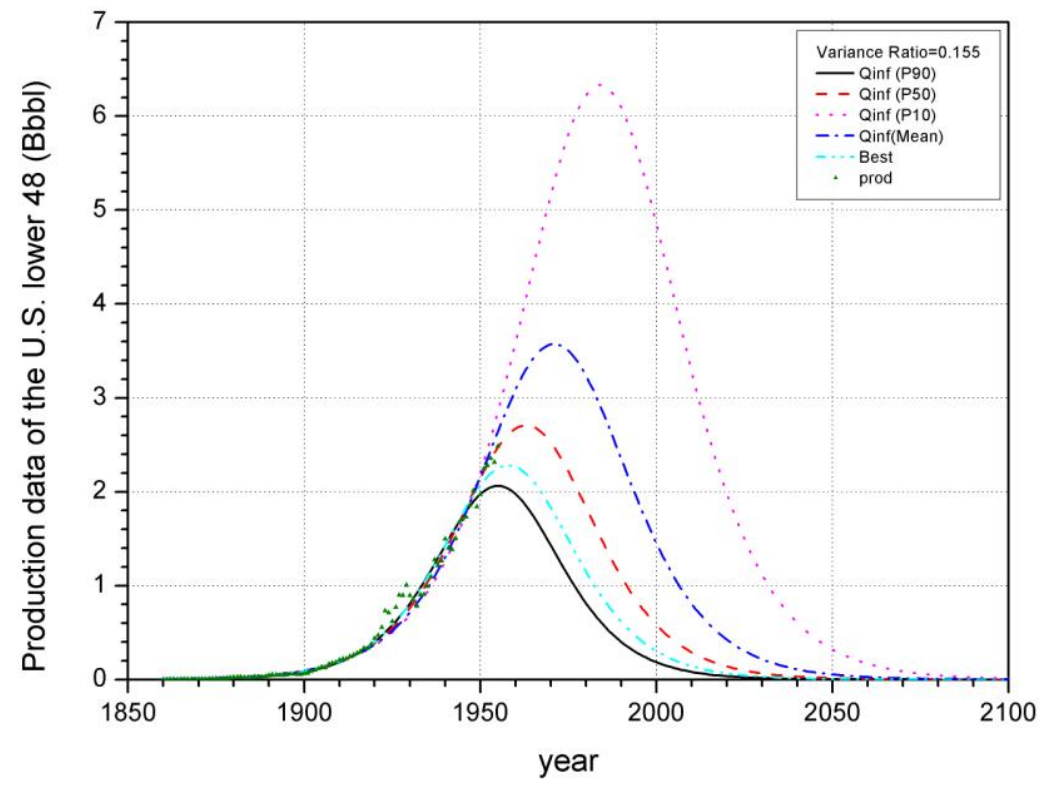

Fig. 26 - Probabilistic forecasts of $\mathrm{Q}_{\infty}$ for Hubbert model with production data up to 1956 of the lower U.S. $48(\mathrm{R}=0.155)$

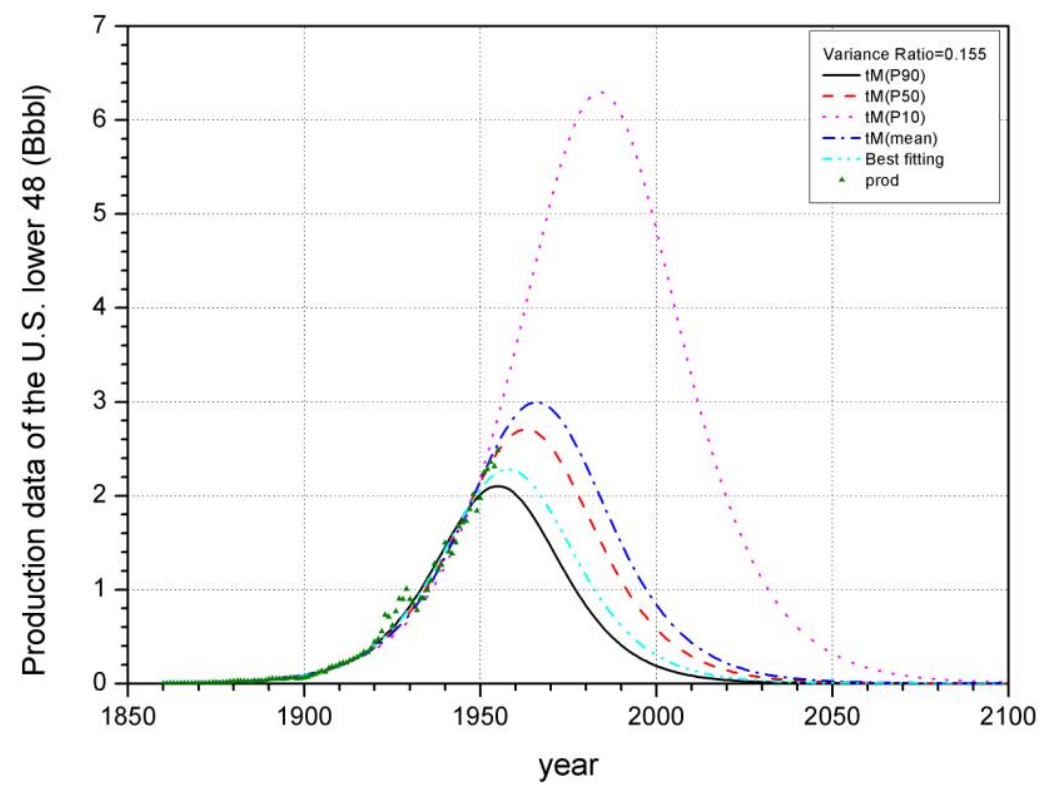

Fig. 27 - Probabilistic forecasts of $t_{M}$ for Hubbert model with production data up to 1956 of the lower U.S. $48(\mathrm{R}=0.155)$ 


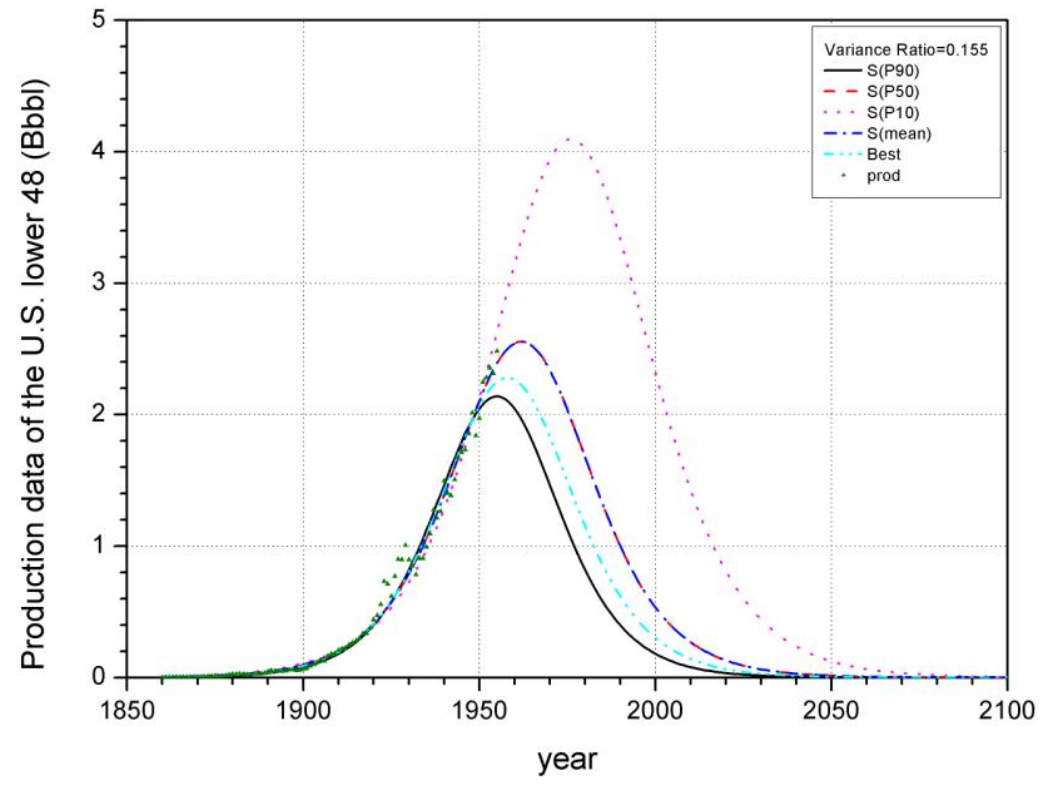

Fig. 28 - Probabilistic forecasts of $S_{L}$ for Hubbert model with production data up to 1956 of the lower U.S. $48(\mathrm{R}=0.155)$ 


\section{Normal Distribution Model with Production Data up to 1956}

Table 16 lists the data intervals and number of data points that define the discretized parameter space for different variance ratios.

Table 16 - Different variance ratio for Normal distribution model with production data up to 1956 of the lower U.S. 48

\begin{tabular}{c|cc|cc}
\hline \multirow{2}{*}{$\begin{array}{c}\text { Variance } \\
\text { Ratio }\end{array}$} & \multicolumn{2}{|c|}{$\mathrm{R}=0.01$} & \multicolumn{2}{|c}{$\mathrm{R}=0.02$} \\
\cline { 2 - 5 } & Data Interval & points & Data Interval & points \\
\hline $\mathrm{Q}_{\infty}$ & $101 \sim 1099$ & 500 & $101 \sim 1598$ & 500 \\
$(\mathrm{Bbbl})$ & & & & \\
$\mathrm{t}_{\mathrm{M}}(\mathrm{yr})$ & $1961 \sim 2020.4$ & 100 & $1961 \sim 2040.2$ & 100 \\
$\mathrm{~S}_{\mathrm{N}}(1 / \mathrm{yr})$ & $21 \sim 50.7$ & 100 & $21 \sim 50.7$ & 100 \\
\hline
\end{tabular}

Fig. 29, Fig. 31, and Fig. 33 are the plots of normalized PDF for each parameter $\mathrm{Q}_{\infty}, \mathrm{t}_{\mathrm{M}}$, and $\mathrm{S}_{\mathrm{N}}$. Fig. 30, Fig. 32, and Fig. 34 are the plots of CDF for these three parameters, respectively. I obtained the P90, P50, P10, and mean value from the CDF of each parameter, in which are shown in Table 17. Parameter sets found with maximum likelihood function value by taking the probabilistic value of each parameter are listed in Table 18, and Table 19, and the sum-of-square norm $\left(\mathrm{S}_{\mathrm{o}} \mathrm{S}\right)$ values are also calculated. I choose one scenario $(\mathrm{R}=0.01)$ to plot the probabilistic forecasts for each parameter (Fig. 35, Fig. 36, and Fig. 37). 


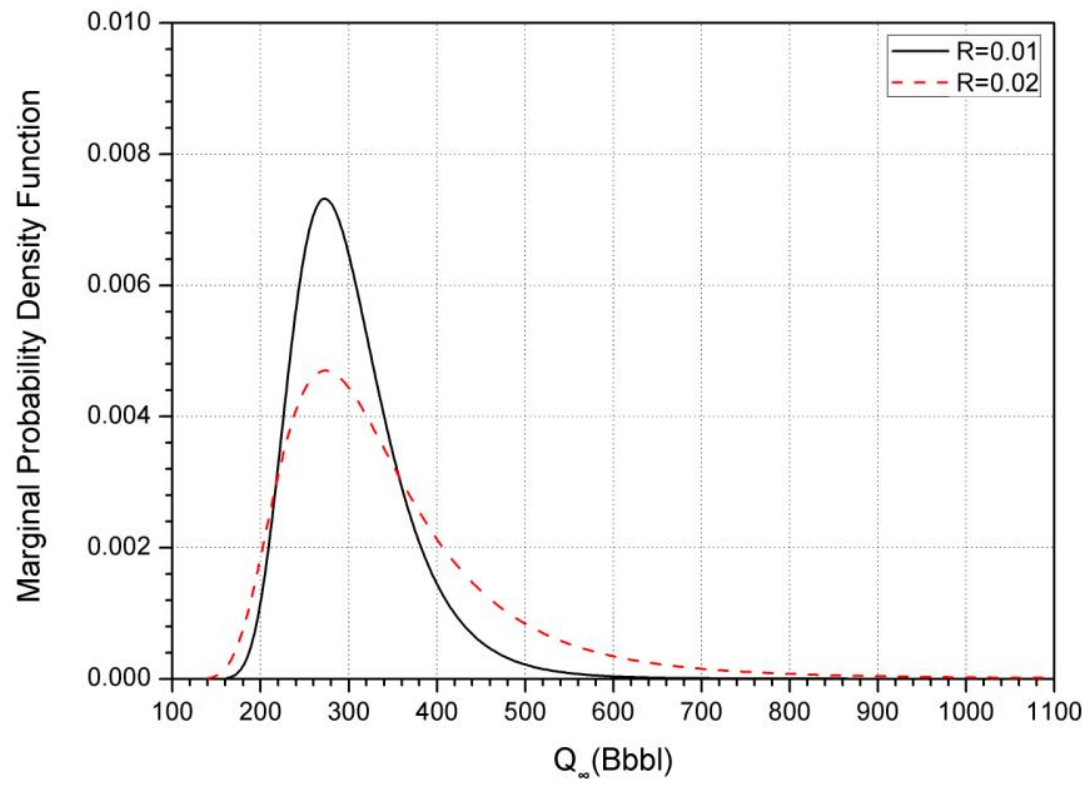

Fig. 29 - Marginal PDF of $\mathrm{Q}_{\infty}$ for Normal distribution model with production data up to 1956 of the lower U.S. 48

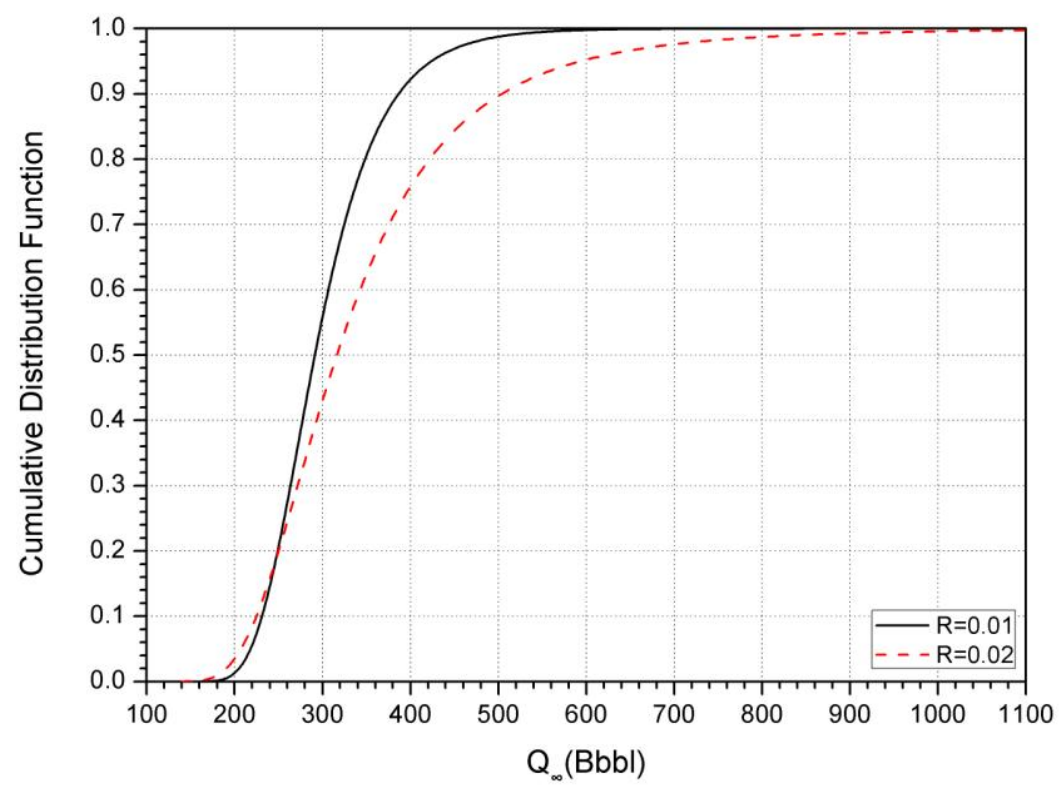

Fig. 30 - CDF of $Q_{\infty}$ for Normal distribution model with production data up to 1956 of the lower U.S. 48 


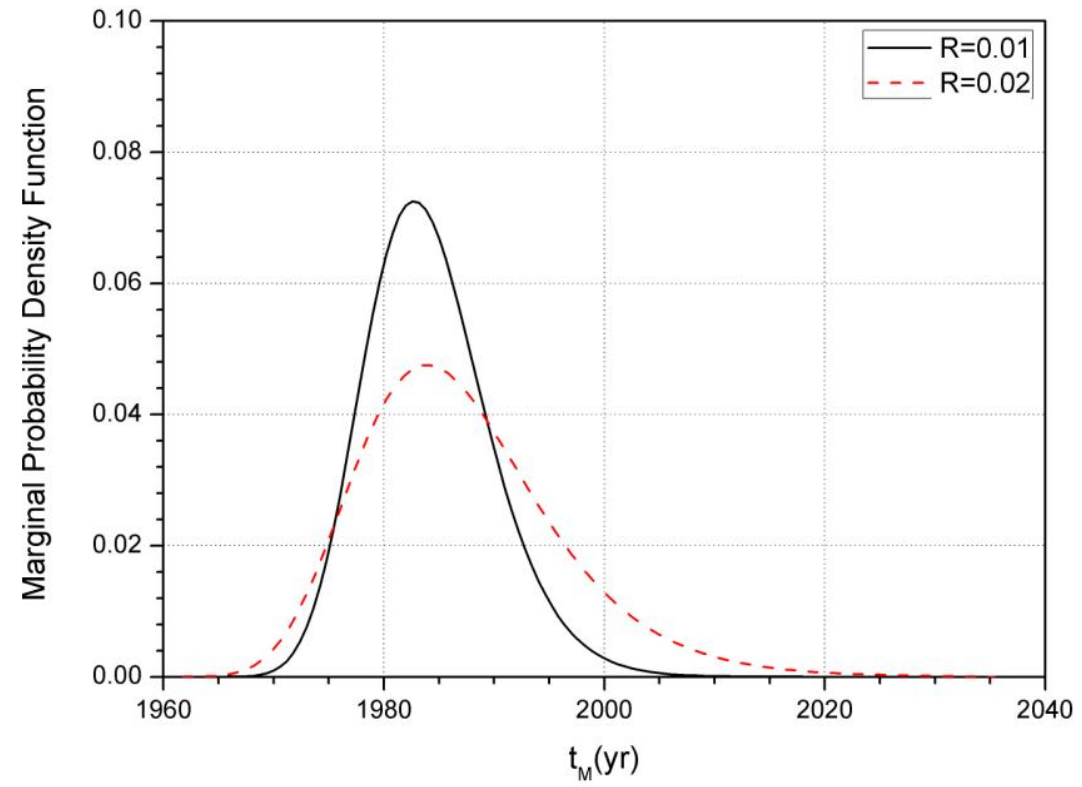

Fig. 31 - Marginal PDF of $t_{M}$ for Normal distribution model with production data up to 1956 of the lower U.S. 48

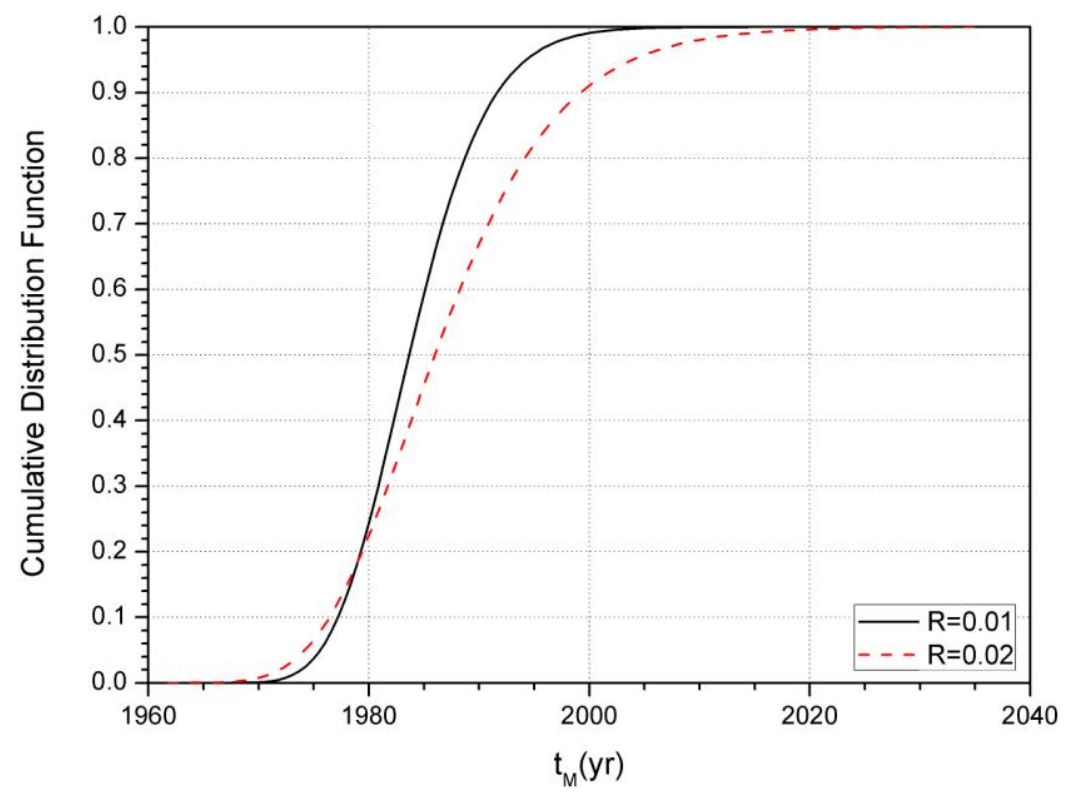

Fig. 32 - CDF of $t_{M}$ for Normal distribution model with production data up to 1956 of the lower U.S. 48 


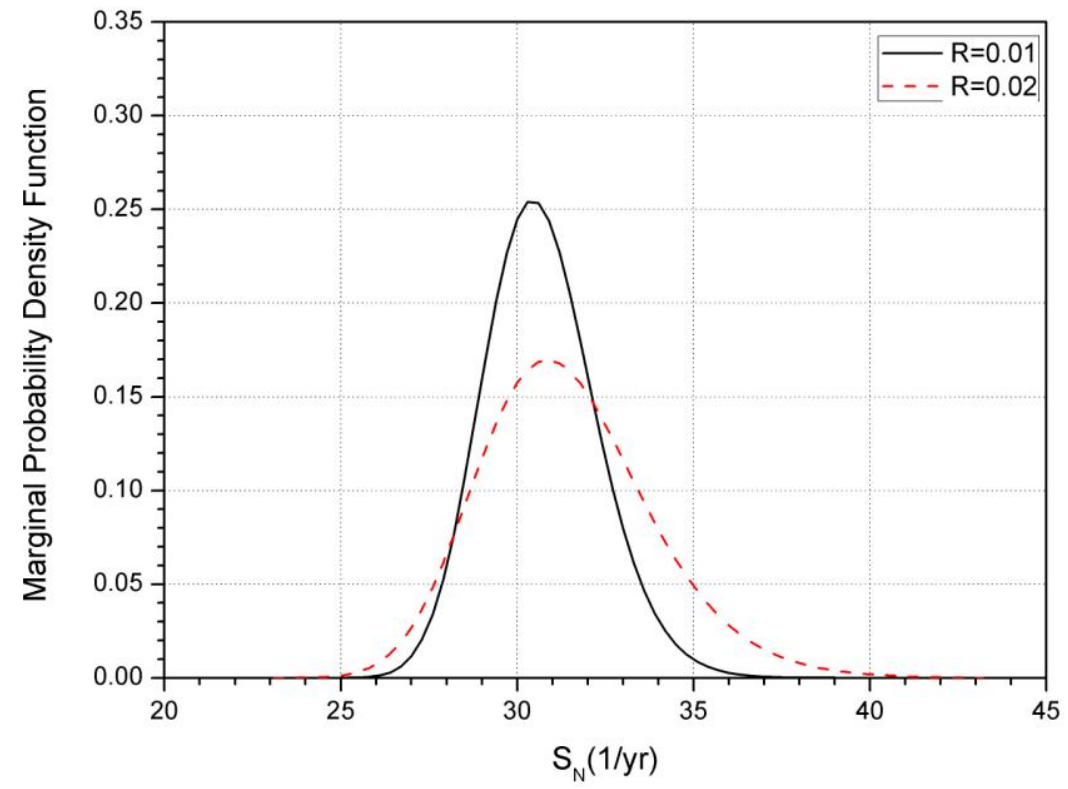

Fig. 33 - Marginal PDF of $\mathrm{S}_{\mathrm{N}}$ for Normal distribution model with production data up to 1956 of the lower U.S. 48

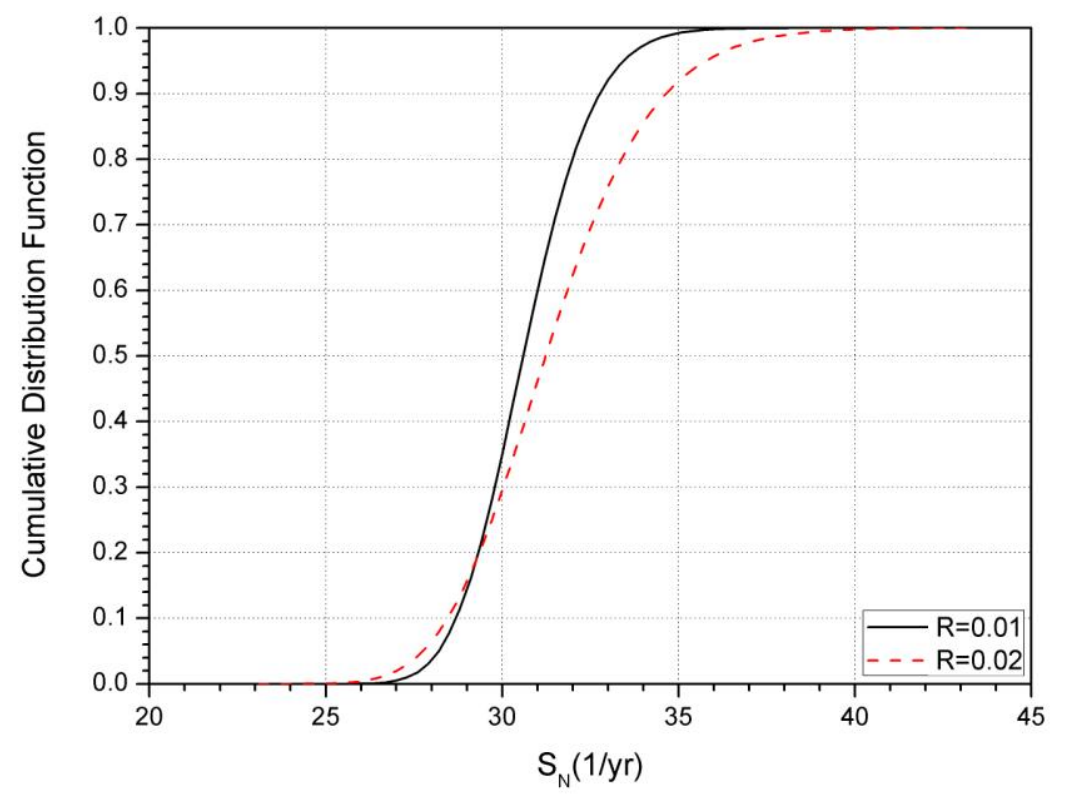

Fig. 34 - CDF of $S_{N}$ for Normal distribution model with production data up to 1956 of the lower U.S. 48 
Table 17 - Probabilistic values of each parameter for Normal distribution model with production data up to 1956 of the lower U.S. 48

\begin{tabular}{c|ccc|ccc}
\hline $\begin{array}{c}\text { Variance } \\
\text { Ratio }\end{array}$ & \multicolumn{3}{|c|}{$\mathrm{R}=0.01$} & \multicolumn{3}{c}{$\mathrm{R}=0.02$} \\
& $\mathrm{Q}_{\infty}$ & $\mathrm{t}_{\mathrm{M}}$ & $\mathrm{S}_{\mathrm{N}}$ & $\mathrm{Q}_{\infty}$ & $\mathrm{t}_{\mathrm{M}}$ & $\mathrm{S}_{\mathrm{N}}$ \\
& $(\mathrm{Bbbl})$ & $(\mathrm{yr})$ & $(1 / \mathrm{yr})$ & $(\mathrm{Bbbl})$ & $(\mathrm{yr})$ & $(1 / \mathrm{yr})$ \\
\hline P90 & 231.00 & 1977.189 & 28.695 & 224.67 & 1976.43 & 28.455 \\
P50 & 291.19 & 1983.645 & 30.594 & 316.22 & 1985.970 & 31.231 \\
P10 & 386.41 & 1991.638 & 32.762 & 503.47 & 1999.193 & 34.644 \\
Mean & 302.22 & 1984.117 & 30.676 & 347.73 & 1987.100 & 31.425 \\
Best-fit & 281 & 1982.6 & 30.3 & 281 & 1982.6 & 30.3 \\
\hline
\end{tabular}

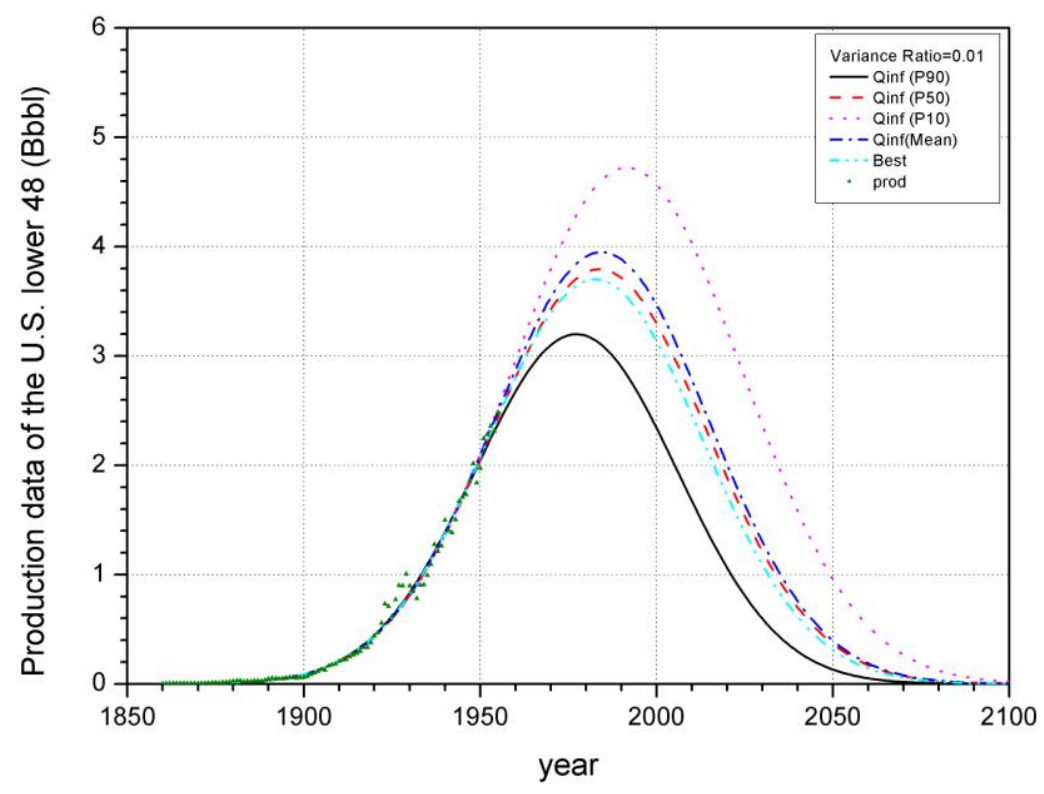

Fig. 35 - Probabilistic forecasts of $\mathrm{Q}_{\infty}$ for Normal Distribution model with production data up to 1956 of the lower U.S. $48(\mathrm{R}=0.01)$ 


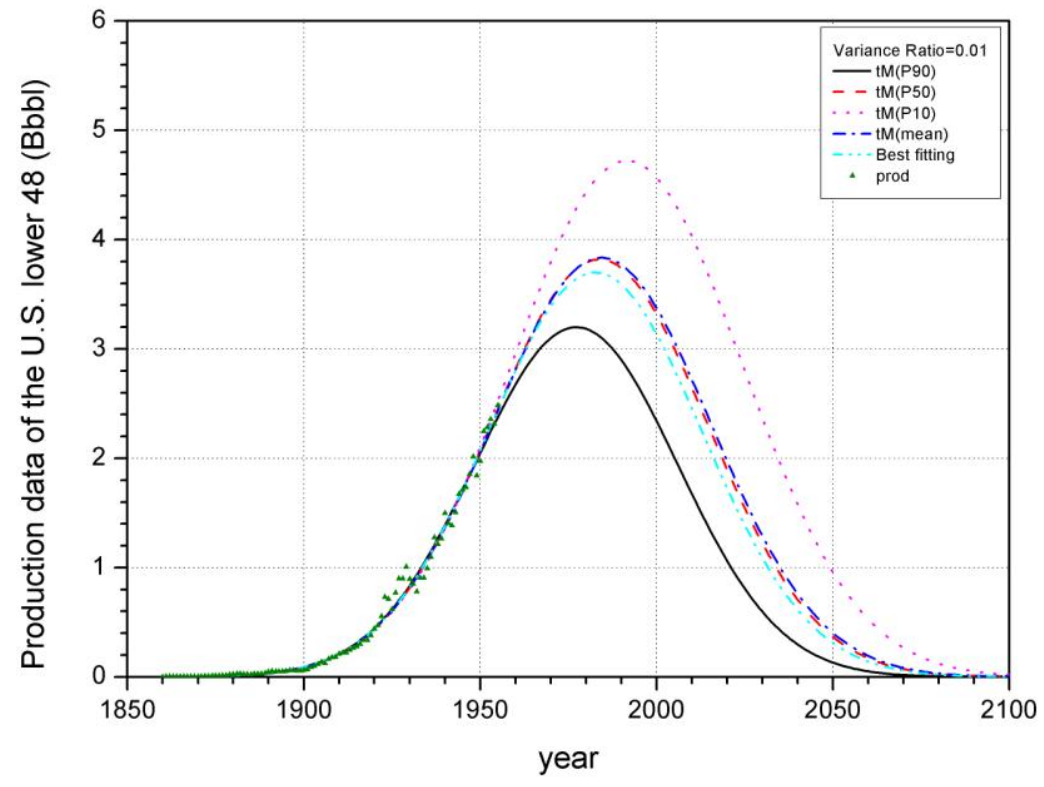

Fig. 36 - Probabilistic forecasts of $t_{M}$ for Normal Distribution model with production data up to 1956 of the lower U.S. $48(\mathrm{R}=0.01)$

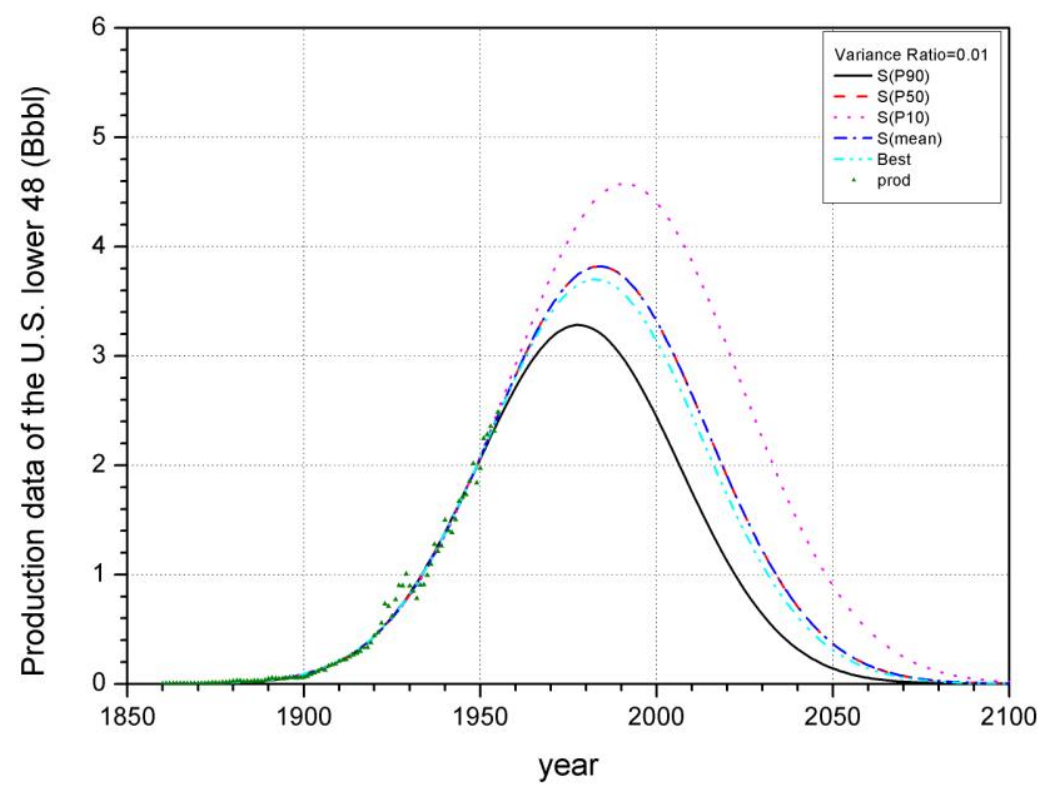

Fig. 37 - Probabilistic forecasts of $S_{N}$ for Normal Distribution model with production data up to 1956 of the lower U.S. $48(\mathrm{R}=0.01)$ 
Table 18 - Parameter sets for Normal distribution model with production data up to 1956 of the lower U.S. 48 (R=0.01)

\begin{tabular}{|c|c|c|c|c|c|c|c|c|c|c|c|c|}
\hline \multirow{2}{*}{$\mathrm{R}=0.01$} & \multicolumn{4}{|c|}{$\mathrm{Q}_{\infty}$} & \multicolumn{4}{|c|}{$\mathrm{t}_{\mathrm{M}}$} & \multicolumn{4}{|c|}{$\mathrm{S}_{\mathrm{N}}$} \\
\hline & $\begin{array}{c}\mathrm{Q}_{\infty} \\
(\mathrm{Bbbl})\end{array}$ & $\begin{array}{c}\mathrm{t}_{\mathrm{M}} \\
(\mathrm{yr})\end{array}$ & $\begin{array}{c}\mathrm{S}_{\mathrm{N}} \\
(1 / \mathrm{yr})\end{array}$ & $\mathrm{S}_{\mathrm{o}} \mathrm{S}$ & $\begin{array}{c}\mathrm{Q}_{\infty} \\
(\mathrm{Bbbl})\end{array}$ & $\begin{array}{c}\mathrm{t}_{\mathrm{M}} \\
(\mathrm{yr})\end{array}$ & $\begin{array}{c}\mathrm{S}_{\mathrm{N}} \\
(1 / \mathrm{yr})\end{array}$ & $\mathrm{S}_{\mathrm{o}} \mathrm{S}$ & $\begin{array}{c}\mathrm{Q}_{\infty} \\
(\mathrm{Bbbl})\end{array}$ & $\begin{array}{c}\mathrm{t}_{\mathrm{M}} \\
(\mathrm{yr})\end{array}$ & $\begin{array}{c}\mathrm{S}_{\mathrm{N}} \\
(1 / \mathrm{yr})\end{array}$ & $\mathrm{S}_{\mathrm{o}} \mathrm{S}$ \\
\hline P90 & 231 & 1977.2 & 28.8 & 0.5346 & 231 & 1977.2 & 28.8 & 0.5346 & 237 & 1977.8 & 28.8 & 0.5336 \\
\hline P50 & 291 & 1983.8 & 30.6 & 0.5300 & 293 & 1983.8 & 30.6 & 0.5267 & 293 & 1983.8 & 30.6 & 0.5267 \\
\hline P10 & 387 & 1991.6 & 32.7 & 0.5544 & 387 & 1991.6 & 32.7 & 0.5544 & 375 & 1991 & 32.7 & 0.5535 \\
\hline Mean & 303 & 1984.4 & 30.6 & 0.5346 & 297 & 1984.4 & 30.9 & 0.5292 & 293 & 1983.8 & 30.6 & 0.5267 \\
\hline
\end{tabular}

Table 19 - Parameter sets for Normal distribution model with production data up to 1956 of the lower U.S. 48 (R=0.02)

\begin{tabular}{|c|c|c|c|c|c|c|c|c|c|c|c|c|}
\hline \multirow[b]{2}{*}{$\mathrm{R}=0.02$} & \multicolumn{4}{|c|}{$\mathrm{Q}_{\infty}$} & \multicolumn{4}{|c|}{$t_{M}$} & \multicolumn{4}{|c|}{$\mathrm{S}_{\mathrm{N}}$} \\
\hline & $\begin{array}{c}\mathrm{Q}_{\infty} \\
(\mathrm{Bbbl})\end{array}$ & $\begin{array}{c}\mathrm{t}_{\mathrm{M}} \\
(\mathrm{yr})\end{array}$ & $\begin{array}{c}\mathrm{S}_{\mathrm{N}} \\
(1 / \mathrm{yr})\end{array}$ & $\mathrm{S}_{\mathrm{o}} \mathrm{S}$ & $\begin{array}{c}\mathrm{Q}_{\infty} \\
(\mathrm{Bbbl})\end{array}$ & $\begin{array}{c}\mathrm{t}_{\mathrm{M}} \\
(\mathrm{yr})\end{array}$ & $\begin{array}{c}\mathrm{S}_{\mathrm{N}} \\
(1 / \mathrm{yr})\end{array}$ & $\mathrm{S}_{\mathrm{o}} \mathrm{S}$ & $\begin{array}{c}\mathrm{Q}_{\infty} \\
(\mathrm{Bbbl})\end{array}$ & $\begin{array}{c}\mathrm{t}_{\mathrm{M}} \\
(\mathrm{yr})\end{array}$ & $\begin{array}{c}\mathrm{S}_{\mathrm{N}} \\
(1 / \mathrm{yr})\end{array}$ & $\mathrm{S}_{\mathrm{o}} \mathrm{S}$ \\
\hline P90 & 224 & 1976.2 & 28.5 & 0.2709 & 224 & 1976.2 & 28.5 & 0.2709 & 230 & 1977.0 & 28.5 & 0.2703 \\
\hline P50 & 317 & 1985.8 & 31.2 & 0.2676 & 314 & 1985.8 & 31.2 & 0.2653 & 314 & 1985.8 & 31.2 & 0.2653 \\
\hline P10 & 503 & 1999.4 & 34.8 & 0.3023 & 503 & 1999.4 & 34.8 & 0.3023 & 491 & 1998.6 & 34.5 & 0.2983 \\
\hline Mean & 347 & 1988.2 & 31.8 & 0.2737 & 335 & 1987.4 & 31.5 & 0.2690 & 323 & 1986.6 & 31.5 & 0.2675 \\
\hline
\end{tabular}




\section{Summary of Uncertainty Analyses for the Lower U.S. 48 by Mathematical}

\section{Modeling}

1. Because the conventional oil production curve of the lower U.S. 48 is declining significantly (Fig. 1), there are no large differences between the probabilistic forecasts of the Hubbert and Normal distribution models even if I apply a larger variance ratio (Table 2, Table 7).

2. The results by applying the scarcity of production data to develop the uncertainty quantification demonstrate the significant influence and discrepancy for the probabilistic forecasts of both two models, and a tiny variance ratio $(\mathrm{R}=0.01)$ results in wider range of probabilistic forecasts for normal distribution model than Hubbert model (Table 12, Table 17). Furthermore, due to the scarcity of production data or unclear declining production curve, it will make us easily recognize much uncertainty within the forecasts by applying the mathematical models to predict.

3. For the Hubbert's model, there are existed the noticeable differences in the results of uncertainty analyses between the pre-1956 (pre peak) and overall (post peak). For example, the range of probabilistic values of $\mathrm{Q}_{\infty}$ and $\mathrm{t}_{\mathrm{M}}$ with $\mathrm{R}=0.155$ in pre-peak data analyses (Table 12) is wider than the scenario $\mathrm{R}=0.2$ in post-peak (Table 2). Besides, it also can be observed the similar results for Normal distribution model. Because of this, it will provide insights into the world analysis (pre peak).

4. From Table 12 and Table 17, I find that the $\mathrm{P} 10$ value of $\mathrm{Q}_{\infty}(\mathrm{R}=0.155)$ in Hubbert model is nearly equal to the corresponding value of the scenario $(\mathrm{R}=0.01)$ in Normal distribution model, and it means that there is much uncertainty for applying normal 
distribution model to forecast the production trend.

5. Although the Hubbert model is derived based on the concept of peak oil and logistic curve, I compare the sum-of-square norm $\left(\mathrm{S}_{\mathrm{o}} \mathrm{S}\right)$ values of both models, and it shows that normal distribution model fits the production data well than Hubbert model.

6. The tiny difference between best fitting values for different variance ratio in Hubbert model and Normal distribution model is due to numerical errors. 


\section{ANALYSIS FOR CONVENTIONAL OIL RESOURCES OF THE WORLD}

I obtained conventional oil production data of the world from Energy Information Administration of the U.S. (EIA, 1996; 2009).

Fig. 38 is the production trend from the year 1860 to 2008 . While there is a local peak in the 1970's, there is no overall peak in world oil production rate.

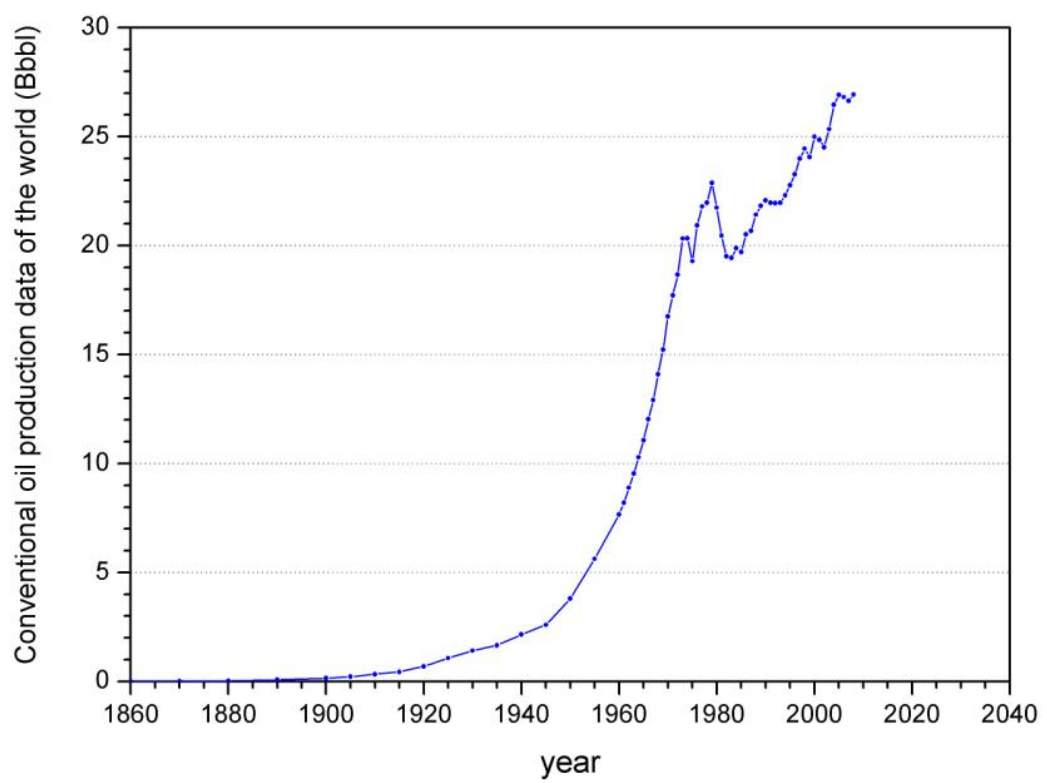

Fig. 38 - Production curve of world conventional oil

Here, I only take all production data up to 2008 to analyze with both Hubbert's model and Normal distribution model, and compare and interpret the results of uncertainty analyses for these two schemes in the summary section. 


\section{Hubbert Model with Production Data up to 2008}

Table 20 lists the data intervals and number of data points that define the discretized parameter space for different variance ratios.

Table 20 - Different variance ratio for Hubbert model with production data up to 2008 of the world

\begin{tabular}{c|cc|cc|cc}
\hline $\begin{array}{c}\text { Variance } \\
\text { Ratio }\end{array}$ & \multicolumn{2}{|c|}{$\mathrm{R}=2$} & \multicolumn{2}{|c}{$\mathrm{R}=4$} & \multicolumn{2}{|c}{$\mathrm{R}=8$} \\
\hline & Data Interval & points & Data Interval & points & Data Interval & points \\
\hline $\begin{array}{c}\mathrm{Q}_{\infty} \\
(\mathrm{Bbbl})\end{array}$ & $1001 \sim 3098$ & 1000 & $101 \sim 6095$ & 1000 & $101 \sim 10090$ & 1000 \\
$\mathrm{t}_{\mathrm{M}}$ & $1951 \sim 2050$ & 100 & $1951 \sim 2099.5$ & 100 & $1951 \sim 2099.5$ & 100 \\
$(\mathrm{yr})$ & & & & & & \\
$\mathrm{S}_{\mathrm{L}}$ & $5 \sim 24.8$ & 100 & $5 \sim 54.5$ & 100 & $5 \sim 54.5$ & 100 \\
$(1 / \mathrm{yr})$ & & & & & & \\
\hline
\end{tabular}

Fig. 39, Fig. 41, and Fig. 43 are the plots of normalized PDF for each parameter $\mathrm{Q}_{\infty}, \mathrm{t}_{\mathrm{M}}$, and $\mathrm{S}_{\mathrm{L}}$. Fig. 40, Fig. 42, and Fig. 44 are the plots of CDF for these three parameters, respectively. I obtained the P90, P50, P10, and mean value from the CDF of each parameter, which are shown in Table 21. Parameter sets found with maximum likelihood function value by taking the probabilistic value of each parameter are listed in Table 22, Table 23, and Table 24, and the sum-of-square norm $\left(\mathrm{S}_{\mathrm{o}} \mathrm{S}\right)$ values are also calculated. I choose one scenario $(\mathrm{R}=8)$ to plot the probabilistic forecasts for each parameter (Fig. 45, Fig. 46, and Fig. 47). 


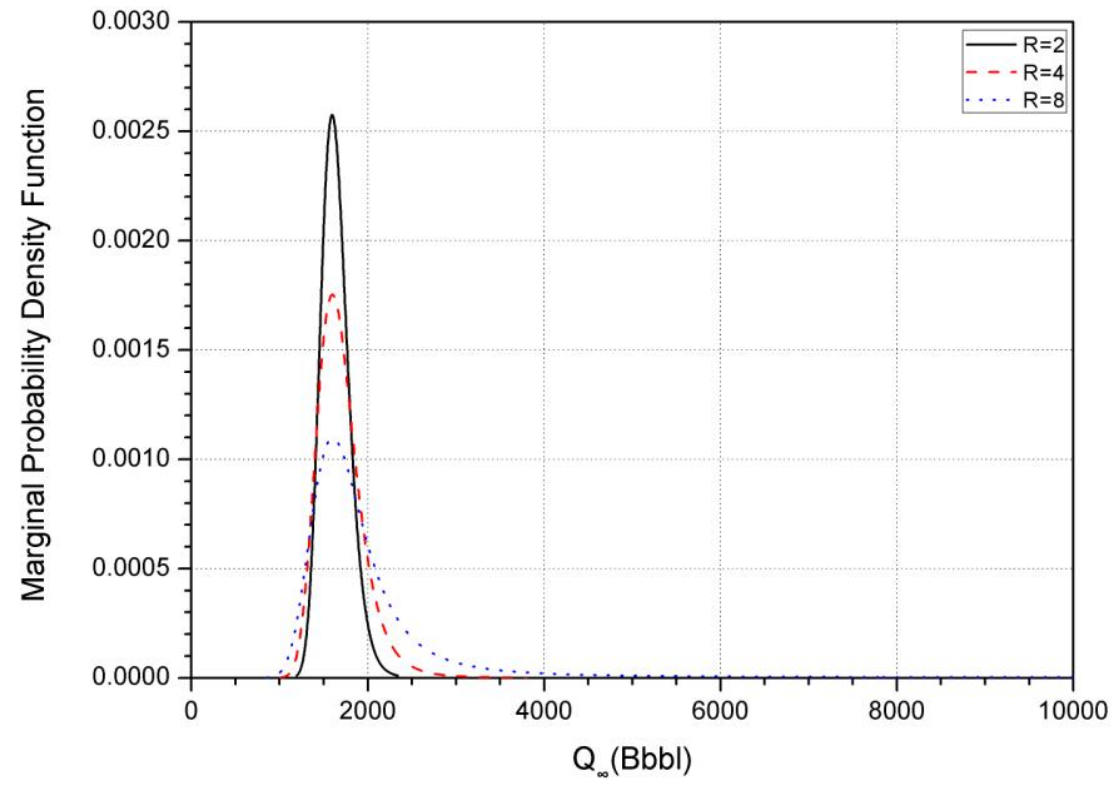

Fig. 39 - Marginal PDF of $\mathrm{Q}_{\infty}$ for Hubbert model with production data up to 2008 of the world

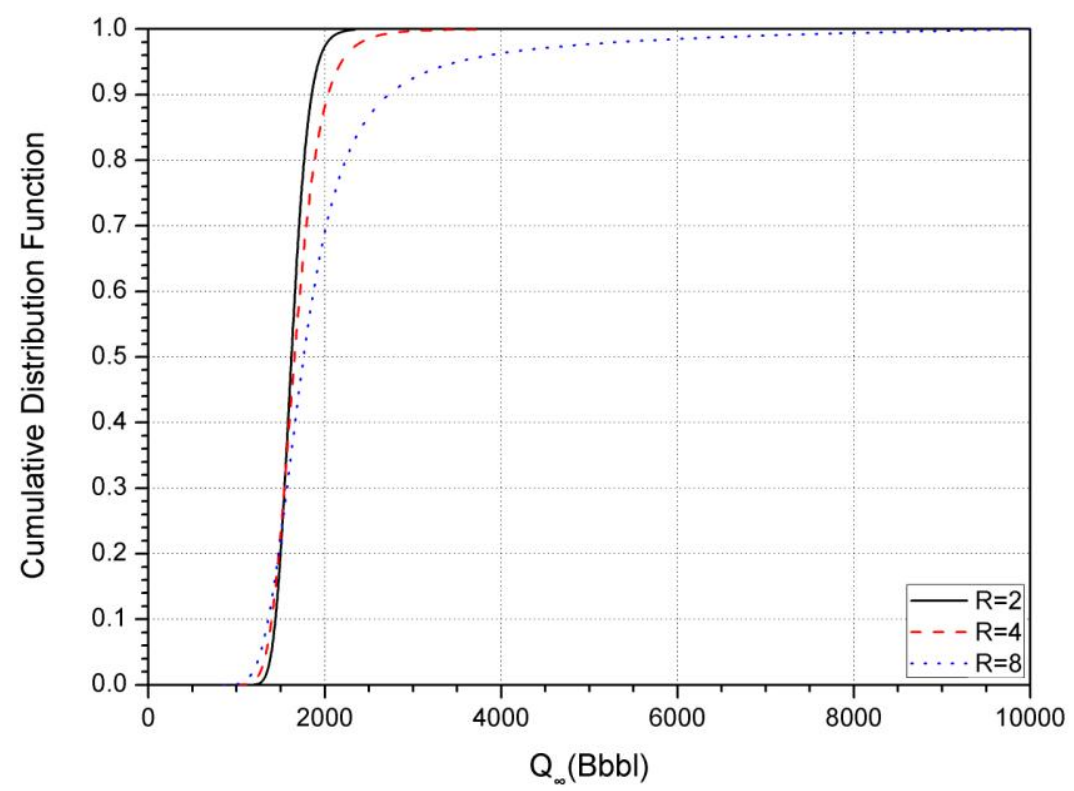

Fig. 40 - CDF of $\mathrm{Q}_{\infty}$ for Hubbert model with production data up to 2008 of the world 


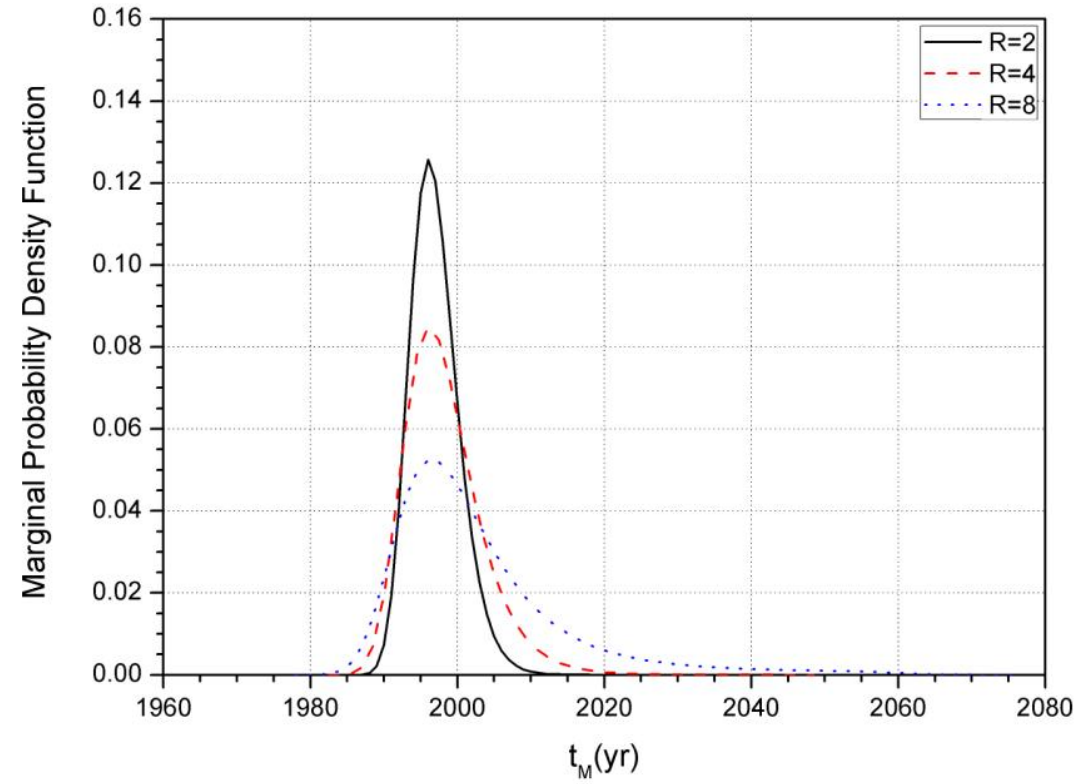

Fig. 41 - Marginal PDF of $t_{M}$ for Hubbert model with production data up to 2008 of the world

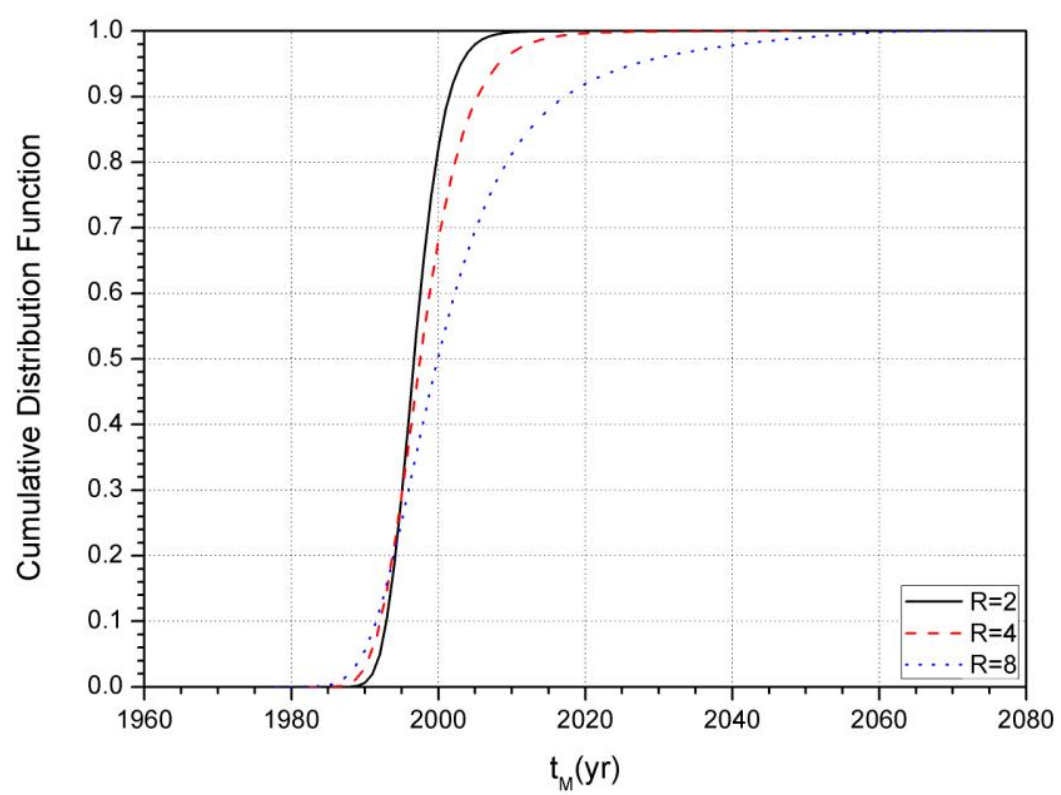

Fig. 42 - CDF of $t_{M}$ for Hubbert model with production data up to 2008 of the world 


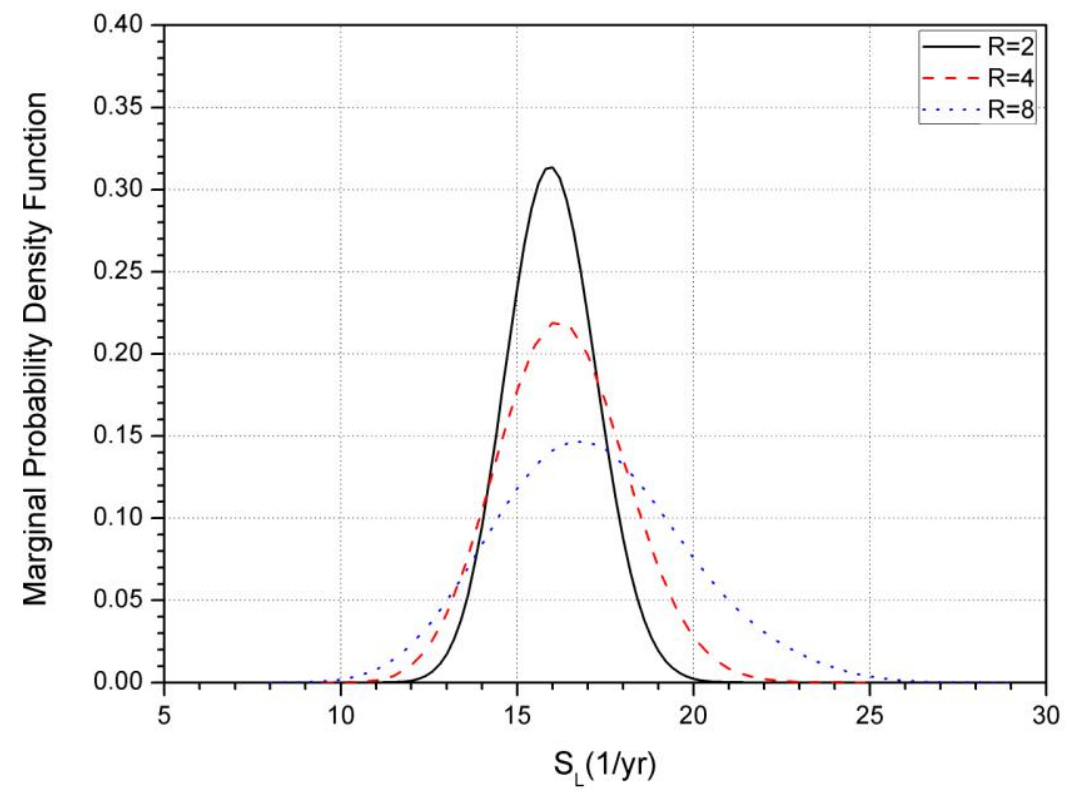

Fig. 43 - Marginal PDF of $\mathrm{S}_{\mathrm{L}}$ for Hubbert model with production data up to 2008 of the world

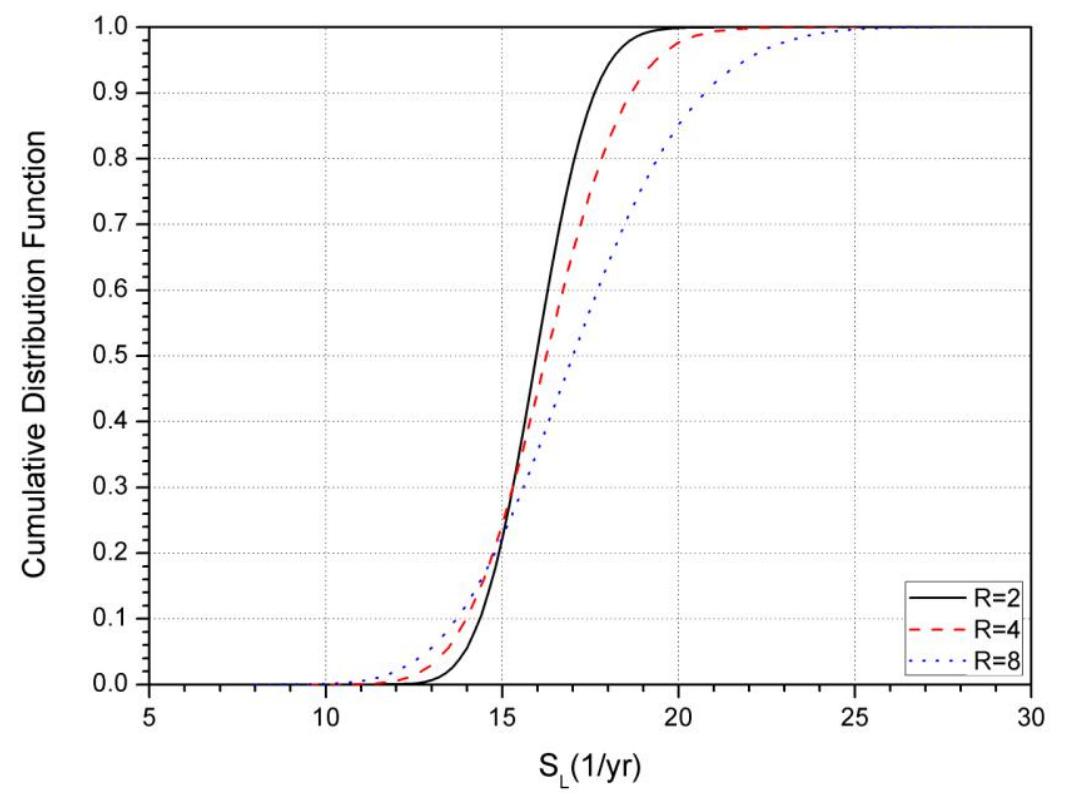

Fig. 44 - CDF of $S_{L}$ for Hubbert model with production data up to 2008 of the world 
Table 21 - Probabilistic values of each parameter for Hubbert model with production data up to 2008 of the world

\begin{tabular}{c|ccc|ccc|ccc}
\hline $\begin{array}{c}\text { Variance } \\
\text { Ratio }\end{array}$ & \multicolumn{3}{c}{$\mathrm{R}=2$} & & & & & \\
& & & & & & \\
& $\mathrm{Q}_{\infty}$ & $\mathrm{t}_{\mathrm{M}}$ & $\mathrm{S}_{\mathrm{L}}$ & $\mathrm{Q}_{\infty}$ & $\mathrm{t}_{\mathrm{M}}$ & $\mathrm{S}_{\mathrm{L}}$ & $\mathrm{Q}_{\infty}$ & $\mathrm{t}_{\mathrm{M}}$ & $\mathrm{S}_{\mathrm{L}}$ \\
& $(\mathrm{Bbbl})$ & $(\mathrm{yr})$ & $(1 / \mathrm{yr})$ & $(\mathrm{Bbbl})$ & $(\mathrm{yr})$ & $(1 / \mathrm{yr})$ & $(\mathrm{Bbbl})$ & $(\mathrm{yr})$ & $(1 / \mathrm{yr})$ \\
\hline P90 & 1439.8 & 1992.939 & 14.366 & 1396.6 & 1992.132 & 13.990 & 1358.6 & 1991.530 & 13.716 \\
P50 & 1621.5 & 1996.680 & 15.961 & 1656.1 & 1997.509 & 16.251 & 1759.4 & 1999.894 & 17.002 \\
P10 & 1850.2 & 2001.428 & 17.612 & 2034.8 & 2005.266 & 18.636 & 2722.2 & 2017.158 & 20.734 \\
Mean & 1636.0 & 1996.991 & 15.978 & 1695.8 & 1998.266 & 16.291 & 2005.3 & 2002.773 & 17.131 \\
Best-Fit & 1598 & 1996 & 15.8 & 1583 & 1996 & 15.5 & 1581 & 1996 & 15.5 \\
\hline
\end{tabular}

Table 22 - Parameter sets for Hubbert model with production data up to 2008 of the world $(\mathrm{R}=2)$

\begin{tabular}{|c|c|c|c|c|c|c|c|c|c|c|c|c|}
\hline \multirow{2}{*}{$\mathrm{R}=2$} & \multicolumn{4}{|c|}{$\mathrm{Q}_{\infty}$} & \multicolumn{4}{|c|}{$\mathrm{t}_{\mathrm{M}}$} & \multicolumn{4}{|c|}{$\mathrm{S}_{\mathrm{L}}$} \\
\hline & $\begin{array}{c}\mathrm{Q}_{\infty} \\
(\mathrm{Bbbl})\end{array}$ & $\begin{array}{c}\mathrm{t}_{\mathrm{M}} \\
(\mathrm{yr})\end{array}$ & $\begin{array}{c}\mathrm{S}_{\mathrm{L}} \\
(1 / \mathrm{yr})\end{array}$ & $\mathrm{S}_{\mathrm{o}} \mathrm{S}$ & $\begin{array}{c}\mathrm{Q}_{\infty} \\
(\mathrm{Bbbl})\end{array}$ & $\begin{array}{c}\mathrm{t}_{\mathrm{M}} \\
(\mathrm{yr})\end{array}$ & $\begin{array}{c}\mathrm{S}_{\mathrm{L}} \\
(1 / \mathrm{yr})\end{array}$ & $\mathrm{S}_{\mathrm{o}} \mathrm{S}$ & $\begin{array}{c}\mathrm{Q}_{\infty} \\
(\mathrm{Bbbl})\end{array}$ & $\begin{array}{c}\mathrm{t}_{\mathrm{M}} \\
(\mathrm{yr})\end{array}$ & $\begin{array}{c}\mathrm{S}_{\mathrm{L}} \\
(1 / \mathrm{yr})\end{array}$ & $\mathrm{S}_{\mathrm{o}} \mathrm{S}$ \\
\hline P90 & 1439 & 1994 & 14.6 & 7.4962 & 1478 & 1993 & 14.8 & 7.4662 & 1475 & 1994 & 14.4 & 7.5031 \\
\hline P50 & 1622 & 1996 & 15.8 & 7.4248 & 1634 & 1997 & 16.0 & 7.4251 & 1634 & 1997 & 16.0 & 7.4251 \\
\hline P10 & 1850 & 2001 & 17.2 & 7.3765 & 1811 & 2001 & 17.2 & 7.3825 & 1796 & 2000 & 17.6 & 7.3422 \\
\hline Mean & 1637 & 1997 & 16.0 & 7.4246 & 1634 & 1997 & 16.0 & 7.4251 & 1634 & 1997 & 16.0 & 7.4251 \\
\hline
\end{tabular}


Table 23 - Parameter sets for Hubbert model with production data up to 2008 of the world $(\mathrm{R}=4)$

\begin{tabular}{|c|c|c|c|c|c|c|c|c|c|c|c|c|}
\hline \multirow{2}{*}{$\mathrm{R}=4$} & \multicolumn{4}{|c|}{$\mathrm{Q}_{\infty}$} & \multicolumn{4}{|c|}{$t_{M}$} & \multicolumn{4}{|c|}{$\mathrm{S}_{\mathrm{L}}$} \\
\hline & $\begin{array}{c}\mathrm{Q}_{\infty} \\
(\mathrm{Bbbl})\end{array}$ & $\begin{array}{c}\mathrm{t}_{\mathrm{M}} \\
(\mathrm{yr})\end{array}$ & $\begin{array}{c}\mathrm{S}_{\mathrm{L}} \\
(1 / \mathrm{yr})\end{array}$ & $\mathrm{S}_{\mathrm{O}} \mathrm{S}$ & $\begin{array}{c}\mathrm{Q}_{\infty} \\
(\mathrm{Bbbl})\end{array}$ & $\begin{array}{c}\mathrm{t}_{\mathrm{M}} \\
(\mathrm{yr})\end{array}$ & $\begin{array}{c}\mathrm{S}_{\mathrm{L}} \\
(1 / \mathrm{yr})\end{array}$ & $\mathrm{S}_{\mathrm{o}} \mathrm{S}$ & $\begin{array}{c}\mathrm{Q}_{\infty} \\
(\mathrm{Bbbl})\end{array}$ & $\begin{array}{c}\mathrm{t}_{\mathrm{M}} \\
(\mathrm{yr})\end{array}$ & $\begin{array}{c}\mathrm{S}_{\mathrm{L}} \\
(1 / \mathrm{yr})\end{array}$ & $\mathrm{S}_{\mathrm{o}} \mathrm{S}$ \\
\hline P90 & 1397 & 1993.0 & 14.5 & 3.7475 & 1433 & 1991.5 & 14.5 & 3.7352 & 1433 & 1993 & 14.0 & 3.7591 \\
\hline P50 & 1655 & 1997.5 & 16.0 & 3.7147 & 1649 & 1997.5 & 16.0 & 3.7152 & 1673 & 1997.5 & 16.5 & 3.6970 \\
\hline P10 & 2033 & 2003.5 & 18.0 & 3.6689 & 1991 & 2005.0 & 18.0 & 3.6841 & 1901 & 2002 & 18.5 & 3.6510 \\
\hline Mean & 1697 & 1997.5 & 16.5 & 3.6950 & 1715 & 1999 & 16.5 & 3.7055 & 1673 & 1997.5 & 16.5 & 3.6970 \\
\hline
\end{tabular}

Table 24 - Parameter sets for Hubbert model with production data up to 2008 of the world ( $\mathrm{R}=8)$

\begin{tabular}{|c|c|c|c|c|c|c|c|c|c|c|c|c|}
\hline \multirow[t]{2}{*}{$\mathrm{R}=8$} & \multicolumn{4}{|c|}{$\mathrm{Q}_{\infty}$} & \multicolumn{4}{|c|}{$t_{M}$} & \multicolumn{4}{|c|}{$\mathrm{S}_{\mathrm{L}}$} \\
\hline & $\begin{array}{c}\mathrm{Q}_{\infty} \\
(\mathrm{Bbbl})\end{array}$ & $\begin{array}{c}\mathrm{t}_{\mathrm{M}} \\
(\mathrm{yr})\end{array}$ & $\begin{array}{c}\mathrm{S}_{\mathrm{L}} \\
(1 / \mathrm{yr})\end{array}$ & $\mathrm{S}_{\mathrm{o}} \mathrm{S}$ & $\begin{array}{c}\mathrm{Q}_{\infty} \\
(\mathrm{Bbbl})\end{array}$ & $\begin{array}{c}\mathrm{t}_{\mathrm{M}} \\
(\mathrm{yr})\end{array}$ & $\begin{array}{c}\mathrm{S}_{\mathrm{L}} \\
(1 / \mathrm{yr})\end{array}$ & $\mathrm{S}_{\mathrm{o}} \mathrm{S}$ & $\begin{array}{c}\mathrm{Q}_{\infty} \\
(\mathrm{Bbbl})\end{array}$ & $\begin{array}{c}\mathrm{t}_{\mathrm{M}} \\
(\mathrm{yr})\end{array}$ & $\begin{array}{c}\mathrm{S}_{\mathrm{L}} \\
(1 / \mathrm{yr})\end{array}$ & $\mathrm{S}_{\mathrm{o}} \mathrm{S}$ \\
\hline P90 & 1361 & 1993 & 14 & 1.8816 & 1431 & 1991.5 & 14.5 & 1.8677 & 1401 & 1993 & 13.5 & 1.8867 \\
\hline P50 & 1761 & 1999 & 17 & 1.8427 & 1781 & 2000.5 & 17 & 1.8480 & 1741 & 1999 & 17.0 & 1.8435 \\
\hline $\mathrm{P} 10$ & 2721 & 2015.5 & 20 & 1.8305 & 2691 & 2017.0 & 20.5 & 1.8306 & 2261 & 2009.5 & 20.5 & 1.8171 \\
\hline Mean & 2001 & 2003.5 & 18 & 1.8356 & 1931 & 2003.5 & 18 & 1.8383 & 1741 & 1999 & 17.0 & 1.8435 \\
\hline
\end{tabular}




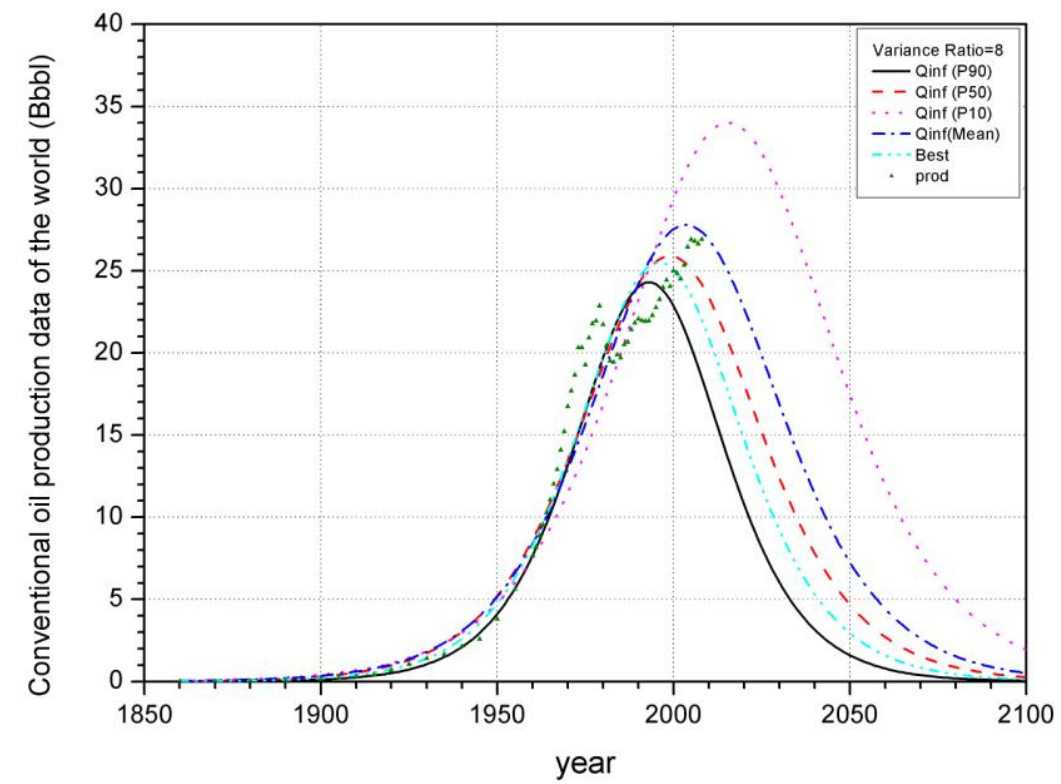

Fig. 45 - Probabilistic forecasts of $\mathrm{Q}_{\infty}$ for Hubbert model with production data up to 2008 of the world $(\mathrm{R}=8)$

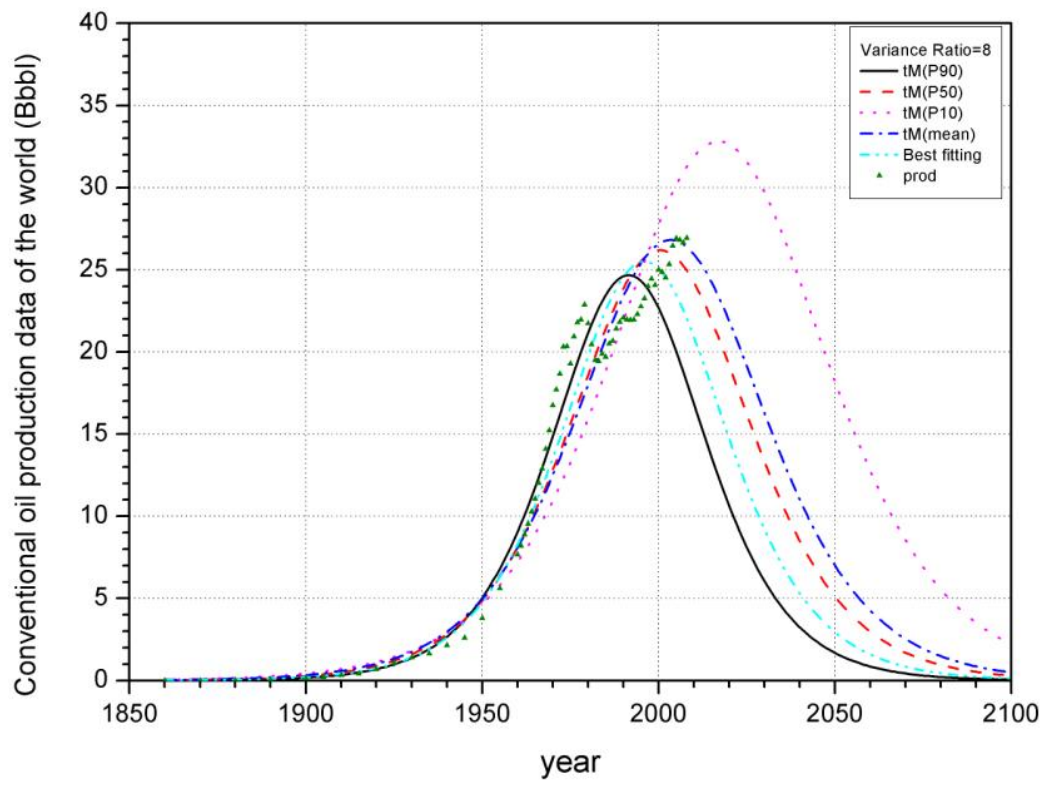

Fig. 46 - Probabilistic forecasts of $t_{M}$ for Hubbert model with production data up to 2008 of the world $(\mathrm{R}=8)$ 


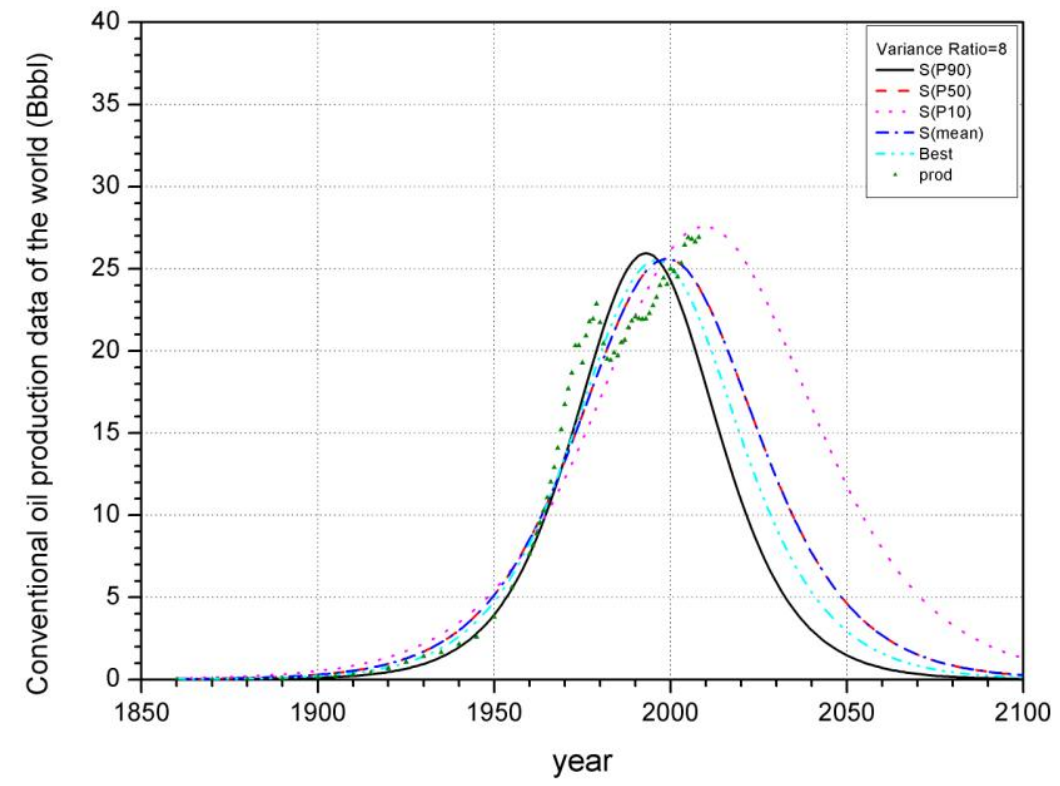

Fig. 47 - Probabilistic forecasts of $S_{L}$ for Hubbert model with production data up to 2008 of the world $(\mathrm{R}=8)$ 


\section{Normal Distribution Model with Production Data up to 2008}

Table 25 lists the data intervals and number of data points that define the discretized parameter space for different variance ratios.

Table 25 - Different variance ratio for normal distribution model with production data up to 2008 of the world

\begin{tabular}{c|cc|rc|cc}
\hline \multirow{2}{*}{$\begin{array}{c}\text { Variance } \\
\text { Ratio }\end{array}$} & \multicolumn{2}{|c|}{$\mathrm{R}=0.2$} & \multicolumn{2}{|c}{$\mathrm{R}=2$} & \multicolumn{2}{|c}{$\mathrm{R}=4$} \\
\cline { 2 - 6 } & Data Interval & points & Data Interval & points & Data Interval & points \\
\hline $\mathrm{Q}_{\infty}$ & $1001 \sim 2999$ & 1000 & $901 \sim 5896$ & 1000 & $900 \sim 10890$ & 1000 \\
$(\mathrm{Bbbl})$ & & & & & & \\
$\mathrm{t}_{\mathrm{M}}(\mathrm{yr})$ & $1981 \sim 2030.5$ & 100 & $1971 \sim 2070$ & 100 & $1971 \sim 2119.5$ & 100 \\
$\mathrm{~S}_{\mathrm{N}}(1 / \mathrm{yr})$ & $21 \sim 40.8$ & 100 & $11 \sim 60.5$ & 100 & $1 \sim 100$ & 100 \\
\hline
\end{tabular}

Fig. 48, Fig. 50, and Fig. 52 are the plots of normalized PDF for each parameter $\mathrm{Q}_{\infty}, \mathrm{t}_{\mathrm{M}}$, and $\mathrm{S}_{\mathrm{L}}$. Fig. 49, Fig. 51, and Fig. 53 are the plots of CDF for these three parameters, respectively. I obtained the P90, P50, P10, and mean value from the CDF of each parameter, which are shown in Table 26. Parameter sets found with maximum likelihood function value by taking the probabilistic value of each parameter are listed in Table 27, Table 28, and Table 29, and the sum-of-square norm $\left(\mathrm{S}_{\mathrm{o}} \mathrm{S}\right)$ values are also calculated. I choose one scenario $(\mathrm{R}=2)$ to plot the probabilistic forecasts of each parameter (Fig. 54, Fig. 55, and Fig. 56). 


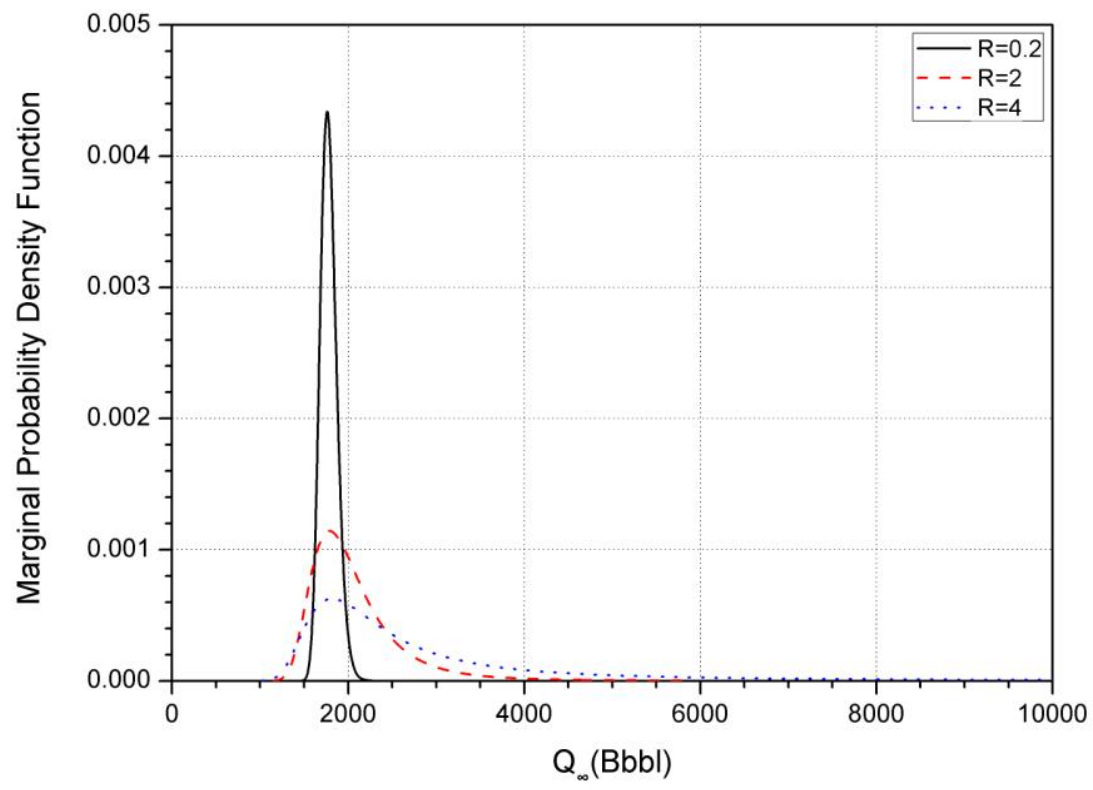

Fig. 48 - Marginal PDF of $\mathrm{Q}_{\infty}$ for Normal distribution model with production data up to 2008 of the world

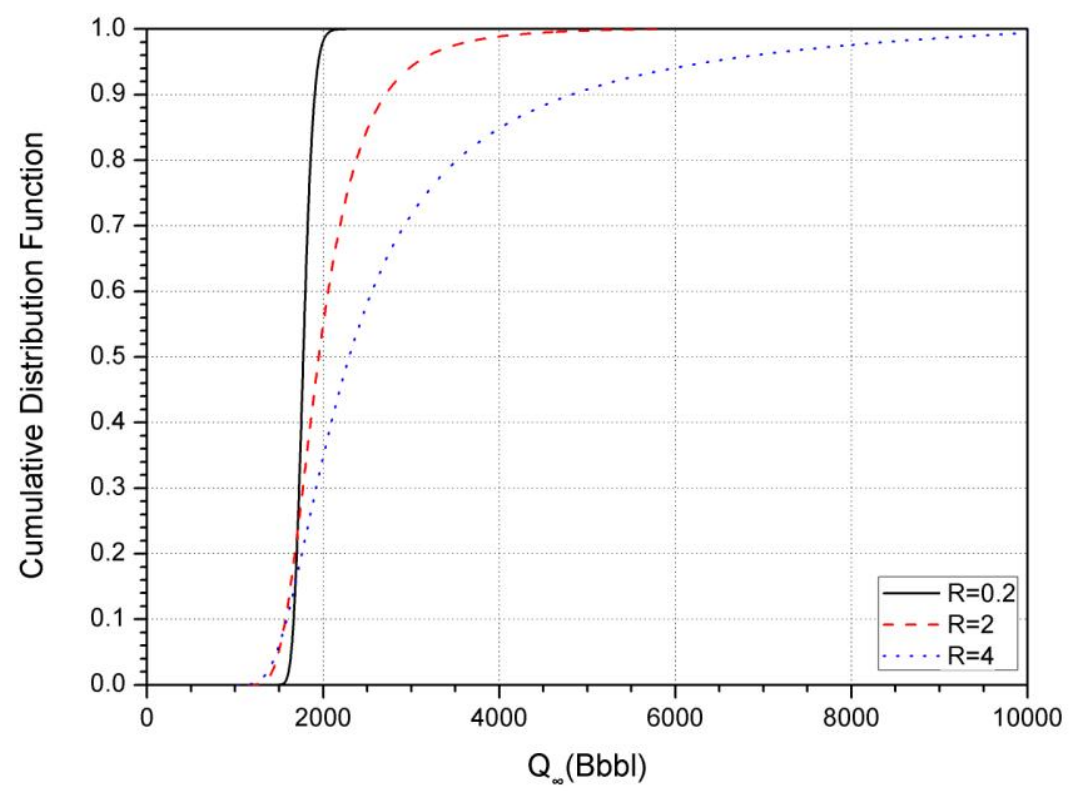

Fig. 49 - CDF of $\mathrm{Q}_{\infty}$ for Normal distribution model with production data up to 2008 of the world 


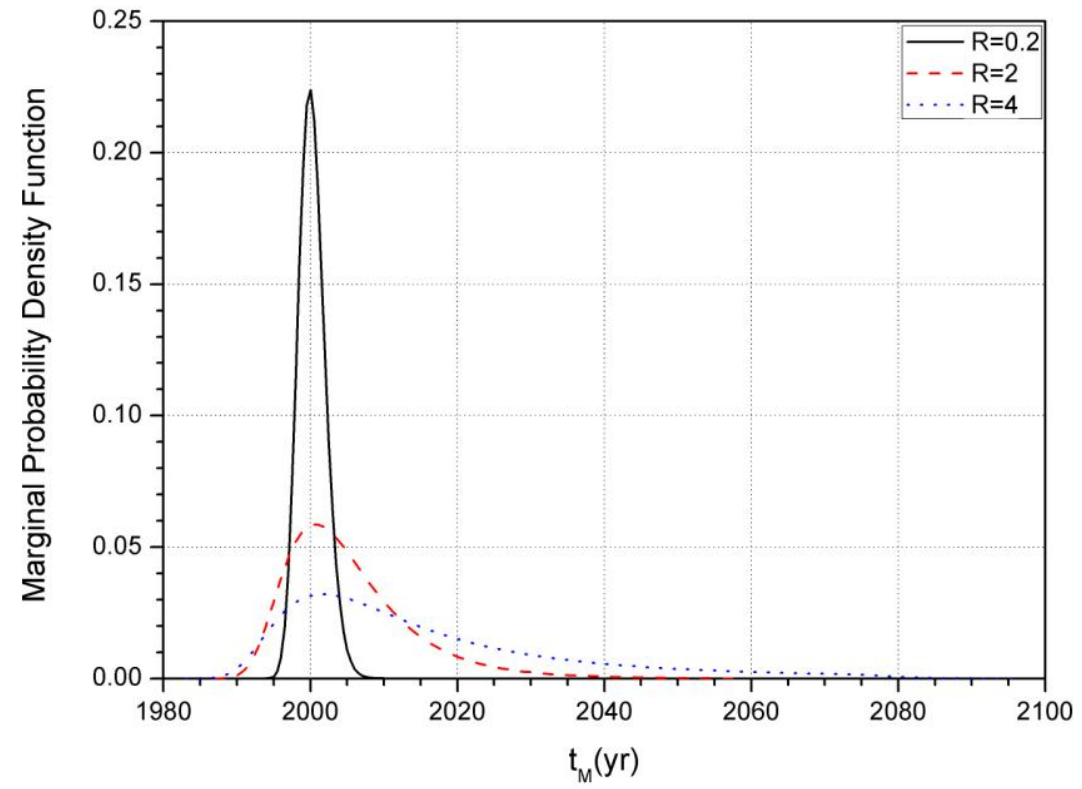

Fig. 50 - Marginal PDF of $t_{M}$ for Normal distribution model with production data up to 2008 of the world

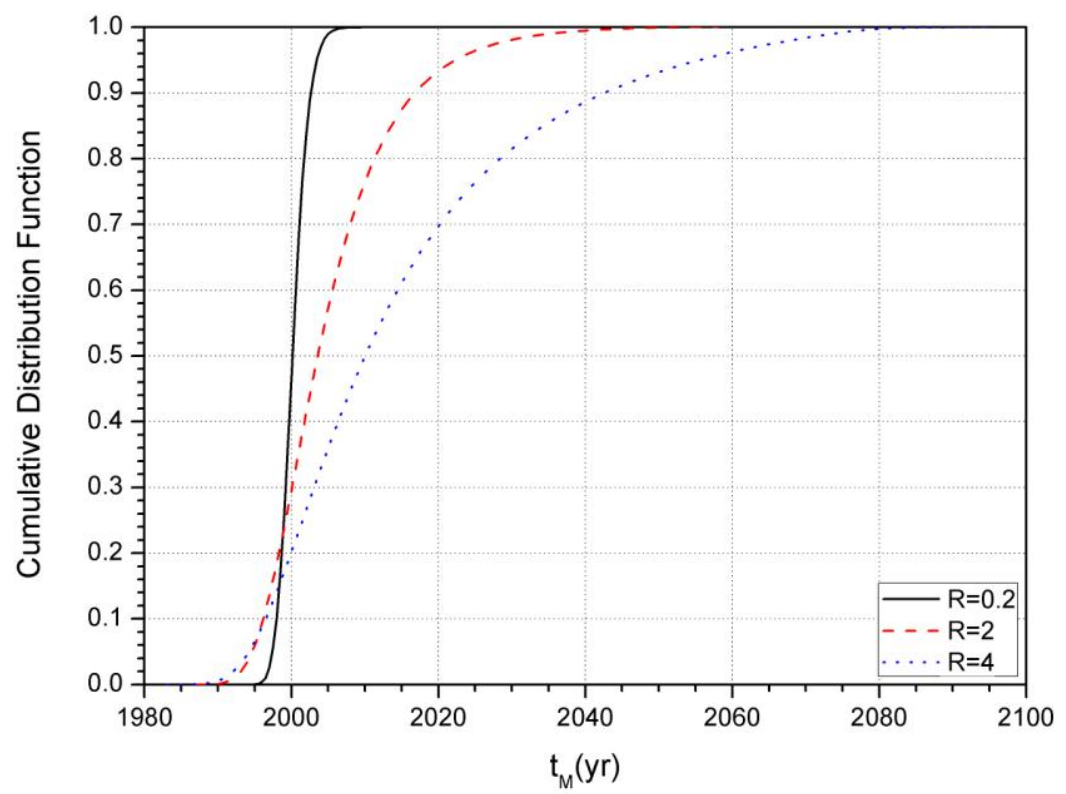

Fig. 51 - CDF of $t_{M}$ for Normal distribution model with production data up to 2008 of the world 


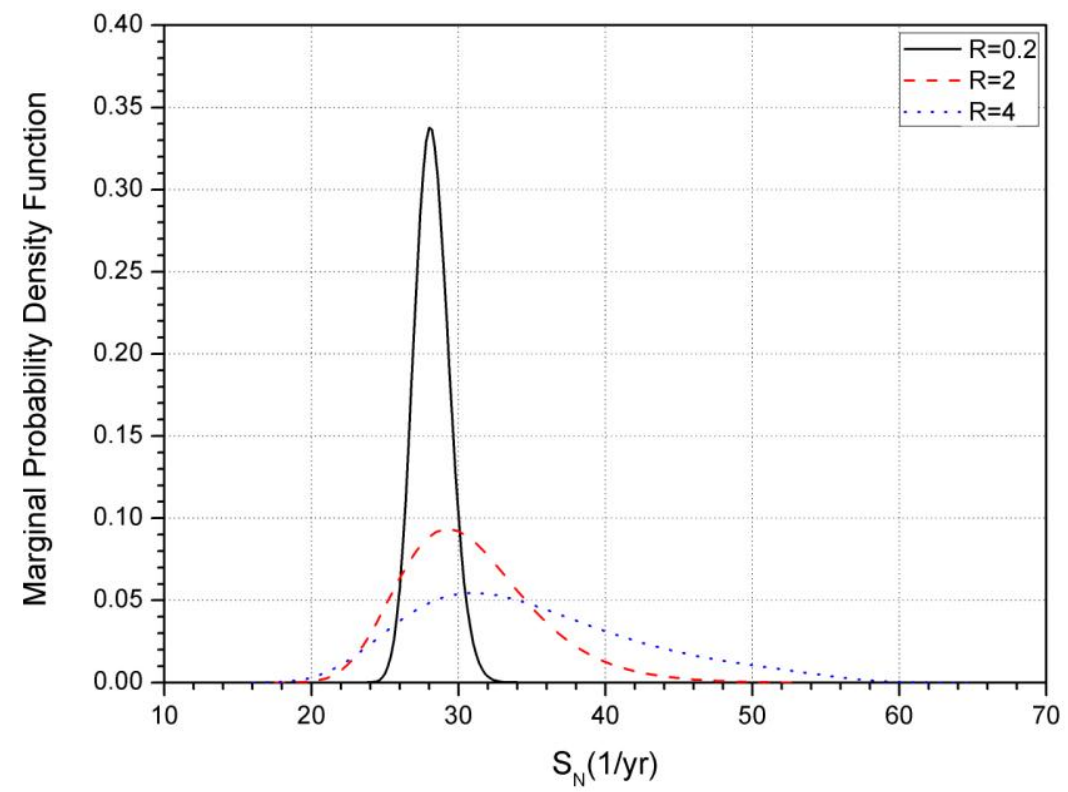

Fig. 52 - Marginal PDF of $\mathrm{S}_{\mathrm{N}}$ for Normal distribution model with production data up to 2008 of the world

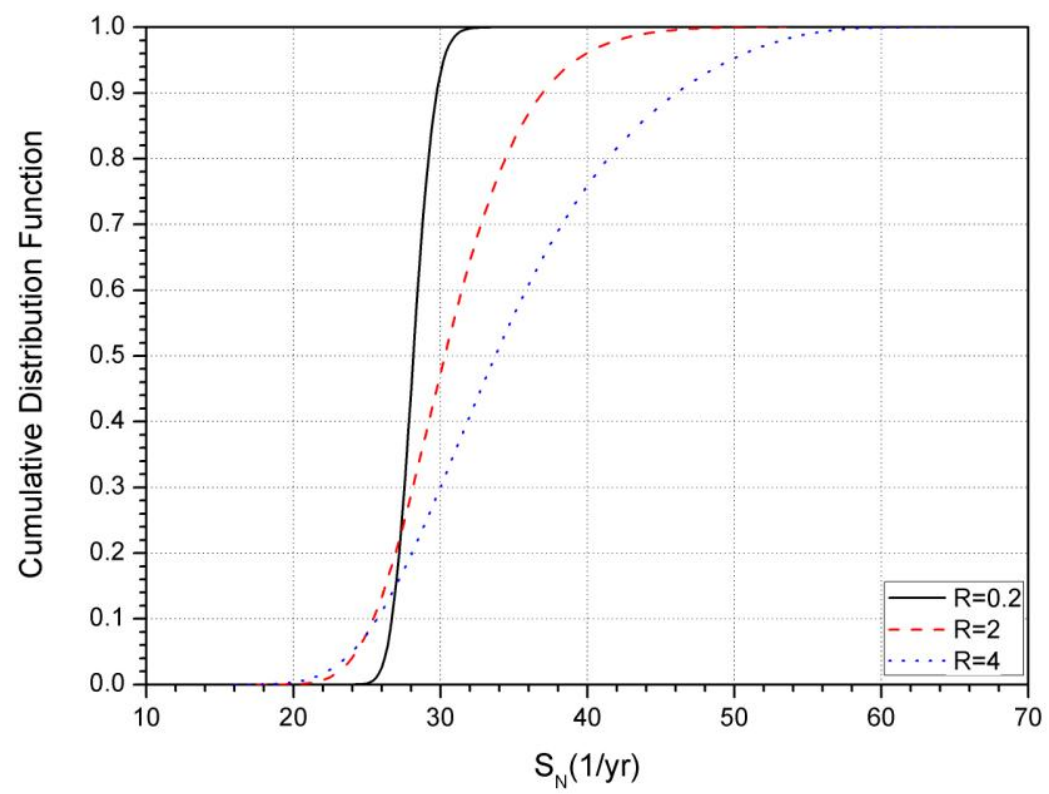

Fig. 53 - CDF of $S_{N}$ for Normal distribution model with production data up to 2008 of the world 
Table 26 - Probabilistic values of each parameter for Normal distribution model with production data up to 2008 of the world

\begin{tabular}{c|ccc|ccc|ccc}
\hline $\begin{array}{c}\text { Variance } \\
\text { Ratio }\end{array}$ & \multicolumn{3}{c}{$\mathrm{R}=0.2$} & & $\mathrm{R}=2$ & & & $\mathrm{R}=4$ \\
& $\mathrm{Q}_{\infty}$ & $\mathrm{t}_{\mathrm{M}}$ & $\mathrm{S}_{\mathrm{N}}$ & $\mathrm{Q}_{\infty}$ & $\mathrm{t}_{\mathrm{M}}$ & $\mathrm{S}_{\mathrm{N}}$ & $\mathrm{Q}_{\infty}$ & $\mathrm{t}_{\mathrm{M}}$ & $\mathrm{S}_{\mathrm{N}}$ \\
& $(\mathrm{Bbbl})$ & $(\mathrm{yr})$ & $(1 / \mathrm{yr})$ & $(\mathrm{Bbbl})$ & $(\mathrm{yr})$ & $(1 / \mathrm{yr})$ & $(\mathrm{Bbbl})$ & $(\mathrm{yr})$ & $(1 / \mathrm{yr})$ \\
\hline P90 & 1664.96 & 1997.987 & 26.701 & 1570.6 & 1996.175 & 25.432 & 1585.2 & 1996.50 & 25.710 \\
P50 & 1774.49 & 2000.131 & 28.155 & 1950.1 & 2003.574 & 30.299 & 2294.9 & 2010.01 & 33.730 \\
P10 & 1904.51 & 2002.640 & 29.742 & 2707.5 & 2016.765 & 36.933 & 4817.3 & 2042.55 & 46.035 \\
Mean & 1780.76 & 2000.243 & 28.196 & 2073.7 & 2005.348 & 30.825 & 2838.6 & 2015.18 & 34.868 \\
Best-fit & 1765 & 2000 & 28.5 & 1766 & 2000 & 28.4 & 1750 & 1999.5 & 28 \\
\hline
\end{tabular}

Table 27 - Parameter sets for Normal distribution model with production data up to 2008 of the world $(\mathrm{R}=0.2)$

\begin{tabular}{|c|c|c|c|c|c|c|c|c|c|c|c|c|}
\hline \multirow{2}{*}{$\mathrm{R}=0.2$} & \multicolumn{4}{|c|}{$\mathrm{Q}_{\infty}$} & \multicolumn{4}{|c|}{$t_{M}$} & \multicolumn{4}{|c|}{$\mathrm{S}_{\mathrm{N}}$} \\
\hline & $\begin{array}{c}\mathrm{Q}_{\infty} \\
(\mathrm{Bbbl})\end{array}$ & $\begin{array}{c}\mathrm{t}_{\mathrm{M}} \\
(\mathrm{yr})\end{array}$ & $\begin{array}{c}\mathrm{S}_{\mathrm{N}} \\
(1 / \mathrm{yr})\end{array}$ & $\mathrm{S}_{\mathrm{o}} \mathrm{S}$ & $\begin{array}{c}\mathrm{Q}_{\infty} \\
(\mathrm{Bbbl})\end{array}$ & $\begin{array}{c}\mathrm{t}_{\mathrm{M}} \\
(\mathrm{yr})\end{array}$ & $\begin{array}{c}\mathrm{S}_{\mathrm{N}} \\
(1 / \mathrm{yr})\end{array}$ & $\mathrm{S}_{\mathrm{o}} \mathrm{S}$ & $\begin{array}{c}\mathrm{Q}_{\infty} \\
(\mathrm{Bbbl})\end{array}$ & $\begin{array}{c}\mathrm{t}_{\mathrm{M}} \\
(\mathrm{yr})\end{array}$ & $\begin{array}{c}\mathrm{S}_{\mathrm{N}} \\
(1 / \mathrm{yr})\end{array}$ & $\mathrm{S}_{\mathrm{o}} \mathrm{S}$ \\
\hline P90 & 1665 & 1998 & 26.8 & 76.009 & 1669 & 1998 & 26.8 & 76.007 & 1683 & 1998.5 & 26.8 & 76.044 \\
\hline P50 & 1775 & 2000 & 28.2 & 75.779 & 1765 & 2000 & 28 & 75.840 & 1773 & 2000 & 28.2 & 75.780 \\
\hline P10 & 1905 & 2002.5 & 29.6 & 75.563 & 1895 & 2002.5 & 29.6 & 75.569 & 1901 & 2002.5 & 29.8 & 75.501 \\
\hline Mean & 1781 & 2000 & 28.2 & 75.776 & 1765 & 2000 & 28 & 75.840 & 1773 & 2000 & 28.2 & 75.780 \\
\hline
\end{tabular}


Table 28 - Parameter sets for Normal distribution model with production data up to 2008 of the world $(\mathrm{R}=2)$

\begin{tabular}{|c|c|c|c|c|c|c|c|c|c|c|c|c|}
\hline \multirow{2}{*}{$\mathrm{R}=2$} & \multicolumn{4}{|c|}{$\mathrm{Q}_{\infty}$} & \multicolumn{4}{|c|}{$t_{M}$} & \multicolumn{4}{|c|}{$\mathrm{S}_{\mathrm{N}}$} \\
\hline & $\begin{array}{c}\mathrm{Q}_{\infty} \\
(\mathrm{Bbbl})\end{array}$ & $\begin{array}{c}\mathrm{t}_{\mathrm{M}} \\
(\mathrm{yr})\end{array}$ & $\begin{array}{c}\mathrm{S}_{\mathrm{N}} \\
(1 / \mathrm{yr})\end{array}$ & $\mathrm{S}_{\mathrm{O}} \mathrm{S}$ & $\begin{array}{c}\mathrm{Q}_{\infty} \\
(\mathrm{Bbbl})\end{array}$ & $\begin{array}{c}\mathrm{t}_{\mathrm{M}} \\
(\mathrm{yr})\end{array}$ & $\begin{array}{c}\mathrm{S}_{\mathrm{N}} \\
(1 / \mathrm{yr})\end{array}$ & $\mathrm{S}_{\mathrm{o}} \mathrm{S}$ & $\begin{array}{c}\mathrm{Q}_{\infty} \\
(\mathrm{Bbbl})\end{array}$ & $\begin{array}{c}\mathrm{t}_{\mathrm{M}} \\
(\mathrm{yr})\end{array}$ & $\begin{array}{c}\mathrm{S}_{\mathrm{N}} \\
(1 / \mathrm{yr})\end{array}$ & $\mathrm{S}_{\mathrm{o}} \mathrm{S}$ \\
\hline P90 & 1571 & 1996 & 25.5 & 7.6178 & 1576 & 1996 & 25.5 & 7.6176 & 1601 & 1997 & 25.5 & 7.6237 \\
\hline P50 & 1951 & 2003 & 30 & 7.5465 & 1971 & 2004 & 30.5 & 7.5411 & 1971 & 2004 & 30.5 & 7.5411 \\
\hline $\mathrm{P} 10$ & 2706 & 2016 & 36.5 & 7.4289 & 2711 & 2017 & 36.5 & 7.4469 & 2661 & 2016 & 37.0 & 7.4089 \\
\hline Mean & 2076 & 2006 & 31.5 & 7.5256 & 2026 & 2005 & 31 & 7.5333 & 1986 & 2004 & 31.0 & 7.5223 \\
\hline
\end{tabular}

Table 29 - Parameter sets for Normal distribution model with production data up to 2008 of the world $(\mathrm{R}=4)$

\begin{tabular}{|c|c|c|c|c|c|c|c|c|c|c|c|c|}
\hline \multirow{2}{*}{$\mathrm{R}=4$} & \multicolumn{4}{|c|}{$\mathrm{Q}_{\infty}$} & \multicolumn{4}{|c|}{$t_{M}$} & \multicolumn{4}{|c|}{$\mathrm{S}_{\mathrm{N}}$} \\
\hline & $\begin{array}{c}\mathrm{Q}_{\infty} \\
(\mathrm{Bbbl})\end{array}$ & $\begin{array}{l}\mathrm{t}_{\mathrm{M}} \\
(\mathrm{yr})\end{array}$ & $\begin{array}{c}\mathrm{S}_{\mathrm{N}} \\
(1 / \mathrm{yr})\end{array}$ & $\mathrm{S}_{\mathrm{O}} \mathrm{S}$ & $\begin{array}{c}\mathrm{Q}_{\infty} \\
(\mathrm{Bbbl})\end{array}$ & $\begin{array}{l}\mathrm{t}_{\mathrm{M}} \\
(\mathrm{yr})\end{array}$ & $\begin{array}{c}\mathrm{S}_{\mathrm{N}} \\
(1 / \mathrm{yr})\end{array}$ & $\mathrm{S}_{\mathrm{O}} \mathrm{S}$ & $\begin{array}{c}\mathrm{Q}_{\infty} \\
(\mathrm{Bbbl})\end{array}$ & $\begin{array}{c}\mathrm{t}_{\mathrm{M}} \\
(\mathrm{yr})\end{array}$ & $\begin{array}{c}\mathrm{S}_{\mathrm{N}} \\
(1 / \mathrm{yr})\end{array}$ & $\mathrm{S}_{\mathrm{O}} \mathrm{S}$ \\
\hline P90 & 1590 & 1996.5 & 26 & 3.8051 & 1600 & 1996.5 & 26 & 3.8049 & 1640 & 1998 & 26 & 3.8098 \\
\hline P50 & 2290 & 2010 & 33 & 3.7558 & 2280 & 2010.0 & 33 & 3.7562 & 2300 & 2010 & 34 & 3.7352 \\
\hline P10 & 4820 & 2041.5 & 45 & 3.6715 & 4860 & 2043.0 & 46 & 3.6589 & 4510 & 2040 & 46 & 3.6387 \\
\hline Mean & 2840 & 2019 & 38 & 3.7010 & 2560 & 2014.5 & 36 & 3.7188 & 2390 & 2011.5 & 35 & 3.7221 \\
\hline
\end{tabular}




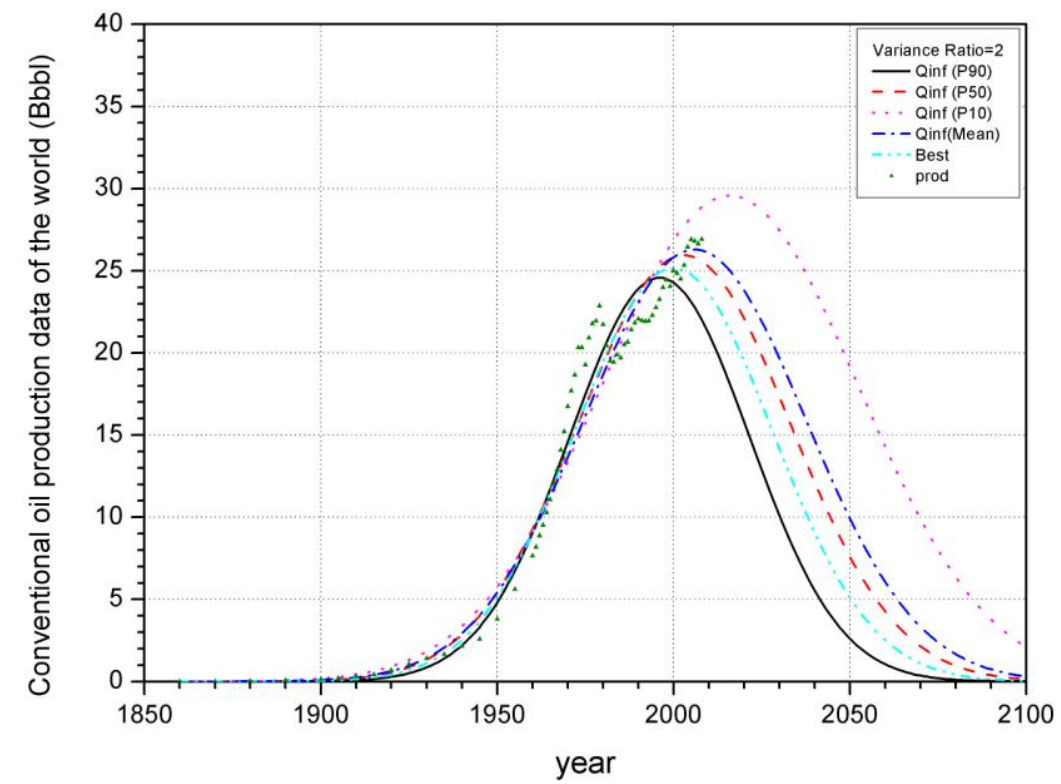

Fig. 54 - Probabilistic forecasts of $\mathrm{Q}_{\infty}$ for Normal Distribution model with production data up to 2008 of the world $(\mathrm{R}=2)$

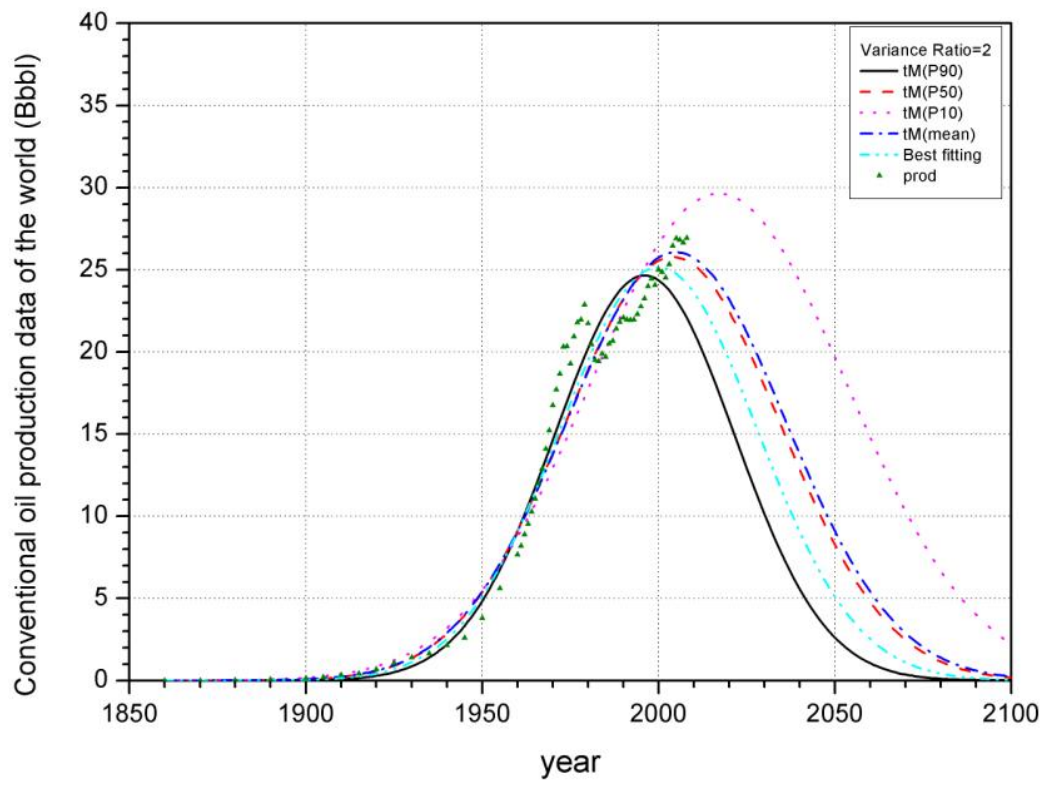

Fig. 55 - Probabilistic forecasts of $t_{M}$ for Normal Distribution model with production data up to 2008 of the world $(\mathrm{R}=2)$ 


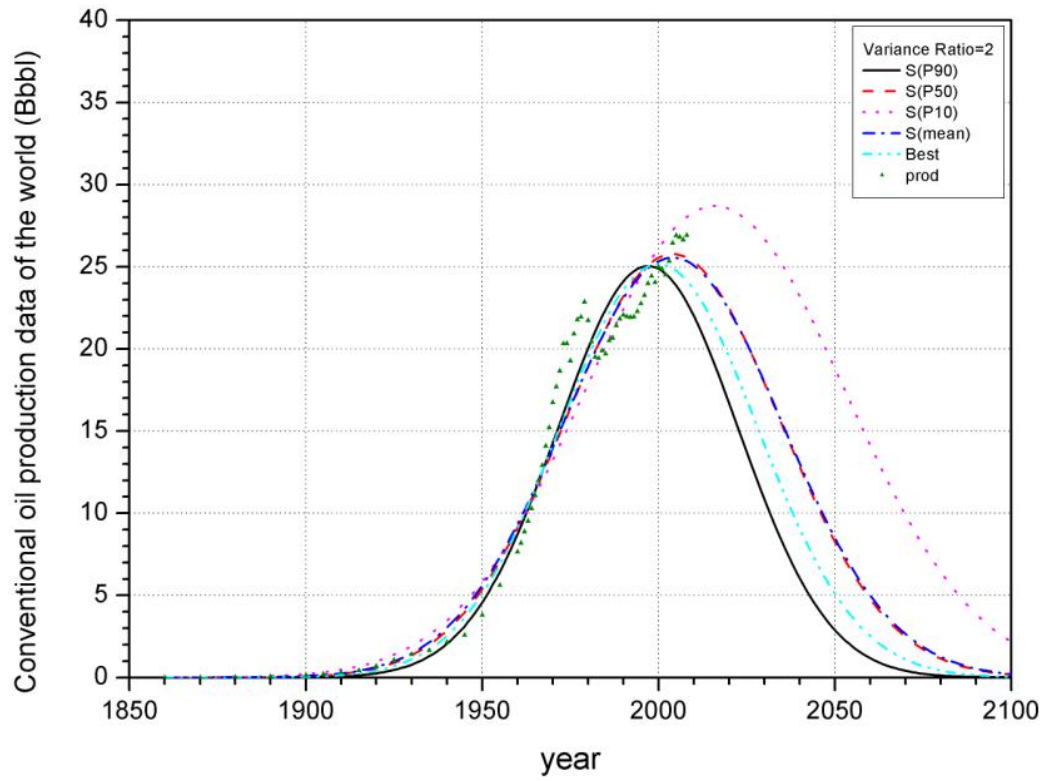

Fig. 56 - Probabilistic forecasts of $\mathrm{S}_{\mathrm{N}}$ for Normal Distribution model with production data up to 2008 of the world $(\mathrm{R}=2)$ 


\section{Summary of Uncertainty Analysis for the World by Mathematical Modeling}

1. By applying different variance ratio for mathematical modeling, it shows that uncertainty from mathematical modeling can be effectively quantified by estimating the probabilistic values - P90, P50, P10, and mean values. The larger variance ratio contributes much uncertainty for world oil production forecasts.

2. In the conventional oil production curve of the world (Fig. 38), there is no overall peak and period of declining production like for the production curve of the lower

U.S. 48 (Fig. 1). Thus, in my analyses for both two models, there indeed existed significant differences in probabilistic forecasts for different variance ratios (Table 21, Table 26).

3. From Table 21 and Table 26, it can be found that the range from P90 to P10 value of $\mathrm{Q}_{\infty}$ and $\mathrm{t}_{\mathrm{M}}(\mathrm{R}=8)$ in the Hubbert model is nearly equal to the corresponding value of the scenario $(\mathrm{R}=2)$ in Normal distribution model, and it means that there existed much uncertainty for applying normal distribution model to forecast the world conventional oil production than Hubbert's model.

4. From the uncertainty analyses in the pre-peak section (production data up to 1956) of the lower U.S. 48, it is indicated that the variation of probabilistic forecasts is wider for global conventional oil production than the lower U.S. 48, because there is no peak and declining production curve for the world conventional oil production. It is implied there is lots of uncertainty in forecasting the world conventional oil production by using mathematical modeling.

5. I compare the sum-of-square norm $\left(\mathrm{S}_{\mathrm{o}} \mathrm{S}\right)$ of both two models, and it shows that the 
Hubbert model is better for fitting the production data than the Normal distribution model.

6. Using the larger variance ratio for the Hubbert and Normal distribution models, the results from mathematical modeling comparable favorably with forecasts predicted by Group 2 and 3 in Bentley's (2008) paper. In particular, the uncertainty from mathematical modeling encompasses Group 2 and 3 estimates. 


\section{MULTIPLE EXPERTS ANALYSIS OF WORLD CONVENTIONAL OIL}

\section{RESOURCES}

Since Hubbert proposed the "peak oil" concept and attempted to predict the lower U.S 48 and world oil ultimate recoverable resources in 1956, there has been existed a great deal of publications related to forecasting global oil production. Bentley et al. (2008) reviewed the literatures relevant to the forecasts and methodologies of global oil production since 1956, and this paper classified the forecasts into three different groups: Group 1- quantitative analyses which predict that global oil production will come to a resource-limited peak in the near term and certainly before 2020; Group 2forecasts that use quantitative methods, but which appear to have no production peak within the forecasted time period (2020 or 2030); Group 3- non-quantitative analyses that do not predict a resource-limited oil peak within the foreseeable future.

Before utilizing multiple experts analysis of world conventional oil resources, I need to find one distribution of each expert's estimates. By Bentley's (2008) paper, I regard the forecasts made by individuals, organizations and institutions as my experts. Unfortunately, these forecasts give only certain values for ultimate recoverable resources rather than a distribution. However, I can still combine these values to build a distribution for world conventional resources.

My objective is to analyze world conventional oil resources; hence, I take ultimate recoverable resources of world convention oil data from both Group 1 and Group 2 of Bentley's (2008) paper - Table 30. Examining these results, I observed that 
estimates of world conventional oil resources increase gradually with time (Fig. 57). Apparently, it means that there existed lots of uncertainty for these forecasts.

From the results of mathematical modeling in forecasting world conventional oil production, it can be found that large uncertainty ranges that encompass both groups of forecasts (imminent peak and no imminent peak). Because of this, I regard each forecast as the possible scenario, and classify those results into three groups such as in Bentley's paper (2008). Thus, if I apply multiple experts system to analyze world conventional oil resources, it is needed to encapsulate all possible forecasts (beliefs) made by the experts .

Group 3 did not predict a resource-limited oil peak within the predictable future (i.e., before 2030). Because there were no quantitative estimates from Group 3, I decided to use Hubbert mathematical modeling to generate a quantitative estimate that could be integrated with the estimates from Groups 1 and 2. My method was to assume, conservatively, year 2031 as the peak year for Group 3 estimates, and develop a probabilistic value for ultimate recoverable resources, $\mathrm{Q}_{\infty}$, by applying the mathematical modeling mentioned above. 
Table 30 - World conventional oil ultimate recoverable resources from Group 1 \& Group 2 of Bentley et al. (2008)

\begin{tabular}{|c|c|c|c|}
\hline category & Date & Author & Ultimate (Bbbl) \\
\hline \multirow{18}{*}{ Group 1} & 1956 & Hubbert & 1250 \\
\hline & 1969 & Hubbert & $1350 ; 2100$ \\
\hline & 1972 & ESSO & 2100 \\
\hline & 1972 & Report: UN Conference & 2500 \\
\hline & 1974 & SPRU, UK & $1800-2480$ \\
\hline & 1977 & Hubbert & 2000 \\
\hline & 1977 & Ehrlich et al & 1900 \\
\hline & 1978 & WEC/IFP & 1803 \\
\hline & 1981 & WorldBank & 1900 \\
\hline & 1992 & Meadows et al & $1800-2500$ \\
\hline & 1995 & Petroconsultants $(\mathrm{xN})$ & 1800 \\
\hline & 1996 & Ivanhoe & 2000 \\
\hline & 1997 & Edwards & 2836 \\
\hline & 1998 & IEA & 2300 \\
\hline & 1999 & USGS & 2000 \\
\hline & 2000 & Bartlett & $2000 \& 3000$ \\
\hline & 2002 & BGR & 2670 \\
\hline & 2003 & Energyfiles Ltd & 2338 \\
\hline \multirow{4}{*}{ Group 2} & 2000 & $\operatorname{IEA}(+\mathrm{N})$ & 3345 \\
\hline & 2001 & US DoE/EIA & 3303 \\
\hline & 2002 & Shell $(+\mathrm{N})$ & 3000 \\
\hline & 2003 & EU (WETO study) & 4500 \\
\hline
\end{tabular}




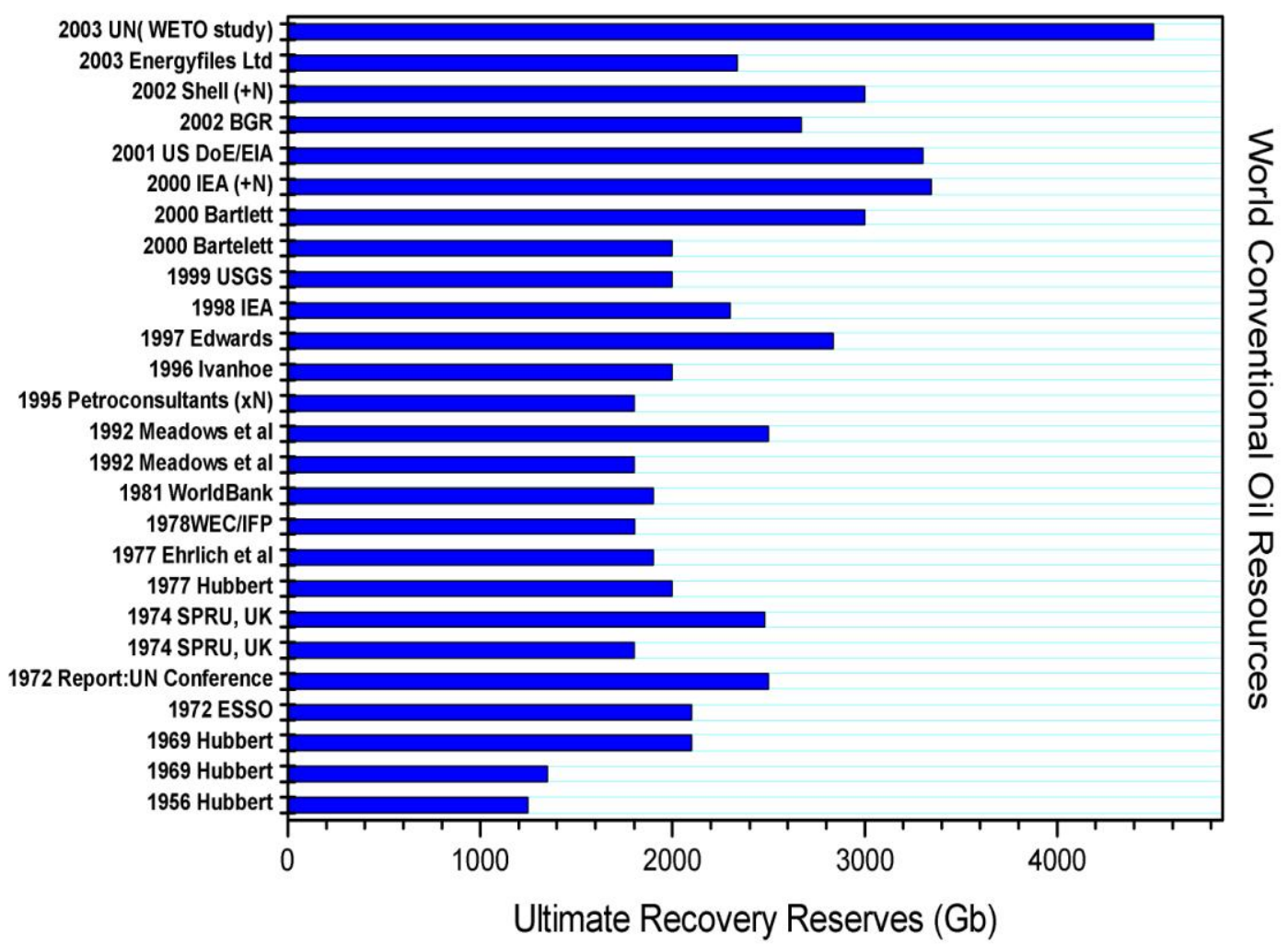

Fig. 57 - World conventional oil ultimate recoverable resources from Group 1 \& Group 2 of Bentley et al. (2008)

Here, I use the variance ratio $\mathrm{R}=8$ to do the analyses, and the probabilistic values of $\mathrm{Q}_{\infty}$ and $\mathrm{S}_{\mathrm{L}}$ at a peak year of 2031 are listed in Table 31. Parameter sets found with maximum likelihood function value by taking the probabilistic value of $\mathrm{Q}_{\infty}$ and $\mathrm{S}_{\mathrm{L}}$ are listed in Table 32. The plots of probabilistic forecasts of $\mathrm{Q}_{\infty}$ and $\mathrm{S}_{\mathrm{L}}$ are shown in Fig. 58 and Fig. 59. 
Table 31 - Probabilistic values of $\mathrm{Q}_{\infty}$ and $\mathrm{S}_{\mathrm{L}}$ at a peak year of 2031 for Hubbert model with overall production data of the world

\begin{tabular}{c|cc||ccccc}
\hline \multirow{2}{*}{$\begin{array}{c}\text { Variance } \\
\text { Ratio }\end{array}$} & \begin{tabular}{c}
\multicolumn{7}{c}{$\mathrm{R}=8, \mathrm{t}_{\mathrm{M}}=2031 \mathrm{yr}$} \\
Interval
\end{tabular} & points & P90 & P50 & P10 & Mean & Best-Fit \\
\cline { 2 - 7 } & $1001 \sim 6000$ & 5000 & 3437.4 & 3929 & 4426.7 & 3930.9 & 3933 \\
\hline $\begin{array}{c}\mathrm{Q}_{\infty} \\
(\mathrm{Bbbl})\end{array}$ & & & & & & & \\
$\mathrm{S}_{\mathrm{L}}$ & $5 \sim 54.9$ & 500 & 19.967 & 21.867 & 23.615 & 21.821 & 22 \\
$(1 / \mathrm{yr})$ & & & & & & & \\
\hline
\end{tabular}

Table 32 - Parameter sets at the peak time 2031 for Hubbert model with overall production data of the world $(\mathrm{R}=8)$

\begin{tabular}{c|cccc|cccc}
\hline \multirow{2}{*}{$\mathrm{R}=8$} & \multicolumn{3}{|c|}{$\mathrm{Q}_{\infty}$} & \multicolumn{4}{c}{$\mathrm{S}_{\mathrm{L}}$} \\
\cline { 2 - 10 } & $\mathrm{Q}_{\infty}$ & $\mathrm{t}_{\mathrm{M}}$ & $\mathrm{S}_{\mathrm{L}}$ & $\mathrm{S}_{\mathrm{o}} \mathrm{S}$ & $\mathrm{Q}_{\infty}$ & $\mathrm{t}_{\mathrm{M}}$ & $\mathrm{S}_{\mathrm{L}}$ & $\mathrm{S}_{\mathrm{O}} \mathrm{S}$ \\
& $(\mathrm{Bbbl})$ & $(\mathrm{yr})$ & $(1 / \mathrm{yr})$ & & $(\mathrm{Bbbl})$ & $(1 / \mathrm{yr})$ & \\
\hline P90 & 3437 & 2031 & 22.5 & 1.8381 & 4063 & 2031 & 20.0 & 1.8545 \\
P50 & 3929 & 2031 & 21.9 & 1.8346 & 3941 & 2031 & 21.9 & 1.8346 \\
P10 & 4427 & 2031 & 21.5 & 1.8309 & 3781 & 2031 & 23.6 & 1.8321 \\
Mean & 3931 & 2031 & 22 & 1.8339 & 3949 & 2031 & 21.8 & 1.8353 \\
\hline
\end{tabular}




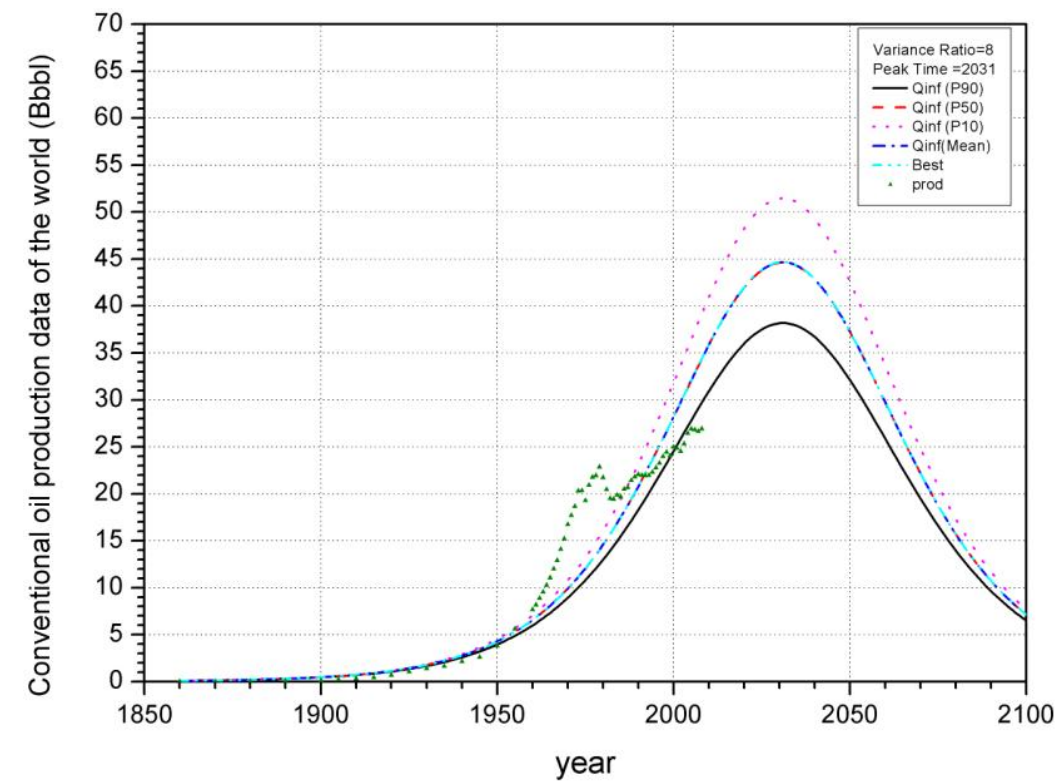

Fig. 58 - Probabilistic forecasts of $\mathrm{Q}_{\infty}$ at a peak year of 2031 for Hubbert model with overall production data of the world $(\mathrm{R}=8)$

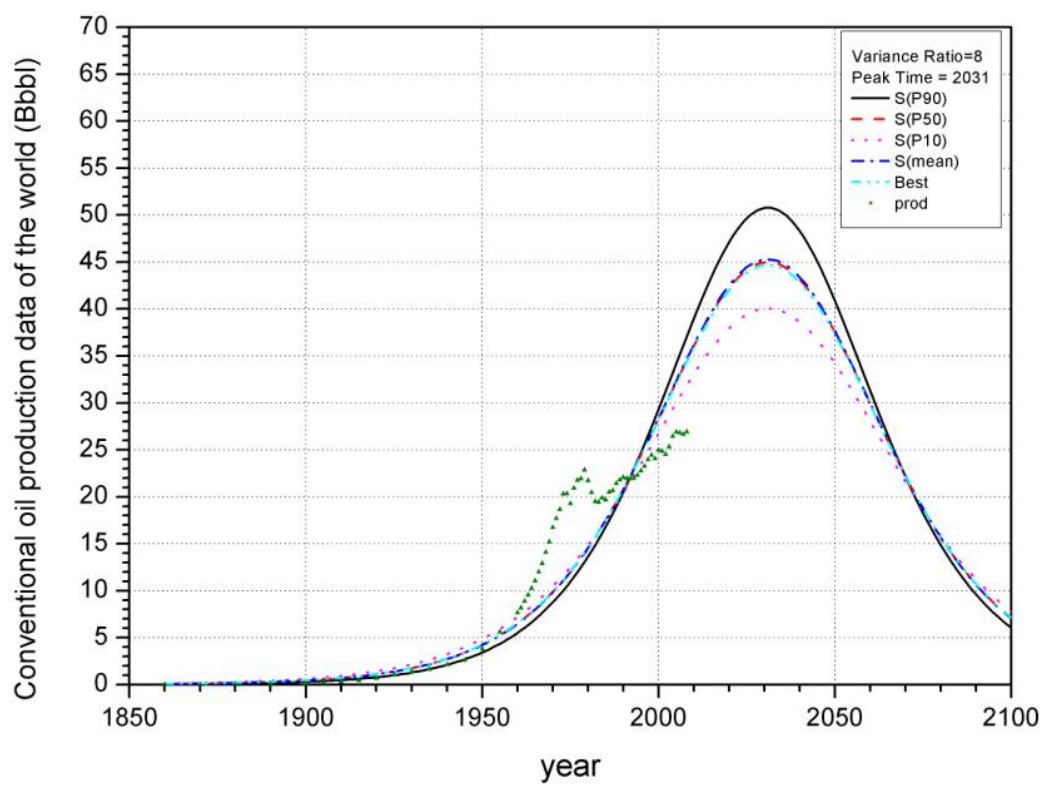

Fig. 59 - Probabilistic forecasts of $S_{L}$ at a peak year of 2031 for Hubbert model with overall production data of the world $(\mathrm{R}=8)$ 
Here, in order to make the linear pooling, I only take the P90, P50, P10, and mean values of ultimate recoverable resources $\mathrm{Q}_{\infty}$ as the forecasts for Group 3. It means that I have four forecasts to represent Group 3 with single values (like the mean), and then pool with the single values from Groups 1 and 2 to obtain a probabilistic distribution.

Before applying the multiple experts method to get a probabilistic distribution for the world ultimate recoverable resources, it is needed to decide which mathematical technique is appropriate to combine the forecasts from these three groups. By comparing the results from mathematical modeling with the forecasts made by different groups in Bentley's paper (2008), I find that the forecasts from Groups 1 to 3 are all possible, and encompass the full range of opinions from all experts represented in the literature. Thus, the linear opinion pool is appropriate and each forecast from different groups should be given equal weighting.

Combining all forecasts from Group 1, Group 2, and Group 3, I get a histogram and cumulative distribution function for these all possible estimates (Fig. 60). Estimates in world conventional resources increase with the time (Fig. 57); thus, the question arises as to whether all forecasts should be integrated in the analysis or whether only more recent forecasts should be used. Next, I omit the forecasts before 1990 and generate another histogram and cumulative distribution function (Fig. 61). The probabilistic values of ultimate recoverable resources from both distributions generated by multiple experts system are listed in Table 33. 

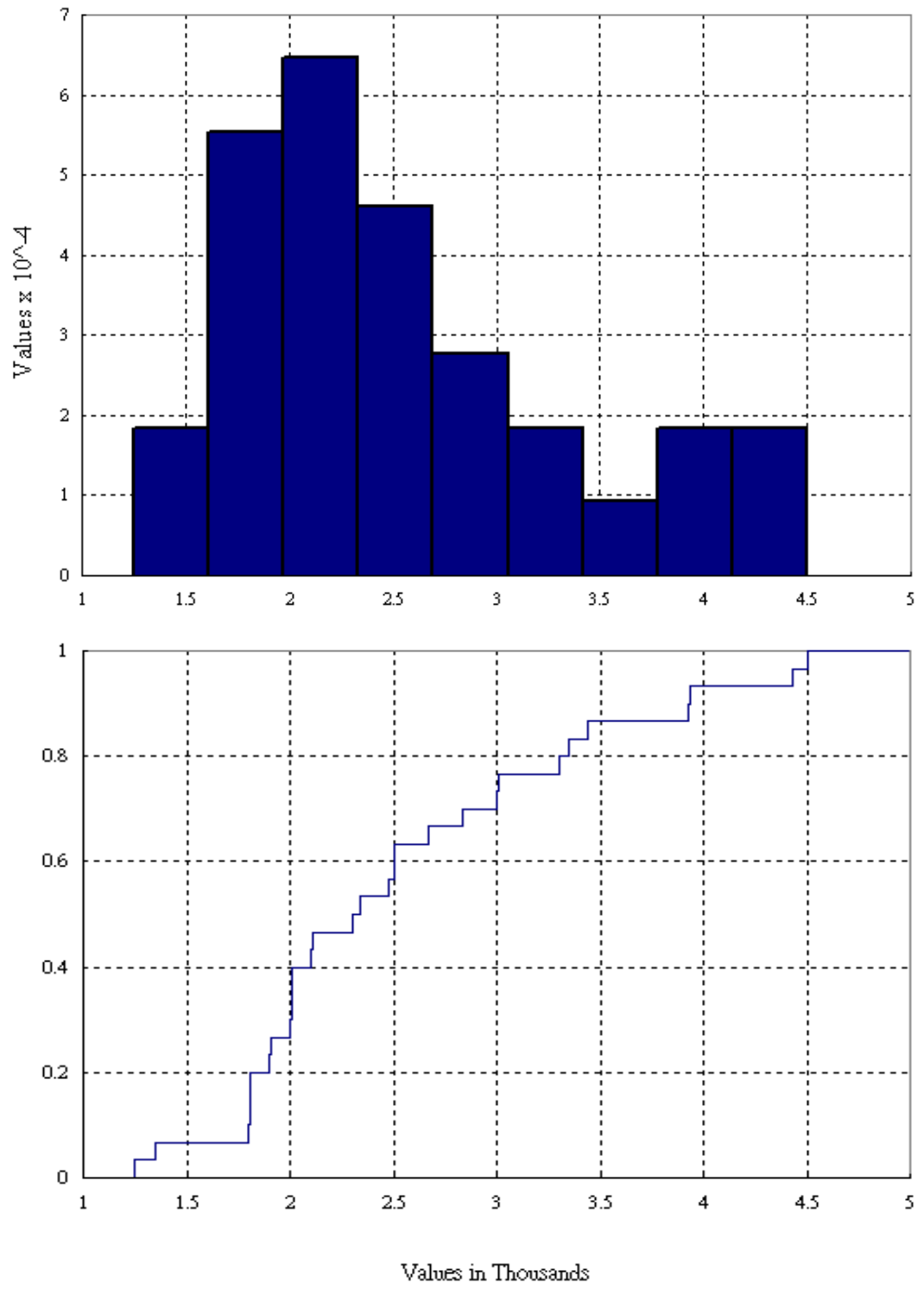

Fig. 60 - Histogram and CDF combining all forecasts of the three different groups 

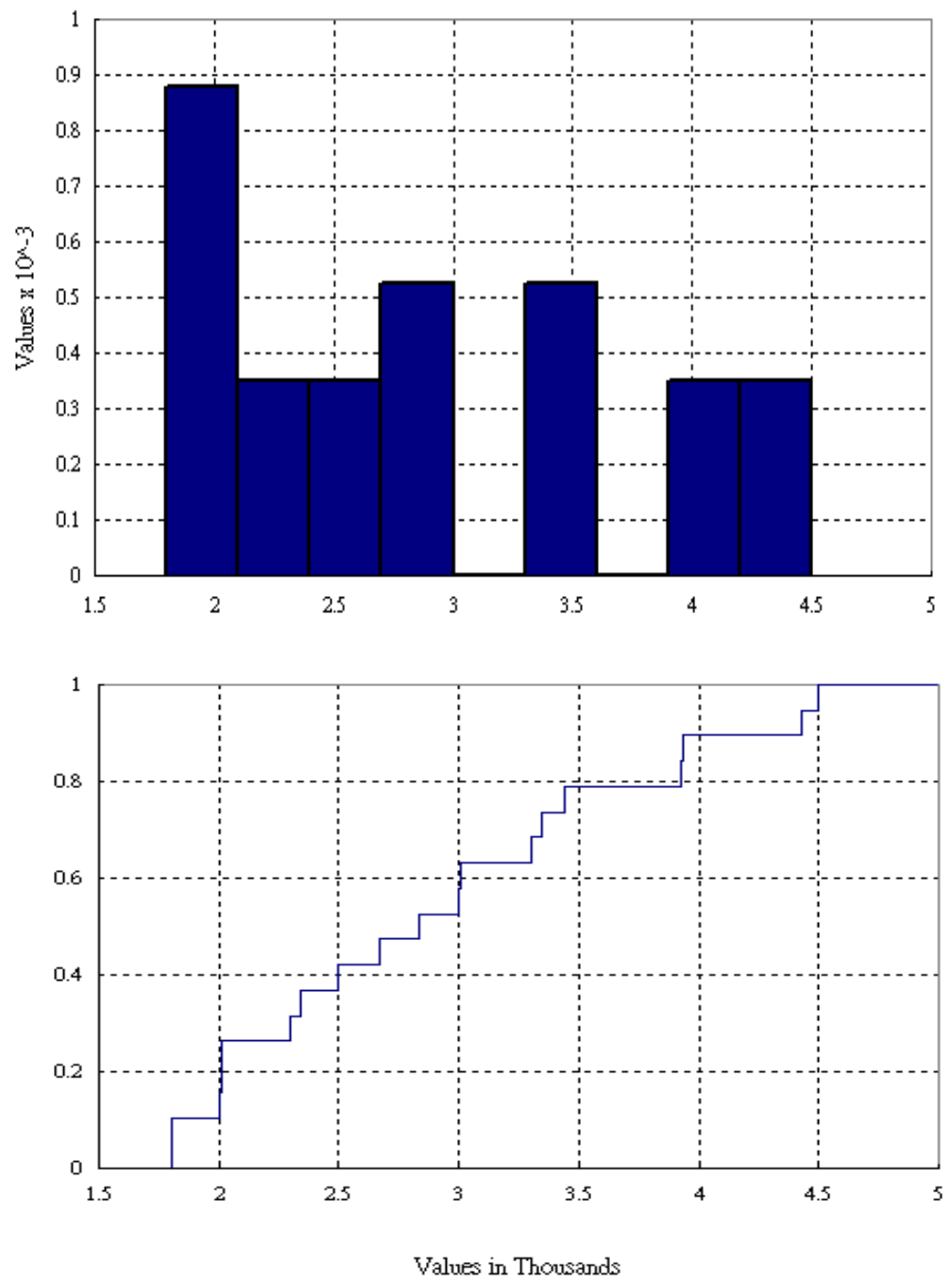

Fig. 61 - Histogram and CDF combining all forecasts after 1990 of the three different groups

Table 33 - Estimates of world conventional oil resources using multiple experts pooling

\begin{tabular}{ccc}
\hline $\mathrm{Q}_{\infty}(\mathrm{Bbbl})$ & All Forecasts & Forecasts after 1990 \\
\hline P90 & 1800.0 & 1800.0 \\
P50 & 2319.0 & 2836.0 \\
P10 & 3929.0 & 4427.0 \\
Mean & 2543.3 & 2900.8 \\
\hline
\end{tabular}


From the mean values of ultimate recoverable resources in Table 33, we also can estimate the timing of peak oil for these two cases. Parameter sets found with maximum likelihood function value by taking the probabilistic values of $t_{M}$ and $S_{L}$ for both cases are listed in Table 34 and Table 35. The plots of probabilistic forecasts of $Q_{\infty}$ and $S_{L}$ are shown in Fig. 62 and Fig. 63.

Table 34 - Parameter sets at the $\mathrm{Q}_{\infty}=2543.3 \mathrm{Bbbl}$ for Hubbert model with overall production data of the world $(\mathrm{R}=8)$

\begin{tabular}{c|cccc|cccc}
\hline \multirow{2}{*}{$\mathrm{R}=8$} & \multicolumn{3}{|c|}{$\mathrm{t}_{\mathrm{M}}$} & \multicolumn{4}{c}{$\mathrm{S}_{\mathrm{L}}$} \\
\cline { 2 - 9 } & $\mathrm{Q}_{\infty}$ & $\mathrm{t}_{\mathrm{M}}$ & $\mathrm{S}_{\mathrm{L}}$ & $\mathrm{S}_{\mathrm{o}} \mathrm{S}$ & $\mathrm{Q}_{\infty}$ & $\mathrm{t}_{\mathrm{M}}$ & $\mathrm{S}_{\mathrm{L}}$ & $\mathrm{S}$ \\
& $(\mathrm{Bbbl})$ & $(\mathrm{yr})$ & $(1 / \mathrm{yr})$ & & $(\mathrm{yr})$ & $(1 / \mathrm{yr})$ & $\mathrm{S}_{\mathrm{o}} \mathrm{S}$ \\
\hline P90 & 2543.3 & 2009.1 & 19.5 & 1.8174 & 2543.3 & 2012.5 & 18.1 & 1.8516 \\
P50 & 2543.3 & 2013.5 & 19.9 & 1.8294 & 2543.3 & 2013.1 & 19.9 & 1.8280 \\
P10 & 2543.3 & 2018.3 & 20.5 & 1.8387 & 2543.3 & 2014.9 & 21.7 & 1.8185 \\
Mean & 2543.3 & 2013.6 & 19.9 & 1.8298 & 2543.3 & 2013.1 & 19.9 & 1.8280 \\
\hline
\end{tabular}

Table 35 - Parameter sets at the $\mathrm{Q}_{\infty}=2900.8 \mathrm{Bbbl}$ for Hubbert model with overall production data of the world $(\mathrm{R}=8)$

\begin{tabular}{c|cccc|cccc}
\hline \multirow{2}{*}{$\mathrm{R}=8$} & \multicolumn{5}{|c|}{$\mathrm{t}_{\mathrm{M}}$} & \multicolumn{4}{c}{$\mathrm{S}_{\mathrm{L}}$} \\
\cline { 2 - 10 } & $\mathrm{Q}_{\infty}$ & $\mathrm{t}_{\mathrm{M}}$ & $\mathrm{S}_{\mathrm{L}}$ & $\mathrm{S}_{\mathrm{o}} \mathrm{S}$ & $\mathrm{Q}_{\infty}$ & $\mathrm{t}_{\mathrm{M}}$ & $\mathrm{S}_{\mathrm{L}}$ & $\mathrm{S}_{\mathrm{o}} \mathrm{S}$ \\
& $(\mathrm{Bbbl})$ & $(\mathrm{yr})$ & $(1 / \mathrm{yr})$ & & $(\mathrm{Bbbl})$ & $(\mathrm{yr})$ & $(1 / \mathrm{yr})$ & \\
\hline P90 & 2900.8 & 2014.6 & 20.2 & 1.8199 & 2900.8 & 2017.7 & 18.8 & 1.8505 \\
P50 & 2900.8 & 2018.8 & 20.6 & 1.8303 & 2900.8 & 2018.4 & 20.6 & 1.8289 \\
P10 & 2900.8 & 2023.4 & 21.4 & 1.8365 & 2900.8 & 2020.2 & 22.4 & 1.8227 \\
Mean & 2900.8 & 2018.9 & 20.6 & 1.8306 & 2900.8 & 2018.4 & 20.6 & 1.8289 \\
\hline
\end{tabular}




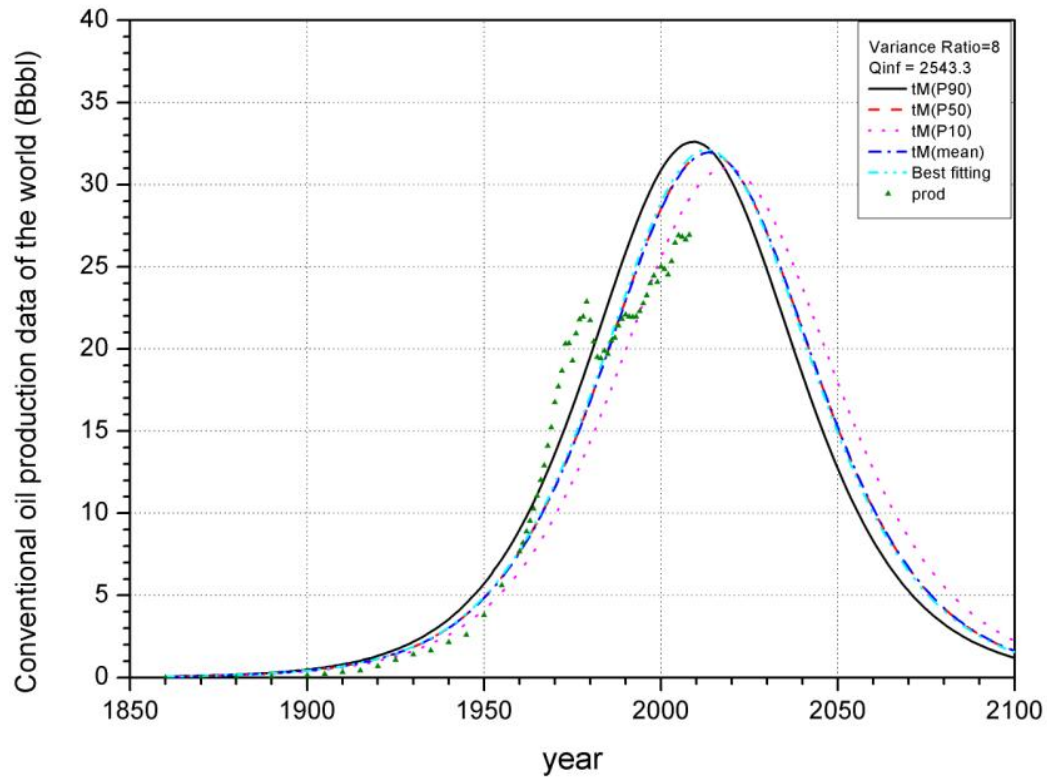

Fig. 62 - Probabilistic forecasts of $t_{M}$ at the $Q_{\infty}=2543.3 \mathrm{Bbbl}$ for Hubbert model with overall production data of the world $(\mathrm{R}=8)$

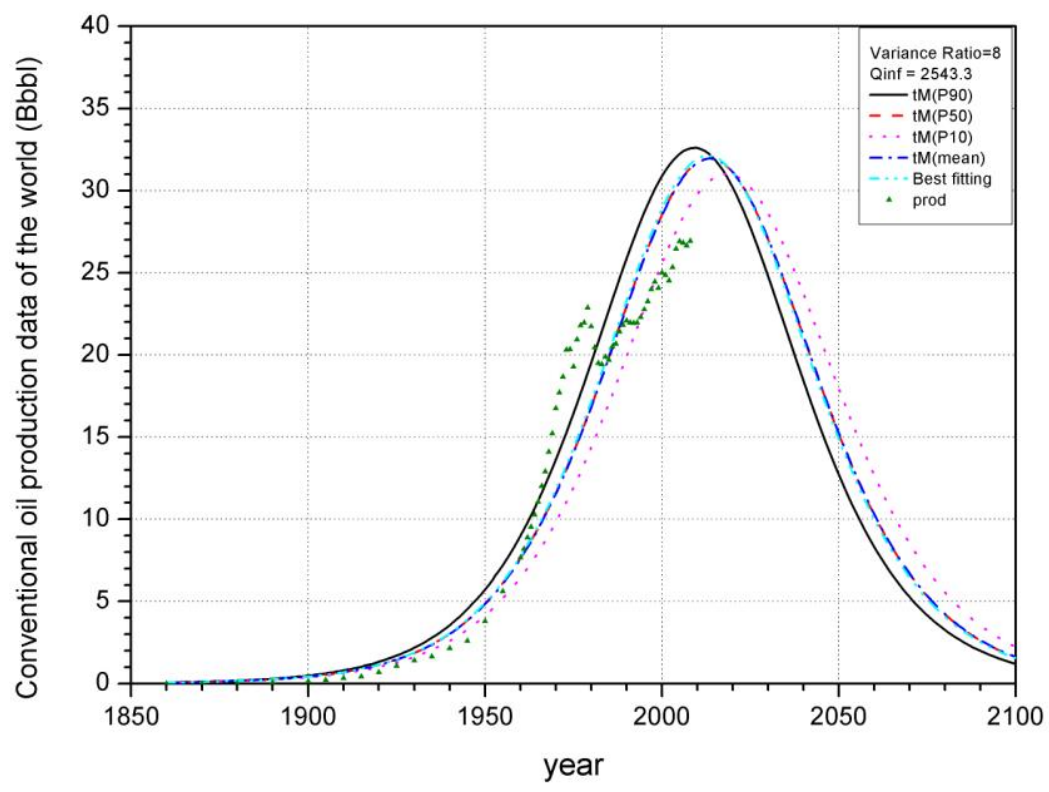

Fig. 63 - Probabilistic forecasts of $t_{M}$ at the $Q_{\infty}=2900.8$ Bbbl for Hubbert model with overall production data of the world $(\mathrm{R}=8)$ 
It is worth noting that I used conservative probabilistic forecasts for Group 3 for the multiple experts analysis. Group 3 authors did not quantify oil resources because they depend on economic and societal theory to explain that resources will grow from the improvement of technology, knowledge and economic incentives. Thus, the results obtained by the multiple experts analysis yields a conservative estimate for world conventional oil resources. Furthermore, because of the conservative estimation for Group 3, there is additional upside potential that is not represented in the composite distributions shown in Fig. 60, Fig. 61, and Table 33. Thus, these distributions also underestimate the uncertainty in ultimate world conventional oil resources. From Fig. 57, it indicated that the estimates for world conventional oil have significantly increased since 1990. Based on this reason, and because it results in larger uncertainty, it is better to represent the uncertainty in world conventional oil resources by taking the probabilistic distribution made with the forecasts after 1990. 


\section{CONCLUSIONS AND RECOMMENDATIONS}

\section{Conclusions}

There have been countless debates over world remaining oil resources and the timing of peak oil. The very fact that there is wide diversity of opinion and heated debate indicates that there is a lot of uncertainty, which my studies confirm. I draw the following conclusions from the analyses described above:

1. The uncertainty in world conventional oil resources is best expressed by the results from the multiple experts analysis, taking the probabilistic distribution made with the forecasts after 1990. The results show that the mean value of ultimate recoverable resources is $2900.8 \mathrm{Bbbl}$. The P90 value is $1800 \mathrm{Bbbl}$, the P50 value is $2836 \mathrm{Bbbl}$, and the P10 value is $4427 \mathrm{Bbbl}$. The mean and standard deviation are both underestimated; i.e., there is actually more uncertainty than I have quantified, due to conservatively assuming the peak year of 2031 for the forecasts of Group3.

2. The results of uncertainty analyses from mathematical modeling show that we potentially have large uncertainty in conventional oil estimates of the world and the lower U.S. 48 when we only take data regression or model fitting as the forecasting tools. Furthermore, due to the scarcity of production data or indistinct declining production curve, it also makes us recognize much uncertainty within the forecasts by applying the mathematical models to predict.

3. Giving due consideration to uncertainty, Hubbert-type mathematical modeling results in large uncertainty ranges that encompass both groups of forecasts (imminent peak 
and no imminent peak). In short, the industry does not have enough information at this time to say with any reliability what the ultimate world conventional oil production will be. It could peak soon, somewhere in the distant future, or somewhere in between. It would be wise to consider all of these possible outcomes in planning and making decisions regarding capital investment and formulation of energy policy.

4. Combining of expert assessments from the literatures, I can effectively build one distribution to encapsulate all beliefs regarding agreement or disagreement with “peak oil”. However, I attempt to conservatively estimate world conventional oil resources for the group that did not predict the peak oil. The resulting forecast distribution covers large uncertainty ranges similar to the results from the analyses of mathematical modeling.

\section{Recommendation for Future Work}

I expect that both methodologies can be applied to evaluate the uncertainty for conventional gas and unconventional hydrocarbon resources produced from tight gas reservoirs, coalbed methane, oil sands, gas shales, and gas hydrates. 


\section{NOMENCLATURE}

b:

$\mathrm{C}_{\mathrm{D}}$

$\mathrm{d}^{\text {obs }}$

$\mathrm{n}_{\mathrm{d}}$

$\mathrm{N}_{0}$

$\mathrm{g}(\mathrm{x})$

q

$\mathrm{q}_{\mathrm{M}}$

$\mathrm{R}$

$\mathrm{R}_{\mathrm{MS}}$

$\mathrm{S}_{\mathrm{N}}$

$\mathrm{S}_{\mathrm{L}}$

$\mathrm{S}_{\mathrm{o}} \mathrm{S}$

$\mathrm{t}$

$t_{M}$

$t_{0}$

Q

$\mathrm{Q}_{0}$

$\mathrm{Q}_{\infty}$
The constant describing the shape of production curve (1/yr)

The constant describing the shape of production curve (1/yr)

Covariance matrix

The vector of observed production data of every year

The number of measured (observed) data points

Dimensionless cumulative production factor

Forward model

Production rate $(\mathrm{Bbbl} / \mathrm{yr})$

The maximum peak production rate $(\mathrm{Bbbl} / \mathrm{yr})$

The variance ratio of production data

Root mean square

The width parameter for normal distribution (yr)

The width parameter for Hubbert model (yr)

The sum of square norms

The calendar time (yr)

The year at maximum production rate $(\mathrm{yr})$

Arbitrary time or reference point (yr)

Cumulative production (Bbbl)

Cumulative production at an arbitrary time or reference point (Bbbl)

Ultimate recovery resource $(\mathrm{Bbbl})$ 
$\mathrm{Q}_{\mathrm{M}} \quad$ Maximum cumulative production (Bbbl)

Subscript

$M$

$\mathrm{N}$

Maximum

Normal

$\mathrm{L}$

Logistic

$\infty$

Ultimate or infinity

Superscript

$\begin{array}{ll}\text { cal } & \text { Calculated } \\ \text { obs } & \text { Observed }\end{array}$




\section{REFERENCES}

Al-Jarri, A.S. and Startzman, R.A. 1997. Worldwide Petroleum-Liquid Supply and Demand (Includes Associated Papers 52597 and 52598 ). SPE Journal of Petroleum Technology 49 (12): 1329-1338. DOI: 10.2118/38782-ms

Bartlett, A.A. 2000. An Analysis of U.S. And World Oil Production Patterns Using Hubbert-Style Curves. Mathematical Geology 32 (1): 1-17.

Bentley, R. and Boyle, G. 2008. Global Oil Production: Forecasts and Methodologies. Environment and Planning B: Planning and Design 35: 609-626.

Brandt, A.R. 2007. Testing Hubbert. Energy Policy 35: 3074-3088.

Campbell, C.J. 2003. Industry Urged to Watch for Regular Oil Production Peaks, Depletion Signals. Oil \& Gas Journal 101 (27): 38-47.

Clemen, R.T. 1989. Combining Forecasts: A Review and Annotated Bibliography. International Journal of Forecasting 5 (4): 559-583.

Edwards, J.D. 1997. Crude Oil and Alternate Energy Production Forecasts for the Twenty-First Century: The End of the Hydrocarbon Era. American Association Petroleum Geologists Bulletin 81 (8): 1292-1305.

Energy Information Administration, Annual Energy Review 1995, U.S. Washington, DC., July 1996.

Energy Information Administration, Annual Energy Review 2008, U.S. Washington, DC., June 2009.

Hubbert, M.K. 1956. Nuclear Energy and the Fossil Fuels. Paper presented at the Drilling and Production Practice. American Petroleum Institute.

Hubbert, M.K. 1962. Energy Resource: A Report to the Committee on Natural Resources of the National Academy of Sciences. Publication, 1000-D. National Research Council, Washington, DC.

Hubbert, M.K. 1982. Techniques of Prediction as Applied to the Production of Oil and Gas. Paper presented at the Symposium of US Department of Commerce, 
Washington D.C.

Laherrere, J.H. 1997 Multi-Hubbert Modeling. http://www.hubbertpeak.com/laherrere/multihub.htm.

Laherrere, J.H. 2000. Learn Strengths, Weaknesses to Understand Hubbert Curve. Oil \& Gas Journal 98 (16): 63-76.

Laherrere, J.H. 2007 Uncertainty of Data and Forecasts for Fossil Fuels. Association for the Study of Peak Oil. http://www.oilcrisis.com/laherrere/Castilla200704.pdf.

Lynch, M.C. 2003. Petroleum Resources Pessimism Debunked in Hubbert Model and Hubbert Modelers' Assessment. Oil \& Gas Journal 101 (27): 38-47.

O’Hagan, A., Buck, C.E., A., D. et al. 2006. Uncertain Judgements: Eliciting Experts' Probabilities. Statistics in Practice, New York John Wiley \& Sons, Ltd. Original edition.

Ryan, J.M. 1966. Limitations of Statistical Methods for Predicting Petroleum and Natural Gas Reserves and Availability. SPE Journal of Petroleum Technology 18 (3): 281-287. DOI: $10.2118 / 1256-$ pa 


\section{VITA}

Name: Chih-Ming. Tien

Address: $\quad$ No.2, Ln. 518, Sec. 3, Zhongshan Rd., Changhua City, Changhua County 500, Taiwan

Email Address: tiencm1005@gmail.com

Education: $\quad$ B.A., Chemical Engineering, Tunghai University, 1999

M.S., Chemical Engineering, National Taiwan University, 2001

M.S., Petroleum Engineering, Texas A\&M University, 2009 